\title{
CONTAGEM DE CÉLULAS SOMÁTICAS E PRODUÇÃO DE LEITE EM VACAS HOLANDESAS CONFINADAS
}

\author{
ARLEI COLDEBELLA
}

Tese apresentada à Escola Superior de Agricultura

"Luiz de Queiroz", Universidade de São Paulo, para obtenção do título de Doutor em Agronomia, Área de Concentração: Ciência Animal e Pastagens.

P I R A C I C A B A

Estado de São Paulo - Brasil

Setembro - 2003 


\title{
CONTAGEM DE CÉLULAS SOMÁTICAS E PRODUÇÃO DE LEITE EM VACAS HOLANDESAS CONFINADAS
}

\author{
ARLEI COLDEBELLA \\ Médico Veterinário \\ Orientador: Prof. Dr. PAULO FERNANDO MACHADO \\ Co-Orientadora: Prof. Dra. CLARICE GARCIA BORGES DEMÉTRIO
}

\begin{abstract}
Tese apresentada à Escola Superior de Agricultura
“Luiz de Queiroz”, Universidade de São Paulo, para obtenção do título de Doutor em Agronomia, Área de Concentração: Ciência Animal e Pastagens.
\end{abstract}

P I R A C I C A B A Estado de São Paulo - Brasil

Setembro - 2003 


\section{Dados Internacionais de Catalogação na Publicação (CIP) DIVISÃO DE BIBLIOTECA E DOCUMENTAÇÃO - ESALQ/USP}

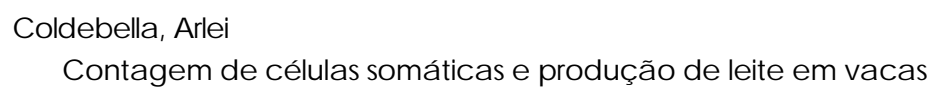

Tese (doutorado) - Escola Supenior de Agric ultura Luiz de Queiroz, 2003. Bibliografia.

1. Confina mento animal2. Gado holandês 3. Lactação animal4. Leite - Pro-dução 5. Mastite animal I. Título

CDD 636.234 


\section{Dedicatória}

Dedico esta tese aos meus pais, Armando e Lourdes, por vislumbrarem na educação uma forma de mudar o futuro de seus filhos. 


\section{Agradecimentos}

À Fundação de Amparo à Pesquisa do Estado de São Paulo (FAPESP), o auxílio financeiro.

À Escola Superior de Agricultura "Luiz de Queiroz" (ESALQ), que desde de seus primórdios foi inovadora e incentivadora das pesquisas voltadas para agropecuária brasileira, por acolher e formar mais um de seus alunos.

Ao professor Paulo Fernando Machado, a orientação e a dedicação sempre presentes, os conselhos de amigo que foi, e por nunca duvidar da minha capacidade como profissional.

À professora Clarice Garcia Borges Demétrio, a coorientação, a amizade e a presteza na sua colaboração neste trabalho.

Ao professor Paulo Justiniano Ribeiro Júnior, suas sugestões criativas e a sincera amizade que sempre esteve presente.

Ao professor Gabriel Adrian Sarriés, o incentivo no início desta caminhada.

Aos professores Wilson Roberto Soares Mattos, Décio Barbin e João Walter Dürr, a participação no exame de qualificação e as sugestões para melhoria deste trabalho.

Aos professores e funcionários do Departamento de Produção Animal, por tornarem possivel a minha estada nesse curso. 
Aos professores e funcionários do Departamento de Ciências Exatas, por fazerem parte da minha formação de mestrado, e por trazerem informações inestimáveis para o meu doutoramento.

Aos funcionários da Clínica do Leite, o trabalho árduo que dedicam a essa instituição, e principalmente, a amizade e o companheirismo.

À Fazenda Colorado, em especial ao proprietário Lair Antonio de Souza e aos médicos veterinários Antônio Carlos Sobreira e Sergio Soriano, e demais funcionários, que permitiram e viabilizaram a execução deste trabalho na fazenda.

À Empresa Brasileira de Pesquisa Agropecuária (EMBRAPA), Centro Nacional de Pesquisa de Suínos e Aves (CNPSA).

Aos meus colegas de pós-graduação, em especial ao Carlos, à Paula, à Karyne e ao Laerte, a amizade e o companheirismo.

À família Alves, por me acolher desde o início da caminhada na pós-graduação e por sempre se fazer presente.

À minha família, fonte de alegria e de força para continuar a caminhar e a crescer sempre.

À minha amada esposa, Auria, que não mediu esforços para que eu chegasse até aqui, contemplando mais um importante dia na minha vida.

Enfim, a todos e a tudo, que de alguma forma colaboraram com este trabalho, o meu

\section{muito obrigado!!!}




\section{SUMÁRIO}

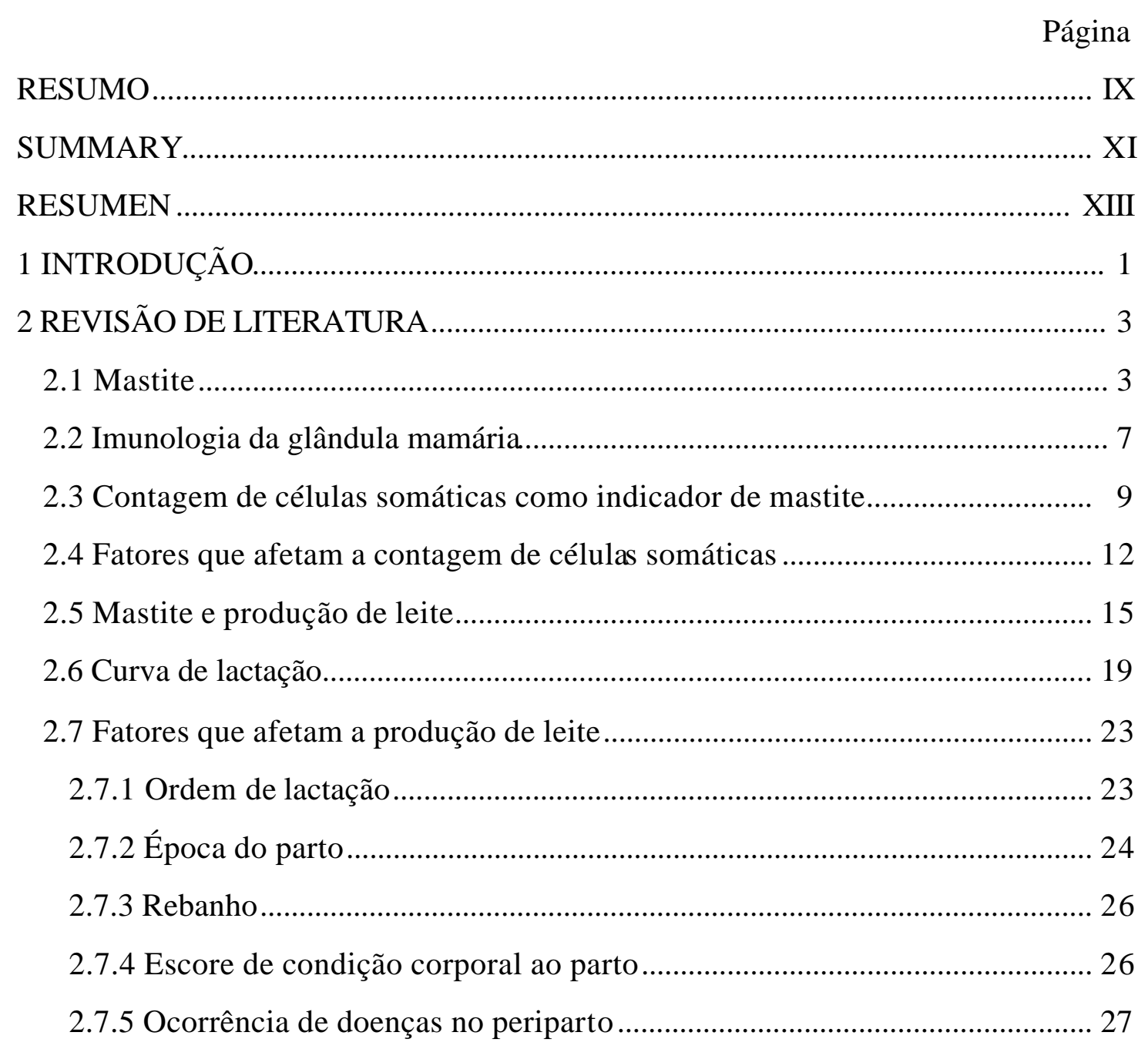

3 CONTAGEM DE CÉLULAS SOMÁTICAS E PRODUÇÃO DE LEITE EM VACAS HOLANDESAS DE ALTA PRODUÇÃO ............................................... 29

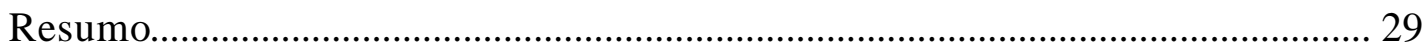

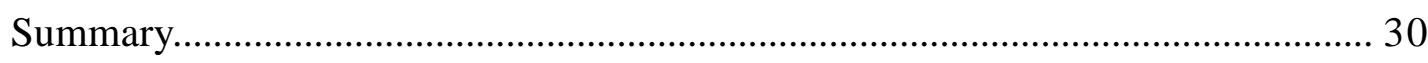

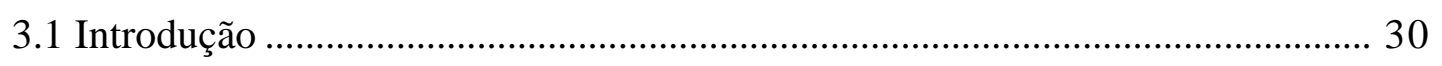

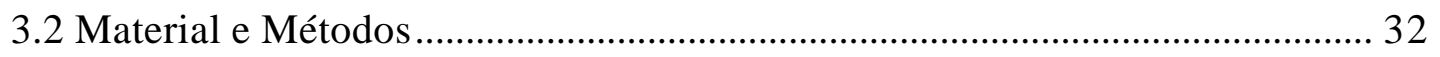

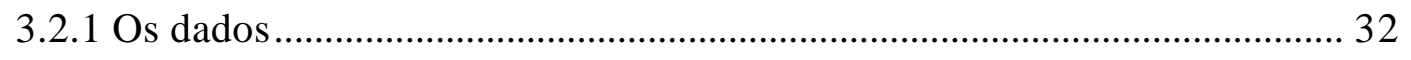

3.2.2 Modelo para descrever a curva de lactação ............................................... 33 
3.2.3 Ajuste do modelo usado para descrever a curva de lactação ...................... 34

3.2.4 Seleção do modelo para curva de lactação .................................................. 34

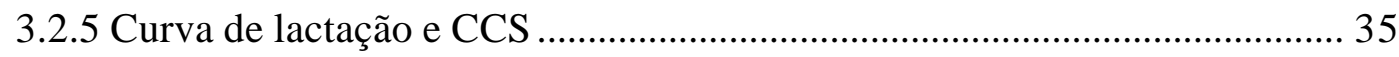

3.2.6 Ajuste e seleção do modelo para CCS....................................................... 36

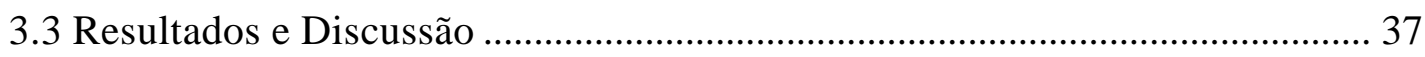

3.3.1 Seleção do modelo para curva de lactação .................................................. 37

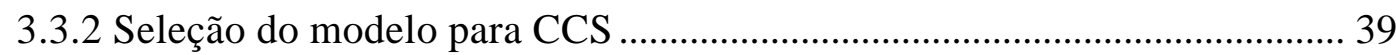

3.3.3 Estimativas dos parâmetros do modelo escolhido para CCS ..................... 39

3.3.4 Utilização prática dos resultados ................................................................. 43

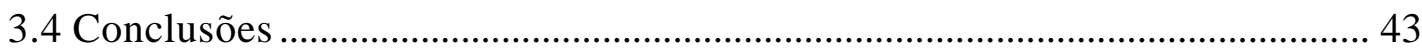

4 CONTAGEM DE CÉLULAS SOMÁTICAS E PRODUÇÃO DE LEITE EM

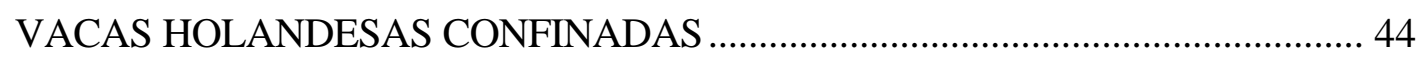

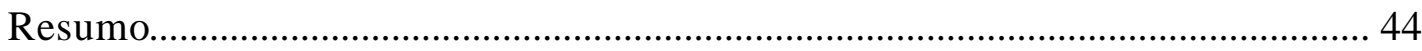

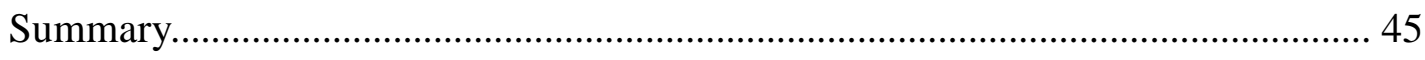

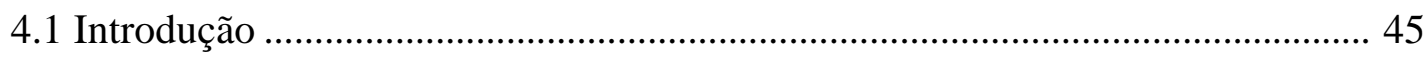

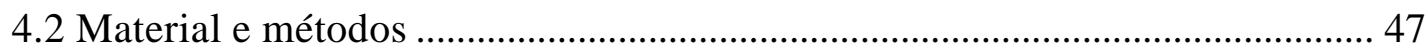

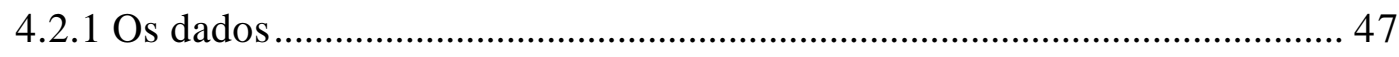

4.2.2 Modelo usado para descrever a curva de lactação ...................................... 48

4.2.3 Ajuste do modelo usado para descrever a curva de lactação ...................... 49

4.2.4 Seleção do modelo para curva de lactação ................................................. 49

4.2.5 Curva de lactação e CCS ........................................................................... 50

4.2.6 Ajuste e seleção do modelo para CCS........................................................ 51

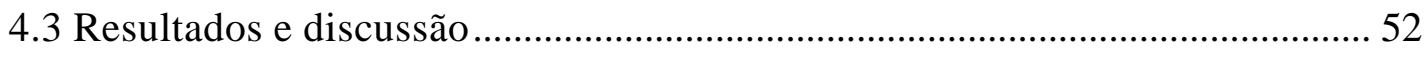

4.3.1 Seleção do modelo para curva de lactação ................................................. 52

4.3.2 Seleção do modelo para CCS ....................................................................... 52

4.3.3 Estimativas dos parâmetros do modelo escolhido para CCS ..................... 57

4.3.4 Utilização prática dos resultados .............................................................. 61

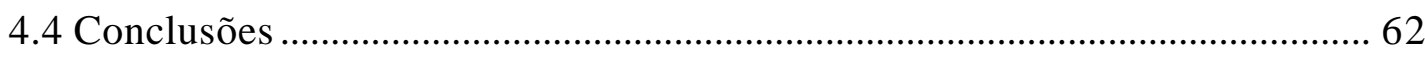


5 CONCLUSÕES. 63

ANEXO A. AJUSTE DO MODELO USADO PARA DESCREVER A CURVA DE LACTAÇÃO. 66

ANEXO B. ESTIMAÇÃO DE $x_{0}$ VIA AJUSTE DE UM ÚNICO MODELO 69 ANEXO C. ESTIMAÇÃO DE $x_{0}$ VIA AJUSTE DE VÁRIOS MODELOS 72

REFERÊNCIAS BIBLIOGRÁFICAS 76 


\title{
CONTAGEM DE CÉLULAS SOMÁTICAS E PRODUÇÃO DE LEITE EM VACAS HOLANDESAS CONFINADAS
}

\author{
Autor: ARLEI COLDEBELLA \\ Orientador: Prof. Dr. PAULO FERNANDO MACHADO \\ Co-Orientadora: Prof. ${ }^{a}$ Dra. CLARICE GARCIA BORGES DEMÉTRIO
}

\section{RESUMO}

O objetivo do presente trabalho foi verificar se as perdas na produção de leite devidas ao aumento do número de células somáticas do leite (CCS) são proporcionais à produção (dependentes dela), ou absolutas (independentes dela). Além disso, pesquisou-se a partir de que valor de CCS as vacas começam a diminuir a produção de leite. Para concretizar o objetivo deste trabalho foram realizados dois estudos. No primeiro foram usadas 7.756 observações, colhidas mensalmente de um único rebanho, durante o período de setembro de 2000 a junho de 2002, enquanto que no segundo utilizaram-se 13.725 observações, colhidas mensalmente de 6 rebanhos, durante o período de janeiro de 2001 a junho de 2002. Em ambos os casos o modelo utilizado para curva de lactação foi baseado na função gama incompleta; no primeiro estudo foram considerados os efeitos de ordem de lactação, época do parto, ocorrência de doenças no periparto e escore de condição corporal ao parto, e no segundo, os efeitos de ordem de lactação, época do parto e rebanho. A CCS foi incluída nesse modelo de duas formas: como fator 
multiplicativo (representando perdas relativas) e como fator aditivo (representando perdas absolutas). A escolha do melhor modelo foi baseada no critério de informação de Schwarz (BIC). Nos dois estudos concluiu-se que as perdas na produção de leite são absolutas e variam apenas com a ordem de lactação (vacas primíparas e multíparas). No primeiro estudo os dados mostraram que as perdas iniciam a partir de 14.270 células/mL, e para cada aumento unitário na escala do logaritmo natural a partir desse valor estimam-se perdas de 184 e 869 g/dia para vacas primíparas e multíparas, respectivamente. No segundo, estimou-se que as perdas começam a ocorrer a partir de 17.000 células/mL e são de 238 e 868 g/dia para vacas primíparas e multíparas, respectivamente, para cada aumento unitário na escala do logaritmo natural a partir desse valor. 


\title{
SOMATIC CELLS COUNT AND MILK YIELD IN CONFINED HOLSTEIN COWS
}

\author{
Author: ARLEI COLDEBELA \\ Adviser: Dr. PAULO FERNANDO MACHADO \\ Co-Adviser: Dra. CLARICE GARCIA BORGES DEMÉTRIO
}

\section{SUMMARY}

The objective of the present study was to evaluate whether milk yield losses due to increasing in milk somatic cells count (SCC) are proportional to milk yield (dependent of it), or absolute (independent of it). Also, it was investigated starting from which value of SCC the losses become evident. To achieve the objective of this research, two studies were done. In the first one, 7,756 observations were used, collected monthly from a single herd, from September/2000 up to June/2002, while in the second one, 13,725 observations were used, collected monthly from 6 herds, from January/2001 up to June/2002. In both cases, the analysis model for lactation curve was based upon the incomplete gamma function; in the first study the effects of lactation order, calving season, peripartum disorder incidence and body condition score at calving were considered, and in the second one, the effects of lactation order, calving season and herd were added. Somatic cells count entered in that model in two ways: as multiplicative factor (representing relative losses) and as additive factor (representing absolute 
losses). The best model was chosen based on the information criteria of Schwarz (BIC). In both studies, it was concluded that losses are absolute and just vary with the lactation order (primiparous and multiparous cows). In the first case, losses become evident starting from 14,270 cells/mL, and for each unitary increase in the natural logarithm scale from that value, there are losses of 184 and $869 \mathrm{~g} / \mathrm{day}$ for primiparous and multiparous cows, respectively. In the second study, it was estimated that losses start from 17,000 cells/mL and are of 238 and $868 \mathrm{~g} / \mathrm{day}$ for primiparous and multiparous cows, respectively, for each unitary increase in the natural logarithm scale from that value. 


\title{
RECUENTO DE LAS CÉLULAS SOMÁTICAS Y PRODUCCIÓN DE LECHE EN VACAS HOLANDESAS CONFINADAS
}

\author{
Autor: ARLEI COLDEBELA \\ Orientador: PAULO FERNANDO MACHADO \\ Co-orientador: CLARICE GARCIA BORGES DEMÉTRIO
}

\section{RESUMEN}

El objetivo del presente trabajo fue verificar si las pérdidas en la producción lechera debido al aumento del recuento de las células somáticas en la leche (RCS) son proporcionales a la producción (dependiente de ella), o absolutas (independiente de ella). Además, se investigó a partir de que valor de RCS las pérdidas empiezan a ser evidentes. Para concretar el objetivo de esta pesquisa, se hicieron dos estudios. En el primero, fueron utilizadas 7.756 observaciones, cogidas mensualmente de un solo rebaño, de septiembre/2000 hasta junio/2002, mientras en el segundo, se utilizaron 13.725 observaciones, cogidas mensualmente de 6 rebaños diferentes, de enero/2001 hasta junio/2002. En ambos los casos, el modelo del análisis para la curva de lactación era basado en la función gamma incompleta; en el primer estudio fueron considerados los efectos del orden de la lactación, época del parto, manifestación de alguna enfermedad en el periparto y resultado de la condición corporal al, y en el segundo, parto los efectos del orden de la lactación, época del parto y rebaño. La RCS fué inclusa en ese modelo de dos 
maneras: como factor multiplicativo (representando las pérdidas relativas) y como factor adictivo (representando las pérdidas absolutas). La elección del mejor modelo fue basada en el criterio de información de Schwarz (BIC). En los dos estudios, se concluyó que las pérdidas son absolutas y varían solamente con el orden de la lactación (vacas primíparas y multíparas). En el primer caso los datos enseñaram que las pérdidas son evidentes desde 14.270 células/mL, y para cada aumento unitario en la escala del logaritmo natural a partir de ese valor, evalúanse pérdidas de 184 y 869 g/día para las vacas primíparas y multíparas, respectivamente. En el segundo estudio, se estimó que las pérdidas empiezan a partir de 17.000 células/mL y son de 238 y 868 g/día para las vacas primíparas y multíparas, respectivamente, para cada aumento unitario en la escala del logaritmo natural a partir de ese valor. 


\section{INTRODUÇÃO}

Grandes desafios são postos para a humanidade neste século XXI, entre eles o de produzir alimentos para uma população em constante crescimento, sem degradar os recursos naturais e o meio ambiente. É preciso desenvolver pesquisas que, além de aumentarem a produção, criem empregos e renda, permitindo o desenvolvimento sustentável das pessoas e regiões envolvidas neste ato. Isso não pode ocorrer de forma isolada, deve ser um trabalho conjunto de diferentes instituições, áreas de pesquisa, ou mesmo, países, todos convergindo para um objetivo semelhante.

A produção de leite, como qualquer atividade produtiva, deve gerar lucro ao produtor, de modo a mantê-lo na atividade. O lucro da atividade é função da produtividade, dos custos de produção e do preço do leite pago ao produtor, principalmente. Uma forma de aumentar o lucro é diminuindo as perdas econômicas advindas da ocorrência de doenças, as quais podem diminuir a produtividade e aumentar os custos.

Nesse sentido, a mastite, inflamação da glândula mamária, é tida como o fator que mais contribui para as perdas econômicas da cadeia produtiva do leite. Giraudo et al. (1997) relatam que as perdas econômicas mundiais causadas por esta doença chegam a 35 bilhões de dólares por ano, e Politis et al. (1995) estimam que somente nos Estados Unidos os prejuízos anuais são da ordem de 2 a 4 bilhões de dólares. 
Apesar da abundância internacional de estudos que quantificam as perdas de produção devidas à mastite, trabalhos dessa natureza ainda são escassos no Brasil. Esse fato é um indicativo de que as estimativas acerca das perdas de produção de leite ocasionadas pela mastite em nosso país estão viesadas, pois elas normalmente são baseadas em dados do exterior e que provêm de rebanhos em condições diferentes das brasileiras. Logo, existe a necessidade de realização de trabalhos relacionados a essa temática para se dar a devida importância ao problema, considerando as condições em que os nossos rebanhos são explorados.

O objetivo do presente trabalho foi de avaliar o impacto da mastite subclínica, medida através da contagem de células somáticas (CCS), sobre a produção de leite de vacas holandesas confinadas, considerando a curva de lactação e fatores que possam influenciá-la, buscando responder se as perdas são absolutas (independentes da produção de leite), ou relativas (proporcionais à produção de leite), e a partir de qual número de células somáticas elas começam a ocorrer.

Para tal foram realizados dois estudos. No primeiro foram usados dados de um único rebanho, o qual dispunha das informações ordem de lactação, época do parto, escore de condição corporal e ocorrência de doenças no periparto, que foram considerados no ajuste da curva de lactação e no modelo para CCS do leite. Já, no segundo estudo, os dados utilizados são provenientes de 6 rebanhos, com informações de ordem de lactação e de época do parto.

Para cada estudo foram utilizadas estratégias diferentes para estimar o valor da CCS a partir do qual as perdas começam a ocorrer, sendo essa estimação uma das diferenças essenciais entre este trabalho e a literatura consultada. 


\section{REVISÃO DE LITERATURA}

Para melhor entendimento do texto este capítulo foi dividido entre a revisão de curvas de lactação e de mastite, englobando o efeito desta última sobre a produção de leite, maior interesse do presente estudo.

\subsection{Mastite}

A mastite é um processo inflamatório da glândula mamária, acompanhada da redução de secreção de leite e mudança de permeabilidade da membrana dos ácinos, o que ocasiona mudança na sua composição. A inflamação caracteriza-se por aumento do volume, da temperatura, vermelhidão, dor e/ou distúrbio funcional, resultando em diminuição da produção de leite e em alterações físicas, químicas e bacteriológicas do mesmo (Langoni, 2000; Park \& Jacobson, 1996).

Segundo Neave et al. (1969), 90\% dos casos de mastite são causados por bactérias, principalmente Staphylococcus aureus e bactérias do gênero Streptococcus. Além destes patógenos, também podem ocorrer mastites causadas por fungos, leveduras, algas (Blood \& Radotitis, 1989; Langoni, 1996) e vírus. Porém, as mastites causadas por este último patógeno são extremamente raras (Guidry, 1985).

Mais recentemente, Watts (1988) cita que existem na literatura 137 citações de agentes envolvidos na etiologia da mastite, ao passo que Philpot (2002) já relata a identificação de mais de 140 microrganismos relacionados a ela.

A mastite pode ser classificada em clínica e subclínica (Blood \& Radotitis, 1989; Costa et al., 1995b; Philpot \& Nickerson, 1991), sendo que na forma clínica ocorrem 
anormalidades na secreção láctea, tamanho, consistência e temperatura da glândula mamária, e possivelmente reação sistêmica. A forma subclínica é aquela na qual existe a inflamação, porém, sem a apresentação de sinais visíveis da doença, sendo necessária a análise (como contagem de células somáticas) e/ou cultura do leite para sua detecção (Jain, 1979; Philpot, 1979).

Para Philpot \& Nickerson (1991), praticamente todos os indivíduos que trabalham com gado leiteiro estão bem familiarizados com a forma clínica da mastite, devido à sua evidência explícita e à sua fácil identificação, contudo poucas pessoas têm a consciência da existência e da importância da forma subclínica da doença. Assim, esses autores apontam que é fundamental focar a atenção primariamente sobre a mastite subclínica, pois: a) ela é 15 a 40 vezes mais prevalente do que a forma clínica; b) usualmente precede a mastite clínica; c) é de longa duração; d) é de difícil diagnóstico; e) reduz a produção de leite de forma significativa; f) altera negativamente a composição do leite e g) constitui um reservatório de patógenos causadores de mastite que podem disseminar-se para outras vacas do rebanho.

No Brasil, pode-se afirmar que a mastite subclínica ocorre em todos os rebanhos leiteiros. Vários levantamentos realizados a partir de 1970 indicam alta incidência, com índices variando de $11,9 \%$ a $72,3 \%$ de vacas infectadas por rebanho, como pode ser visto na Tabela 1. Esse resultado é preocupante, já que a forma subclínica é responsável pelas maiores perdas na produção leiteira (Costa et al., 1995a).

Conforme as características dos patógenos causadores de mastite, esta pode ser classificada em contagiosa ou ambiental (Amaral, 1999; Nickerson, 1998a; Philpot \& Nickerson, 1991). A mastite contagiosa é aquela causada por Staphylococcus aureus, Streptococcus agalactiae ou Corynebacterium bovis, cujo habitat preferencial é o interior da glândula mamária. Seu controle é mais fácil, e é realizado através da adoção de medidas higiênicas durante o processo de ordenha (Langoni, 2000).

A mastite ambiental é aquela ocasionada por agentes que partilham o mesmo ecossistema da vaca, tais como: solo, piso, cama, esterco e materiais orgânicos. Dentre eles destacam-se: Escherichia coli, Enterobacter sp., Klebsiella sp., Pseudomonas sp., 
estafilococos coagulase-negativos, Streptococcus uberis e Streptococcus dysgalactiae. A contaminação dos animais por esses microrganismos, embora possa ocorrer durante o processo de ordenha (normalmente por falhas no funcionamento do equipamento), acontece principalmente entre ordenhas. Geralmente, são de difícil controle, porque os seus principais agentes estão disseminados no ambiente dos animais (Langoni, 2000).

Tabela 1. Porcentagens de animais infectados por mastite subclínica

\begin{tabular}{|c|c|c|c|}
\hline Autor & Ano & Local & Animais infectados (\%) \\
\hline Langenegger et al. & 1970 & $\begin{array}{l}\text { Rio de Janeiro } \\
\text { (43 fazendas) }\end{array}$ & $20 \%$ \\
\hline Nader Filho et al. & 1985 & $\begin{array}{l}\text { Ribeirão Preto-SP } \\
\text { (17 Fazendas) }\end{array}$ & $11,9 \%$ \\
\hline Baldassi et al. & 1991 & $\begin{array}{l}\text { Ribeirão Preto-SP } \\
\text { (7 Fazendas) }\end{array}$ & $53,3 \%$ \\
\hline Nicolau et al. & 1992 & $\begin{array}{l}\text { Monte Alto }- \text { SP } \\
\text { (5 fazendas) }\end{array}$ & $38,3 \%$ \\
\hline Brant \& Figueiredo & 1994 & $\begin{array}{l}\text { Minas Gerais } \\
\text { (4 fazendas) }\end{array}$ & 32,69 a $57,14 \%$ \\
\hline Laranja \& Machado & 1994 & $\begin{array}{l}\text { São Paulo } \\
\text { (7 fazendas) }\end{array}$ & 14,4 a $58,8 \%$ \\
\hline Costa et al. & $1995 b$ & $\begin{array}{c}\text { São Paulo e Minas Gerais } \\
\text { (28 fazendas) }\end{array}$ & $72,3 \%$ \\
\hline Samara et al. & 1996 & $\begin{array}{c}\text { Pitangueiras - SP } \\
\text { (20 fazendas) }\end{array}$ & 29,6 a $35,8 \%$ \\
\hline Prado et al. & 1997 & $\begin{array}{c}\text { Divinópolis - MG } \\
\text { (30 fazendas) }\end{array}$ & $20,75 \%$ \\
\hline
\end{tabular}

Philpot (2002) ressalta que as infecções contagiosas tendem a ser subclínicas, de longa duração e acompanhadas por elevação significativa na CCS do rebanho, enquanto que a mastite ambiental se faz presente principalmente na forma clínica, tem curta duração e tem pouco impacto na CCS do rebanho. Isso ocorre, provavelmente, porque o leite de vacas 
com mastite clínica é descartado, enquanto o das vacas com mastite subclínica vai para o tanque de leite.

A disseminação da adoção do pós-imersão, da terapia da vaca seca e a melhoria das práticas de manejo de ordenha resultaram numa redução significativa da mastite contagiosa durante os últimos 40 anos, ocorrendo grandes mudanças na importância de alguns dos principais patógenos causadores de mastite (Philpot, 2002).

Por outro lado, o mesmo autor coloca que a mastite ambiental, causada por organismos como Streptococcus uberis e E. coli, tornourse mais importante. Ainda que sua prevalência seja menor do que era no passado, estes dois microrganismos são agora responsáveis por aproximadamente $60 \%$ de todos os casos clínicos de mastite em muitos países.

Além disso, ele ressalta que o Streptococcus uberis e o Streptococcus dysgalactiae podem ser transmitidos tanto do ambiente, quanto durante o momento da ordenha e, portanto, estes microrganismos não são exclusivamente ambientais.

As bactérias causadoras de mastite podem ser classificadas, ainda, em patógenos maiores ou menores. Os patógenos maiores provocam grandes mudanças na composição do leite, incluindo grande aumento na CCS, e são os responsáveis pelo maior impacto econômico da doença. Eles incluem Staphylococcus aureus, Streptococcus agalactiae e coliformes (Harmon, 1994).

Ao contrário, os patógenos menores, como estafilococos coagulase-negativo e Corynebacterium bovis, não estão associados com grandes mudanças na composição e na produção de leite. Infecções causadas por esses organismos apenas duplicam ou triplicam a CCS em relação aos quartos não infectados (Harmon, 1994).

Finalizando este item, deve ficar claro que a mastite ainda é uma doença não passível de erradicação, e assim, todos os esforços devem ser concentrados no sentido de manter a sua prevalência o mais baixa possível. Para isso, Philpot (2002) ressalta que se deve considerar que a mastite é o resultado final da interação entre diferentes fatores, incluindo: a resistência natural ou susceptibilidade de cada indivíduo; a higiene do ambiente, que 
condiciona a concentração de microrganismos aos quais a vaca está exposta; o estresse a que a vaca está submetida; as diferentes cepas e espécies de microrganismos, com suas diferentes virulências; as estratégias de manejo, incluindo alimentação e funcionamento do equipamento de ordenha; procedimentos de ordenha com ênfase na questão da higiene; conscientização dos funcionários e outros fatores diversos; os quais devem ser considerados em programas de controle da doença.

\subsection{Imunologia da glândula mamária}

A glândula mamária é protegida por grande variedade de mecanismos de defesa, os quais podem ser separados em duas categorias distintas: imunidade inata e imunidade específica (Giraudo, 1996; Sordillo et al., 1997).

A imunidade inata, também conhecida como inespecífica, é a defesa predominante durante os estágios iniciais da infecção. Ela é mediada por barreiras físicas na ponta do teto, por certos fatores solúveis (lactoferrina, lactoperoxidase, lisozima e complemento) (Giraudo, 1996; Sordillo et al., 1997), e por macrófagos, neutrófilos e células semelhartes às células matadoras naturais ("natural killer-like cells”) (Sordillo et al., 1997). Respostas inespecíficas estão presentes ou são ativadas no local da infecção por vários estímulos; contudo, elas não aumentam pela exposição repetida a um mesmo insulto (Sordillo et al., 1997).

Ao contrário, o sistema imune adquirido, ou específico, reconhece o patógeno, o que facilita a sua eliminação seletiva. O reconhecimento dos fatores patogênicos é mediado por anticorpos, macrófagos e por várias populações de linfócitos. Por causa da "memória" de certos linfócitos, respostas imunes específicas podem ser aumentadas pela exposição repetida a um patógeno (Sordillo et al., 1997).

$\mathrm{Na}$ glândula mamária, os fatores de proteção inatos e adquiridos estão coordenados para fornecer uma ótima proteção contra a doença (Sordillo et al., 1997). 
A mastite ocorre quando o microrganismo consegue invadir a glândula mamária através do canal do teto. Graças ao esfíncter muscular que mantém o canal fechado entre ordenhas, impedindo a penetração bacteriana, a ponta do teto é considerada a primeira linha de defesa contra os patógenos invasores (Giraudo, 1996; Persson, 1992; Sordillo et al., 1997).

Além disso, a queratina presente no canal do teto possui ácidos graxos de cadeia intermediária (tais como: mirístico, palmitoleico e linoleico) e proteínas com ação antimicrobiana (Giraudo, 1996; Sordillo et al., 1997). No epitélio da porção distal da roseta de Furstenberg há uma população de linfócitos e células plasmáticas que permitem a produção local de anticorpos e um rápido movimento de neutrófilos, quando da agressão bacteriana (Giraudo, 1996).

As bactérias que conseguem entrar na glândula mamária devem, então, escapar das atividades antibacterianas desse ambiente, para estabelecer a doença. O estabelecimento da infecção intramamária ocorre com a indução das atividades de resistência e o recrutamento de novas populações de leucócitos (Sordillo et al., 1997).

As defesas celulares intramamárias são realizadas por dois grupos de leucócitos, os linfócitos B e T que atuam na imunidade humoral e mediada por células, e os fagócitos (neutrófilos e macrófagos) que atuam pela ingestão e digestão dos patógenos mamários (Paape et al., 1991). Contudo, Giraudo (1996) assume que as células de defesa mais importantes da glândula mamária são os macrófagos e linfócitos, cuja interação constitui a base da imunidade mediada por célula.

A migração (diapedese) dos neutrófilos para o tecido mamário fornece a primeira linha imunológica de defesa depois que a bactéria penetra a barreira física do canal do teto, e sua depleção resulta em aumento dramático da susceptibilidade para a infecção intramamária (Paape \& Capuco, 1997).

Os macrófagos predominam na secreção mamária não infectada, sendo, portanto, responsáveis pelo início do ataque aos patógenos, enquanto na glândula já infeccionada ocorre predomínio dos neutrófilos, chegando a mais de $90 \%$ das células 
somáticas (Giraudo, 1996; Nickerson, 1985; Paape et al., 1979; Rebhun, 1995), na tentativa de eliminar o agente causal da mastite. Os macrófagos são ativos em fagocitar bactérias, células debilitadas e componentes lácteos acumulados (Sordillo \& Nickerson, 1988) e sua atividade fagocítica pode ser substancialmente incrementada na presença de anticorpo patógeno-específico (Sordillo et al., 1997).

Apesar da presença dos neutrófilos polimorfonucleares poder eliminar a infecção, ela também produz danos tissulares pela geração de metabólitos reativos ao oxigênio e pela liberação de enzimas (degranulação) (Giraudo, 1996).

Para funcionar plenamente, os leucócitos necessitam da ajuda dos anticorpos para promover a opsonização, o reconhecimento e a fagocitose das bactérias (Nickerson, 1998b). Além de servir como opsoninas, os anticorpos podem neutralizar toxinas bacterianas, evitar a adesão das bactérias aos tecidos mamários e causar a lise dos microrganismos (Giraudo, 1996; Nickerson, 1998b).

Deve-se ter em mente que os fatores de defesa da glândula mamária atuam em conjunto, sendo que eles interagem, buscando a harmonia dos mecanismos de defesa.

\subsection{Contagem de células somáticas como indicador de mastite}

Segundo Breer et al. (1976) e Langoni (2000), a determinação da CCS através de microscopia ótica direta foi introduzida em 1910, por Prescott \& Breed ${ }^{1}$. Estes últimos sugeriram o uso do termo "células corporais", pois pesquisas ao longo do tempo indicavam que as células do leite eram células epiteliais descamadas, entretanto, depois de 1960 o termo contagem de células "somáticas" (substituindo "corporais") tornourse comum (Harmon, 2001).

\footnotetext{
${ }^{1}$ PRESCOTT, S.C.; BREED, R.S. The determination of the number of body cells in milk by a direct method. Journal of Infectious Disease, v.7, p.632, 1910.
} 
As células somáticas são, normalmente, células de defesa (leucócitos) do organismo que migram do sangue para o interior da glândula mamária com o objetivo de combater agentes agressores, mas podem ser também células secretoras descamadas (Harmon, 1994, 1998a e 2001; Machado et al., 1999 e 2000; Shällibaum, 2001).

Hamann (1996), Philpot (1998) e Sordillo et al. (1997) também reconhecem que as células somáticas do leite são principalmente leucócitos ou células brancas, as quais incluem macrófagos, linfócitos e neutrófilos polimorfonucleares, o que é corroborado pelos resultados de porcentagem de tipos celulares apresentados por Persson (1992) e Lee et al. (1980) (Tabela 2).

A atividade dos microrganismos no interior da glândula mamária libera substâncias que estimulam a migração de leucócitos a fim de combater os agentes agressores (Machado et al., 1998 e 1999), aumentando, dessa maneira, a CCS. Por causa disso, vários autores (Laevens et al., 1997; Machado et al., 1998; Philpot, 1998; Reneau, 1986; Tsenkova et al., 2001; entre outros) relatam que a CCS presente na secreção láctea é um indicador geral da saúde da glândula mamária, amplamente utilizado como indicador de mastite subclínica, sendo aceita, também, como medida padrão para determinar a qualidade do leite (Harmon, 1998a e 2001; Schällibaum, 2001; Zecconi, 1996).

Tabela 2. Porcentagens (\%) de células somáticas em secreções mamárias bovinas

\begin{tabular}{lcccc}
\hline \multicolumn{1}{c}{ Tipo Celular } & Leite Normal * & $\begin{array}{c}\text { Secreção no } \\
\text { Período Seco } *\end{array}$ & Colostro * & Leite Normal ** \\
\hline Neutrófilos & $3-26$ & $3-15$ & $25-37$ & $0-11$ \\
Macrófagos & $35-80$ & $45-89$ & $37-50$ & $66-88$ \\
Linfócitos & $16-28$ & $7-40$ & $\approx 25$ & $10-27$ \\
Epiteliais & $2-15$ & $\approx 1$ & - & $0-7$ \\
\hline
\end{tabular}

Fonte: * Persson (1992); ** Lee et al. (1980).

Segundo Allore et al. (1998) a CCS de cada vaca é usada como medida de saúde do úbere, enquanto a CCS no tanque de leite é utilizada como medida de qualidade. 
Isso se deve ao fato de que o aumento na CCS no tanque de leite está associado com a redução da concentração dos componentes do leite (caseína, principalmente), reduzindo o rendimento industrial do mesmo.

Assim, segundo Edmondson (2002), muitos laticínios utilizam um sistema de bônus, ou penalizações, para estimular a produção de leite com baixa contagem de células somáticas.

Legalmente, os países impõem limites máximos para a CCS do leite do rebanho, sendo que nos Estados Unidos esse limite é de 750.000 células $/ \mathrm{mL}$, enquanto na União Européia, Nova Zelândia e Austrália o valor é 400.000 células/mL (Edmondson, 2002; Santos, 2002).

No Brasil, o Ministério da Agricultura, Pecuária e Abastecimento recentemente alterou a legislação sobre a produção de leite, através da Instrução Normativa n. ${ }^{\circ}$ 51. A adaptação dos produtores a essa nova lei será feita de forma gradual, com valor máximo inicial de CCS igual a 1.000.000 células $/ \mathrm{mL}$, e previsão de decréscimo para 400.000 células/mL após 7 anos da entrada em vigor dessa legislação (Santos, 2002).

Muitos estudos e revisões têm sido realizados mostrando e/ou utilizando limites fisiológicos (pontos de corte) para classificar a glândula mamária como saudável ou infectada em relação à CCS (Beaudeau et al., 2002; Brolund, 1985; Buelow et al., 1996; Detilleux et al., 1999; Dohoo, 1993 e 2001; Dohoo \& Leslie, 1991; Harmon, 1994, 1998a e 2001; Omore et al., 1996; Reneau, 1986; entre outros).

Nesse contexto, Harmon (2001) afirma que em animais saudáveis a CCS geralmente está abaixo de 200.000 células $/ \mathrm{mL}$, mas pode ser menor do que 100.000 células/mL em vacas primíparas. Assim, elevação acima de 200.000 células/mL é considerada anormal e indicativo de inflamação do úbere, sendo que esse valor chega a milhões de células/mL nos casos clínicos (Nickerson, 1985; Guidry, 1985; Reneau, 1986; Sordillo et al., 1997).

Smith (1996) relata que, dependendo do estudo, os pontos de corte da CCS indicativos de inflamação ou mastite variam entre os valores 200.000, 250.000, 283.000, ou 
300.000 células $/ \mathrm{mL}$, sendo o valor de 200.000 células $/ \mathrm{mL}$ o mais utilizado (Dohoo, 2001; Smith, 1996). Já, Geishauser et al. (1999), utilizaram um valor de 100.000 células/mL como ponto de corte para definir mastite subclínica.

Dohoo (2001), porém, afirma que a amplitude da CCS observada em vacas com infecção intramamária se sobrepõe à das vacas sem infecção, e talvez, seja impossível selecionar um único ponto de corte que separe claramente as vacas infectadas daquelas não infectadas.

Pesquisas recentes em amostras de leite de quartos com cultura bacteriológica negativa obtiveram médias de CCS entre 14.000 e 49.400 células/mL (Harmon, 2001; Laevens et al., 1997; Schepers et al., 1997; Wilson et al., 1997).

Portanto, dado que a medida da CCS é fácil e barata quando comparada com os testes bacteriológicos para mastite, ela tem sido usada para monitorar a saúde da glândula e é um instrumento importante para o manejo das vacas leiteiras (Gadini et al., 1997a).

Contudo, deve-se considerar que não existe um padrão internacional para definir a infecção intramamária e os métodos que determinam a saúde da glândula mamária variam (Laevens et al., 1997).

Alguns autores têm especulado a relação entre a CCS e o risco subsequente de mastite clínica (Beaudeau et al., 2002; Rupp et al., 2000; Rupp \& Boichard, 2000; Suriyasathaporn et al., 2000). Contudo, os resultados são controversos, com alguns mostrando que baixa CCS é um fator de risco para a ocorrência de mastite clínica subsequente, enquanto outros encontraram que valores mais altos de CCS aumentam esse risco.

\subsection{Fatores que afetam a contagem de células somáticas}

O fator mais importante afetando a CCS é o grau de infecção da glândula mamária (Brolund, 1985; Hamann, 1996; Harmon, 1994, 1998a; Langoni, 2000; Machado et 
al., 1998, 1999, 2000; Reneau, 1986; RodriguezZas et al., 2000), embora existam outros fatores menos importantes.

Harmon (1998a) aponta que existem poucas evidências de que qualquer outro fator, com exceção da variação diurna normal, tenha influência significativa na CCS na ausência de infecção intramamária. Sabe-se que a ordenha vespertina apresenta maior CCS em relação à ordenha da manhã (Brolund, 1985; Hargrove, 1994; Vasconcelos et al., 1997), fato que pode ser explicado pelo intervalo de tempo desigual entre as ordenhas e conseqüente efeito de diluição das células somáticas (Fuente et al., 1997; Philpot \& Nickerson, 1991). Portanto, logo após a ordenha, a CCS é máxima, permanecendo elevada por 4 horas, e declinando gradualmente até atingir a contagem mínima, imediatamente antes da próxima ordenha (Harmon, 1998a).

Ostrensky et al. (2000), analisando dados de rebanhos paranaenses, verificaram que existem tendências de menores médias de CCS para os animais primíparos, enquanto que as maiores médias foram observadas em animais a partir de cinco lactações. Em relação ao estádio da lactação, os mesmos autores observaram valores elevados de CCS já no início da lactação, com redução até por volta dos 45 dias pós-parto e, a partir daí, valores crescentes até o final da lactação, o que está de acordo com outros dados da literatura, como Hamann (1996), Harmon (1998a) e Sheldrake et al. (1983).

Rodriguez-Zas et al. (2000) propuseram o ajuste de 6 modelos para explicar a variação da CCS no decorrer da lactação, sendo que, dentre eles, o modelo proposto por Morant \& Gnanasakthy (1989) foi o melhor, baseado nos valores da máxima verossimilhança restrita e dos critérios de informação de Akaike (AIC) e de Schwarz (BIC). Nesse mesmo artigo, Rodriguez-Zas et al. (2000) não encontraram diferenças significativas do número de lactações sobre os parâmetros dos 6 modelos, provavelmente porque eles consideraram a presença de infecção intramamária.

Entretanto, fatores como o estádio e a ordem da lactação não afetam significativamente a CCS quando não existe infecção e, portanto, podem ser desconsiderados no diagnóstico de infecção intramamária através de CCS (Hamann, 1996; Laevens et al., 
1997; Pryce et al., 1999; Reneau, 1986; Sheldrake et al., 1983). Existem evidências que o aumento da CCS atribuído ao avanço da lactação, ou ao acréscimo no número de lactações, é devido à infecção (Pryce et al., 1999; Reneau, 1986; Sheldrake et al., 1983).

Dohoo (1993) recomenda que amostras de leite de vacas primíparas nos primeiros 9 dias de lactação, e de multíparas nos primeiros 11 dias não sejam utilizadas para a detecção de mastite subclínica através da CCS, pois nesse período as contagens de células são normalmente elevadas. Ao contrário, Barkema et al. (1999) afirmam que a CCS do quarto mamário pode ser utilizada já no segundo dia do pós-parto, dando indicação do grau da infecção intramamária.

Outro fator a ser considerado é a estação do ano, pois a CCS é, geralmente, menor durante o inverno e maior durante o verão, devido provavelmente às melhores condições ambientais para o crescimento bacteriano durante o verão (Harmon, 1998a; Reneau, 1986).

Outra variável que pode influenciar a CCS é o agente causal da mastite. Essa variação é devida às características do agente etiológico (Amaral, 1999), porém, não é possível identificar o patógeno somente através da CCS (Harmon, 1994), o que foi comprovado também pelo trabalho de Kirk et al. (1996) com novilhas no início da lactação.

Outrossim, estresses de vários tipos têm sido associados ao aumento da CCS, porém experimentos com aplicação de $\mathrm{ACTH}$, ou corticoesteróides, ou com o uso de ambiente controlado em animais não infectados não mostraram efeito sobre a CCS (Paape et al., 1973; Harmon, 1994). Portanto, condições estressantes podem agravar o processo inflamatório em vacas infectadas, mas têm pouco efeito na CCS de vacas não infectadas (Harmon, 1998a).

No Brasil, Vasconcelos et al. (1997) não encontraram diferenças significativas entre as estações do ano para essa variável. Já, Ostrensky et al. (2000), relatam que vacas paridas no inverno apresentaram a menor média de CCS, enquanto que as paridas na primavera tiveram a maior média. 
Em trabalho realizado na Escola Superior de Agricultura "Luiz de Queiroz, Universidade de São Paulo, Meyer et al. (2002) mostraram que o logaritmo natural da CCS foi influenciado significativamente pela interação entre métodos e tempo de armazenamento de amostras de leite, conservadas com bronopol, antes de serem analisadas. Encontraram que as amostras refrigeradas e congeladas tiveram redução linear, respectiva, de 0,01 e 0,006 unidades logarítmicas da CCS por dia de estocagem, ao passo que para as amostras estocadas em temperatura controlada e em temperatura variável (temperatura ambiente $\mathrm{e}$ aquecidas à $40{ }^{\circ} \mathrm{C}$ durante 4 horas/dia), a redução linear foi de 0,069 e 0,226, respectivamente.

Esses resultados indicam que nas condições brasileiras, com temperaturas elevadas e as amostras de leite sendo coletadas sem qualquer procedimento de controle de temperatura, os resultados da análise laboratorial para CCS podem ser comprometidos pela demora entre o dia da coleta e a análise propriamente dita e, também, podem ser mascarados com o aquecimento prévio do leite pelo produtor. Assim, Langoni (2000) sugere que as amostras mantidas em temperatura ambiente devem ser avaliadas em, no máximo, 7 dias após a coleta.

\subsection{Mastite e produção de leite}

As perdas econômicas relacionadas à mastite devem-se à redução na produção de leite, ao leite descartado, ao custo de reposição de animais, à mão-de-obra extra, ao tratamento, aos serviços veterinários (Blosser, 1979; Fetrow et al., 1991; Harmon, 1998b; Kirk \& Bartlett, 1988; Morse et al., 1987; Wilson \& Sears, 1992), à perda de valor para produção de queijo e à penalidade pela alta contagem de células somáticas (Fetrow et al., 2000). Contudo, a redução na produção de leite é o fator mais importante, representando 66 a $80 \%$ das perdas totais (Fetrow et al., 2000; Harmon, 1998b). 
Para Zecconi (1996) as perdas de produção de leite associadas à mastite clínica são fáceis de serem vistas; enquanto as perdas ocasionadas pela mastite subclínica são amplamente subestimadas, particularmente pelos pecuaristas.

Em revisão sobre mastite, Janzen (1970) cita perdas na produção de leite devidas à mastite da ordem de 0,34 a 2,66 kg/dia (9,0 a 43,3\%) por quarto mamário, e entre 5 e $25 \%$ da produção total de leite da vaca.

Hortet \& Seegers (1998) relatam que as perdas de produção associadas à mastite clínica variaram de 0 a $350 \mathrm{~kg}$ na lactação, representando de 0 a 9,5\% da produção na lactação, para 5 trabalhos considerando todas as lactações. Já, para 14 artigos que identificaram a ordem de parto, foram encontradas perdas entre 0 e $749 \mathrm{~kg}$ de leite para vacas primíparas e entre 0 e $860 \mathrm{~kg}$ de leite para vacas multíparas.

Utilizando medidas semanais de produção de leite e modelos de simulação, Lescourret \& Coulon (1994) verificaram que os animais acometidos com mastite clínica no início da lactação apresentaram perdas médias de $911 \mathrm{~kg}$ na lactação inteira, ao passo que quando a mastite clínica ocorreu da metade ao final da lactação as perdas médias foram de $850 \mathrm{~kg}$ na lactação, considerando os casos em que a produção de leite foi mais afetada.

Lucey \& Rowlands (1984) agrupando vacas multíparas segundo o nível de produção na lactação anterior, observaram que vacas com média de $2.000 \mathrm{~kg}$ (em 305 dias) na lactação anterior reduziram sua produção em $250 \mathrm{~kg}$ de leite, ou 7,7\%, devido à mastite clínica, ao passo que vacas com média de 4.450 e $7.000 \mathrm{~kg}$, produziram, respectivamente, 540 e $860 \mathrm{~kg}$ de leite a menos, representado 11,2 e 13,3\%, nesta ordem. Esses resultados mostram que os maiores níveis de produção de leite "a priori” podem estar associados com as maiores perdas de produção de leite (em valores absolutos e em percentuais) (Hortet \& Seegers, 1998).

Estudando o efeito da ocorrência de mastite clínica em diferentes períodos da lactação e comparando vacas que tiveram somente mastite, sem outra doença, com aquelas que não tiveram nenhuma doença durante a lactação inteira, Rajala-Schultz et al. (1999) obtiveram redução de 1,0 a 2,5 kg/dia na produção de leite durante as duas primeiras 
semanas após a ocorrência da doença, enquanto que as perdas em toda a lactação ficaram entre 110 e $552 \mathrm{~kg}$ de leite e dependeram da ordem de lactação e do tempo de ocorrência da mastite.

Bartlett et al. (1991) estimaram redução de $92 \mathrm{~kg}$ na produção de leite durante os primeiros 60 dias após a primeira ocorrência de mastite clínica em vacas primíparas e multíparas. Esse resultado foi obtido através de simulações, considerando a produção das vacas antes da ocorrência da doença e as curvas de lactação das contemporâneas de rebanho sem mastite.

Considerando as diferentes patogenicidades dos microrganismos causadores de mastite, Hortet \& Seegers (1998) informam que na literatura não aparecem trabalhos mostrando diferenças significativas nas perdas de produção de leite em função do patógeno envolvido. Relatam, também, que esse fato é, provavelmente, devido à falta de poder dos testes, por causa do número pequeno de amostras.

Entretanto, Nicolau et al. (1992), em pesquisa realizada no Estado de São Paulo, verificaram uma redução de $31,35 \%$ na produção de leite de quartos infectados de com Sthaphylococcus coagulase positiva quando comparados com os quartos correspondentes sadios, enquanto para os quartos infectados com Sthaphylococcus coagulase negativa a redução foi de $11,17 \%$. Ressalte-se que os autores não relataram diferenças significativas entre os patógenos.

No que se refere àmastite subclínica detectada através do California Mastitis Test (CMT) (Schalm \& Noorlander, 1957), Graaf \& Dwinger (1996), em estudo feito na Costa Rica, estimaram uma perda diária de $1,56 \mathrm{~kg}$, e não encontraram diferenças entre animais primíparos e multíparos. Estimaram, também, que a perda de produção de leite por quarto afetado pela mastite subclínica foi em média 17,6\%.

No Brasil, Brant \& Figueiredo (1994) relataram perdas arescentes, contudo não significativas, da produção leite conforme aumentava a reação positiva do CMT.

Em relação à CCS, Blosser (1979) cita que a mesma já vinha sendo utilizada para quantificar as perdas de produção de leite devidas à mastite, sendo as produções 
comparadas com base nas vacas, ou mesmo, entre os quartos mamários. Esse mesmo autor relata que um número considerável de vacas e de quartos já haviam sido comparados por essa via, mostrando que a redução da produção de leite pode ser estimada a partir da CCS.

Posteriormente, vários autores, como: Bartlett et al. (1990), Gadini et al. (1997b), Gill et al. (1990), Haile-Mariam et al. (2001), Kennedy et al. (1982), Kirk (1984), Miller et al. (1993), entre outros; mostraram associação entre o aumento da CCS (indicador de saúde da glândula mamária) e a diminuição da produção de leite. Mesmo em baixos níveis de CCS, Hortet et al. (1999) citam que ocorreu redução na produção de leite, e que já existem perdas mesmo com CCS entre 100 e 200 mil células/mL (Raubertas \& Shook, 1982).

Hortet et al. (1999), citam também, que para um dado nível de CCS a redução na produção de leite aumenta com o número de parições, ou com o estádio da lactação, na qual a CCS foi observada. Isso pode ser explicado pelo agravamento na saúde do úbere em vacas multíparas e/ou no final da lactação, ocasionado pela maior possibilidade de infecção e dano permanente à glândula por infecções prévias (Bartlett et al., 1990), e também, que vacas mais velhas tendem a ter infecções mais longas, causando danos mais extensos nos tecidos (Reneau, 1986).

Gadini et al. (1997a) apontam que a CCS, por não ter distribuição normal, deve ser transformada em escala logarítmica e convertida em escore de células somáticas, fornecendo, assim, uma distribuição normal com homogeneidade de variâncias, para evidenciar as perdas na produção de leite relacionadas a ela.

O programa nacional de melhoramento do rebanho leiteiro dos EUA (DHI), a fim de padronizar os dados, e melhorar o entendimento e interpretação, adotou em 1984 o método do escore linear (EL) proposto por Shook (1982), de tal forma a permitir uma relação direta (linear) do mesmo com as perdas de produção associadas à mastite (Kirk, 1984). A transformação usada é:

$$
\mathrm{EL}=\log _{2}\left(\frac{\mathrm{CCS}}{100}\right)+3
$$


Deve ficar claro que existem autores que utilizam o EL como medida padrão associada às perdas de produção de leite, porém, outros utilizam a simples transformação logarítmica da CCS.

Desse modo, dados de Wisconsin e Virgínia indicaram que para cada aumento unitário do EL médio da lactação ocorreu diminuição de $181 \mathrm{~kg}$ de leite na lactação inteira (Reneau, 1986), enquanto Fetrow et al. (1988), trabalhando com rebanhos da Carolina do Norte, encontraram queda de $190 \mathrm{~kg}$ de leite na média do rebanho quando a média do EL aumentava em uma unidade no tanque de leite.

Shook (2001) relata que vários estudos mostraram correlação genética positiva entre produção de leite e mastite clínica, o que implica que a seleção genética para produção de leite é acompanhada pelo aumento na susceptibilidade genética para mastite. Esse fato também é válido para a relação genética entre produção de leite e CCS (Gadini et al., 1997b; Kennedy et al., 1982).

Contudo, Haile-Mariam et al. (2001) encontraram correlações genéticas positivas entre produção de leite e CCS apenas no início da primeira lactação, sendo que no início da segunda e terceira lactações as correlações foram próximas de zero, e no final da lactação elas foram negativas em todas as situações.

\subsection{Curva de lactação}

As curvas de lactação, ao representarem a produção de leite, servem como importante ferramenta de tomada de decisão para o manejo dos animais. Portanto, as mesmas devem ser consideradas para a determinação na redução da produção de leite devida à CCS, possibilitando que no futuro sejam desenvolvidas ferramentas computacionais para auxiliar nas tomadas de decisão nas fazendas.

A curva de lactação é definida pelo gráfico da produção diária de leite ao longo do tempo (Kellogg et al., 1977). A produção de leite das vacas aumenta do parto até o 
pico de produção num período de poucas semanas; segue-se, então, declínio gradual até a secagem. O estudo da curva de lactação permite conhecer melhor o desenvolvimento deste processo fisiológico, favorecendo a tomada de decisões em relação ao manejo das vacas lactantes com base no estádio de lactação em que se encontram (Costa et al., 1982).

Segundo Keown \& Van Vleck (1973) a curva de lactação pode ser dividida em três segmentos: 1) a fase desde o dia de parição até o pico da lactação, que é não-linear e aumenta a taxa declinante até o pico; 2) a fase que vai do pico até aproximadamente 270 dias de lactação, que é linear e declina a taxa constante e 3) a fase próxima ao final da lactação, em que a produção declina a taxa ascendente.

Curvas de lactação podem ser geradas e estudadas através de modelos matemáticos. Vários modelos têm sido propostos ao longo dos anos para descrever a curva de lactação e, dentre eles, o modelo baseado na função gama incompleta, desenvolvido por Wood (1967), é um dos mais utilizados, pela facilidade de interpretação dos parâmetros.

O modelo gama tem a possibilidade de gerar curvas de muitos formatos e pode formar curvas de lactação afetadas por diferentes fatores biológicos e ambientais (Congleton Junior \& Everett, 1980). O modelo matemático é dado por:

$$
y_{t}=\alpha t^{\beta} e^{-\gamma t}+\varepsilon,
$$

em que $y_{t}$ é a produção de leite no dia em lactação $t ; \alpha, \beta$, e $\gamma$ são parâmetros desconhecidos a serem estimados; $e$ é a base dos logaritmos naturais e $\varepsilon$, o erro aleatório, suposto homocedástico (com variância $\sigma^{2}$ ), independente e normalmente distribuído.

O parâmetro $\alpha$ está associado à produção de leite no início da lactação (Wood, 1967) e é responsável por abaixar ou elevar toda a curva de lactação, não alterando, entretanto, seu formato geral (Batra, 1986); $\beta$ representa a fase de ascensão da curva no início da lactação (Shanks et al., 1981), sendo o principal responsável pela determinação do formato da curva antes do pico de lactação (Congleton Junior \& Everett, 1980) e $\gamma$ está associado com a fase de declínio da produção de leite após o pico (Shanks et al., 1981) (Figura 1). 
A persistência da lactação é indicada por $\gamma^{-(\beta+1)}$; a data do pico é dada por $t=\frac{\beta}{\gamma}$ e a produção no pico é igual a $\alpha\left(\frac{\beta}{\gamma}\right)^{\beta} e^{-\beta}$ (Wood, 1967).

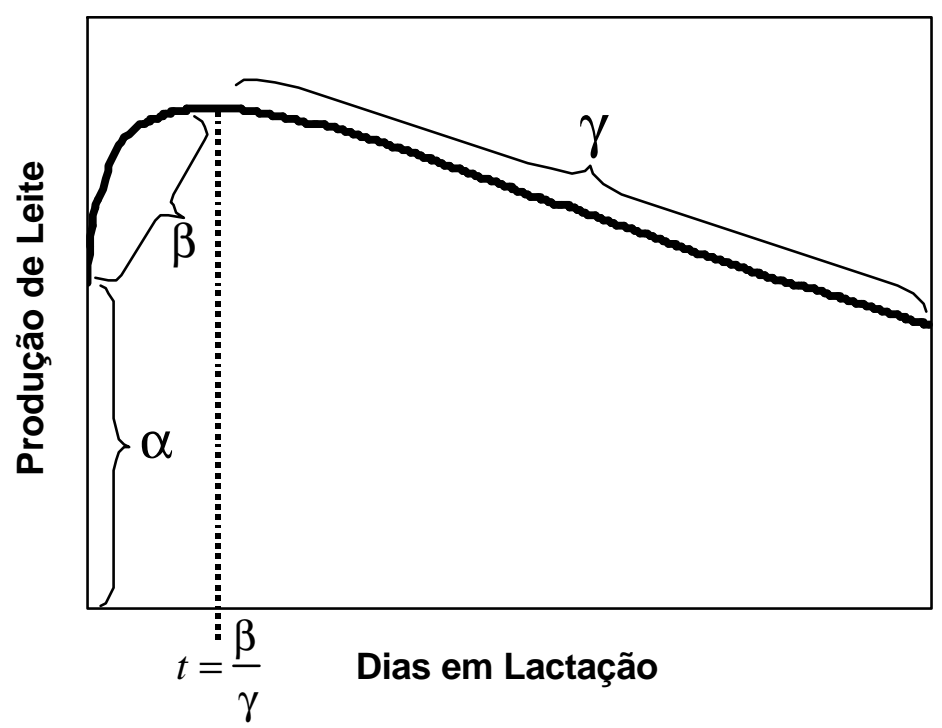

Figura 1 - Representação esquemática do modelo de Wood

O ajuste do modelo (1) e, consequentemente, a obtenção das estimativas dos parâmetros, geralmente é realizado através da regressão linear da transformação logarítmica da função, comprometendo algumas suposições a respeito do erro aleatório. Já, a comparação das estimativas dos parâmetros entre grupos (por exemplo, ordem de lactação) é feita individualmente, desconsiderando a correlação existente entre os parâmetros. Shanks et al. (1981) mostraram que, fenotipicamente, $\beta$ está negativamente correlacionado com $\ln (\alpha)$ e positivamente correlacionado com $\gamma$.

Segundo Ali \& Schaeffer (1987), os parâmetros das curvas geralmente são estimados por simples regressão, o que ignora a covariância entre as produções diárias. Entretanto, estes autores ao testarem o uso da covariância concluíram que sua utilização não torna as predições mais acuradas. 
De acordo com Congleton Junior \& Everett (1980), a alimentação inicial da função gama incompleta com lactações que apresentam períodos variáveis entre a parição e o primeiro controle indica que a duração deste período pode influenciar o formato da curva de lactação.

Assim, se a parte inicial da curva é curta, ou se está faltando informação sobre ela, a regressão linear da equação transformada pelo logaritmo estimará um $\beta$ negativo. Com valores positivos para $\alpha$ e $\gamma$, ambos os componentes da equação $t^{\beta}$ e $\mathrm{e}^{-\gamma \mathrm{t}}$ terão seus valores reduzidos com a elevação dos valores de $t$. A curva resultante terá uma taxa negativa em todos os dias e o pico de produção previsto $\left(t=\frac{\beta}{\gamma}\right)$ ocorrerá antes da parição. Curvas com este formato são responsáveis por grande parte da variação na produção de leite prevista para a primeira semana de lactação (Congleton Junior \& Everett, 1980).

Comparações entre modelos de curva de lactação têm sido realizadas no decorrer dos anos. Dentre elas, um estudo realizado na Austrália por Papajcsik \& Bodero (1988), usando o quadrado médio do resíduo com critério, identificou, dentre 20 modelos, que o de Wood, e uma modificação deste, de modo geral, levaram a melhor representação da curva de lactação. Entretanto, Rook et al. (1993), analisando 13 diferentes modelos matemáticos, concluíram que o modelo de Wood e um modelo Mitscherlich-Exponencial representavam melhor a curva de lactação do que os outros modelos, e que o modelo Mitscherlich-Exponencial, de uma maneira geral, era melhor do que o modelo de Wood.

A produção de leite e a forma da curva de lactação podem ser influenciados por diversos fatores, dentre os quais o ambiente, o ano de parição, a estação de parição, a idade ao parto, ou ordem de lactação, a duração dos períodos seco, de serviço e de gestação (Batra, 1986), e o grupo gené tico (Lopes et al., 1996).

\footnotetext{
${ }^{2}$ TOUCHBERRY, R.W. Environmental and genectic factors in development and maintenance of lactation. In: LARSON, L.; SMITH, V.R. Lactation - A comprehensive treatise. New York: Academic Press, 1974. 3 v. 425 p.
} 
Assim, por exemplo, Touchberry (1974) ${ }^{1}$, citado por Costa et al. (1982), observou que o pico de produção e a própria forma da curva de lactação são dependentes da condição física da vaca ao parto, do seu potencial genético, do estado de saúde e do regime alimentar nos vários estágios de lactação.

Porém, já em 1923, Sanders² citado por Batra (1986) reportou que a diferença na forma da curva de lactação entre vacas é maior do que a diferença entre as curvas de uma mesma vaca em diferentes parições, mostrando efeito genético sobre a curva.

\subsection{Fatores que afetam a produção de leite}

\subsubsection{Ordem de lactação}

É amplamente reconhecido que a ordem de lactação, ou idade da vaca, afeta a produção de leite. Vários autores, incluindo Almeida et al. (1997), Balieiro et al. (1997), Barbosa et al. (1996, 1997), Costa et al. (1982), Gabriel et al. (1998), Lopes et al. (1996), Matos et al. (1996), Miller et al. (1967), Mota et al. (1996), Pires (1984), Ribas et al. (1996a,b), Van Vleck \& Henderson (1961), dentre outros, mostraram que a idade da vaca, ou a ordem de lactação, influencia significativamente as produções mensais e/ou totais de leite.

$\mathrm{Na}$ literatura consultada a maioria dos autores relata que o aumento da ordem de lactação das vacas proporciona um aumento na produção de leite, porém, animais de primeira lactação têm maior persistência ${ }^{3}$, quando comparados com animais mais velhos. No modelo de Wood, esses fatos levam a menores estimativas de $\alpha$ e $\gamma$ para vacas primíparas quando comparados com os valores das multíparas (Kellogg et al. 1977).

Segundo Gabriel et al. (1998), o aumento da produção de leite devido à ordem de lactação, e consequentemente à idade da vaca, ocorre por causa do

\footnotetext{
${ }^{3}$ SANDERS, H.G. The shape of the lactation curve. Journal of Agricultural Science, v.13, p.169-179, 1923.
} 
desenvolvimento e crescimento do sistema mamário até o primeiro período seco. $\mathrm{O}$ animal adulto possui capacidades digestiva, circulatória e respiratória bem desenvolvidas, proporcionando-lhe um melhor desempenho.

As vacas adultas podem produzir $25 \%$ a mais de leite do que as vacas primíparas. O aumento do peso corporal responde por aproximadamente 5\% desse acréscimo, ao passo que os outros $20 \%$ são resultado do desenvolvimento do úbere durante as gestações decorrentes (Lopes et al., 1996).

De uma forma geral, a produção de leite máxima ocorre por volta da 5 . $^{\mathrm{a}}$ lactação (Balieiro et al., 1997; Gabriel et al., 1998; Neiva et al., 1992), correspondendo à idade entre 69 e 105 meses (Balieiro et al., 1997; Durães et al., 2000; Mejia et al., 1982; Pires, 1984).

A curva de lactação de vacas mais jovens é caracterizada por menores níveis de produção ao longo da lactação, mas com decréscimos mensais reduzidos, o que garante elevada persistência quando comparada com a das vacas mais velhas (Batra, 1986; Costa et al., 1982; Miller et al., 1967).

Os efeitos da idade sobre a curva de lactação diferem em função do estágio de lactação (Miller et al., 1967). Aparentemente ocorre um maior efeito inibidor provocado pela gestação em animais mais velhos, devido aos maiores níveis de produção (Costa et al., 1982). Com o aumento da produção total de acordo com a idade da vaca ao parto, a primeira fase de lactação é mais importante, por apresentar maior contribuição para a produção total de leite no período. Em consequiência, a contribuição dos últimos meses é bem menor, o que, de certa forma, está relacionado com a persistência, que tende a diminuir com a idade (Costa et al., 1982). Esse mesmo autor, ainda cita, que uma razão para o rápido declínio da produção de leite no final da lactação é o desenvolvimento do novo feto.

\footnotetext{
${ }^{4}$ A persistência é entendida como a habilidade da vaca de manter a produção de leite ao longo de uma lactação (Molento et al., 1996).
} 


\subsection{2 Época do parto}

Segundo Gasparino (1996), a produção de leite pode ser influenciada, direta ou indiretamente, pela época do parto, por causa de diferenças climáticas entre as estações do ano, oferecendo melhores ou piores condições de temperatura, luminosidade e precipitação pluviométrica, podendo refletir na qualidade e quantidade de forragem e, logicamente, afetando a produção e a reprodução dos animais.

Conseqüentemente, o efeito da época do parto sobre a produção de leite depende amplamente do nível de tecnologia da exploração, isto é, o efeito será tanto mais evidente quanto maior for a dependência de pastagens. Por outro lado, o efeito será reduzido se o suprimento de alimentos de alta qualidade ocorrer durante o ano inteiro (Pires, 1984).

Em animais confinados, desde que a qualidade e a quantidade dos alimentos sejam mantidas, a temperatura é o principal fator que interfere na produção de leite, pois ela afeta o apetite, sobretudo nos primeiros meses de lactação (Costa et al., 1982).

No Brasil, a época do parto, ou estação de parição, tem sido relatada por muitos como um fator que influencia a produção de leite de vacas da raça Holandesa, ou mestiças (Almeida et al., 1997; Barbosa et al., 1996, 1997; Balieiro et al., 1997; Costa et al., 1982; Gabriel et al., 1998; Gasparino, 1996; Matos et al., 1996; Mota et al., 1996; Queiroz et al., 1987; Ribas et al., 1996b), todavia, alguns autores não encontraram diferenças significativas (Lopes et al., 1996; Mcnanus et al., 1997; Neiva et al., 1992; Pires, 1984).

Ribas et al. (1996b), em pesquisa realizada no Estado do Paraná, mostraram que vacas holandesas paridas no inverno apresentaram as maiores produções totais de leite, enquanto aquelas paridas no verão foram as menos produtivas. Esses resultados são corroborados pela maioria da literatura consultada.

No Estado de Minas Gerais, Costa et al. (1982) apontam que lactações iniciadas no inverno foram pouco persistentes, apesar de terem resultado, junto com as 
lactações do outono, nas mais altas produções totais, devido aos maiores níveis de produção no início da lactação. Já, as lactações iniciadas no verão apresentaram níveis mais baixos de produção no início, contudo, com persistência maior do que daquelas iniciadas no inverno, porque o regime alimentar e as condições alimentares foram mais favoráveis na porção final do período lactação.

Na literatura consultada não se encontram artigos que relatem o efeito da interação entre ordem de lactação e época do parto sobre a produção de leite. A partir desse fato pode-se perguntar: Será que a produção de leite para cada época do parto independe da ordem de lactação?

\subsubsection{Rebanho}

O efeito de rebanho sobre a produção de leite é esperado, e fácil de ser explicado, mesmo para rebanhos confinados, pois existem diferenças genéticas entre os animais de diferentes rebanhos. O manejo nutricional (qualidade e quantidade de alimentos, principalmente) e de ordenha também contribuem muito para isso, além das diferenças climáticas e do conforto térmico proporcionado aos animais, dentre outros.

No Brasil, vários autores estudaram o efeito de rebanho sobre a produção de leite de vacas da raça Holandesa e/ou mestiças, ou o incluíram em seus modelos para explicar a produção de leite. Dentre eles podem-se citar: Almeida et al. (1997), Durães et al. (2000, 2001), Ferreira et al. (2000), Freitas et al. (1997), Gasparino (1996), Matos et al. (1996), Ribas et al. (1996b), Teixeira et al. (1997). Entretanto, nenhum desses relatou efeito não significativo de rebanho.

Em sua revisão de literatura, Gasparino (1996) relata que o efeito de rebanho explica entre $11,4 \%$ e $13,8 \%$ da variação total da produção de leite.

\subsubsection{Escore de condição corporal ao parto}

O escore de condição corporal é uma maneira subjetiva de avaliar as reservas energéticas da vaca, baseado na observação visual e na palpação de áreas 
específicas para determinar os depósitos de tecido adiposo e massa muscular (Lago et al., 2001).

O sistema de escores mais utilizado nos Estados Unidos é aquele proposto por Wildman et al. (1982), com escala de 1 a 5, e intervalos de 0,25 pontos para medir o escore de condição corporal (Chalupa et al., 1996; Edmonson et al., 1989; Lago et al., 2001). O valor 1 é indicativo de uma vaca muito magra, com pouca reserva corporal, enquanto o valor 5 indica que a vaca está obesa.

Nesse sentido, Chalupa et al. (1996) e Ferguson et al. (1994) relatam que extremos físicos de obesidade ou magreza ao parto predispõem as vacas leiteiras a problemas sanitários, reprodutivos e produtivos. Todavia, as evidências sobre o efeito do escore de condição corporal ao parto (ECCP) sobre a produção de leite subseqüente são conflitantes, com alguns experimentos mostrando benefício relacionado ao aumento do ECCP, mas outros não, sendo que os resultados podem depender do plano nutricional préparto (Broster \& Broster, 1998; Garnsworthy, 1988).

Ferguson et al. (1994) recomendam o valor de 3,5 como ideal para o ECCP de novilhas e vacas, com intervalo de 3,25 a 3,75, o que é confirmado por Risco et al. (2002).

Dentre as pesquisas que não evidenciaram efeito do ECCP sobre a produção de leite, podem ser citadas as de Pedron et al. (1993) e Ruegg \& Milton (1995). Os primeiros consideraram 3 classes de $\operatorname{ECCP}(3,3,5$ e 4) e não encontraram diferenças significativas entre essas classes para produção de leite aos 305 dias, produção no pico, e para os 3 parâmetros do modelo gama. Já, Ruegg \& Milton (1995), classificaram o ECCP em 4 classes ( $\geq 4$, de 3,5 a 3,75, de 3 a 3,25 e <3), e outrossim, não encontraram diferenças significativas entre essas classes para produção no pico de lactação e aos 305 dias.

Em um dos poucos trabalhos realizados no Brasil relacionado com essa temática, Lago et al. (2001) mostraram que o ECCP não influenciou significativamente a produção de leite até 8 semanas pós-parto. 


\subsubsection{Ocorrência de doenças no periparto}

As doenças podem afetar a eficiência produtiva por reduzir a produção de leite, o desempenho reprodutivo ou a expectativa de vida da vaca leiteira (Dohoo et al., 1983). Contudo, o efeito da ocorrência de doenças no periparto sobre a produção do leite não é fácil de ser estimado, pois depende de vários fatores, como a habilidade em reconhecer os sintomas da doença, a rapidez na execução do tratamento, bem como do manejo geral do rebanho (Ostergaard et al., 2000). Além disso, diferentes critérios de diagnóstico podem afetar as estimativas, ou mesmo, invalidar o estudo.

Assim, Kossaibati \& Esslemont (1997), utilizando várias referências, citaram redução de 300 litros de leite para cada caso de metrite, 385 litros para cada caso de retenção de placenta e 500 litros para cada caso severo de febre do leite.

Joosten et al. (1988), pesquisando outros trabalhos, citam redução de 207 $\mathrm{kg}$ de leite para cada caso de retenção de placenta e assumem que essas perdas ocorrem nos primeiros 60 dias após o parto.

Utilizando concentrações de acetona do leite com o intuito de determinar cetose subclínica, Miettinen \& Setala (1993) encontraram correlação negativa e significativa entre a concentração de acetona no início da lactação e a produção de leite naquele momento e em períodos subseqüentes.

Em estudo realizado no Estado de São Paulo, considerando aborto, retenção de placenta, cetose e deslocamento de abomaso como doenças do periparto, Cassoli et al. (2000) não encontraram diferenças significativas entre vacas acometidas por alguma dessas doenças ou aquelas saudáveis, para a produção de leite aos 305 dias em lactação, tanto para vacas primíparas, quanto para multíparas. O pico de produção de leite das vacas multíparas que apresentaram alguma doença foi significativamente menor do que o das vacas não doentes. 


\section{CONTAGEM DE CÉlulas SOMÁTICAS E PROdUÇÃo DE LEITE EM VACAS HOLANDESAS DE ALTA PRODUÇÃO}

\section{Resumo}

O objetivo do presente trabalho foi verificar se as perdas na produção de leite devidas ao aumento do número de células somáticas (CCS) são proporcionais à produção ou absolutas, ou seja, independentes do nível de produção. Além disso, procuroutse determinar a partir de que valor de CCS as perdas começam a ser evidentes. Para o estudo foram utilizadas 7.756 observações, colhidas mensalmente de um único rebanho, durante o período de setembro de 2000 a junho de 2002. O modelo de análise, para curva de lactação, foi baseado na função gama incompleta, considerando os efeitos de ordem de lactação, época do parto, ocorrência de doenças no periparto e escore de condição corporal ao parto. A CCS foi incluída nesse modelo de duas formas: como fator multiplicativo (representando perdas relativas) e como fator aditivo (representando perdas absolutas). A escolha do melhor modelo foi baseada no critério de informação de Schwarz (BIC). Conclui-se que as perdas são absolutas, iniciam a partir de 14.270 células/mL e para cada aumento unitário na escala do logaritmo natural a partir desse valor, estimam-se perdas de 184 e 869 g/dia para vacas primíparas e multíparas, respectivamente. 


\section{Summary}

The goal of the present study was to evaluate if losses in milk yield due to increase in somatic cells count (SCC) are proportional to the yield, or absolute, i.e., independent of the level of production. The cut-off value from which SCC the losses become evident was also determined. For this study, 7,756 observations were used, monthly collected from a single herd, from September/2000 up to June/2002. The analysis model, for lactation curve, was based upon the incomplete gamma function, considering the effects of lactation order, calving season, peripartum disorder incidence and body condition score at calving. Somatic cells count was added to the model in two different ways: as a multiplicative factor (representing relative losses) and as a addictive factor (representing absolute losses). The best model was chosen based on the information criteria of Schwarz (BIC). The analysis show that losses are absolute, becoming from 14,270 cells $/ \mathrm{mL}$, and they are 184 and $869 \mathrm{~g} /$ day for each unitary increase in the natural logarithm scale, starting from that SCC, for primiparous and multiparous cows, respectively.

\subsection{Introdução}

O estudo da mastite bovina é de extrema importância, pois ela é o fator que mais contribui para as perdas econômicas da cadeia produtiva do leite (Kossaibati \& Esslemont, 1997; Laranja \& Machado, 1994; Lescourret \& Coulon, 1994). Portanto, a tentativa nacional de suprir a demanda por produtos lácteos em quantidade e qualidade deve considerar esse fator. Porém, antes disso, é necessário que as perdas na produção de leite devidas à mastite sejam quantificadas, considerando as condições em que os nossos rebanhos são explorados.

A mastite pode ser classificada em clínica e subclínica (Philpot \& Nickerson, 1991). A forma clínica caracteriza-se por apresentar sinais visíveis; enquanto a forma subclínica exige o emprego de outros métodos de diagnóstico, como a contagem de células somáticas 
(CCS). Essa última variável é afetada principalmente pela infecção intramamária (Harmon, 1994; Machado et al., 2000; Reneau, 1986; Rodriguez-Zas et al., 2000).

Em um rebanho estadunidense típico, a diminuição da produção de leite associada à mastite subclínica representa de 70 a $80 \%$ de todas as perdas econômicas advindas da mastite (Fetrow et al., 2000).

De acordo com Schepers \& Dijkhuizen (1991) as estimativas dos efeitos da mastite no desempenho das vacas leiteiras mostraram grande variação entre estudos. Isso pode ser atribuído às diferenças nas populações estudadas, aos indicadores de mastite e métodos estatísticos utilizados (Lescourret \& Coulon, 1994; Hortet et al., 1999).

Um modelo de perdas de produção devidas à mastite deve considerar outras variáveis que influenciam a produção de leite, tais como: o número de dias em lactação, representado pela curva de lactação (Olori et al., 1999; Rekaya et al., 2001; Wood, 1967), a ordem de lactação, ou idade da vaca (Freitas et al., 2001; Friggens et al., 1999; Pereira, 2000; Rekaya et al., 2001), a época do parto (Durães et al., 2001), a ocorrência de denças no periparto (Joosten et al., 1988; Miettinen \& Setälä, 1993) e o escore de condição corporal ao parto (ECCP) (Ferguson et al., 1994; Broster \& Broster, 1998).

O presente trabalho teve como objetivo encontrar um modelo para as perdas na produção de leite em função do aumento da CCS, baseando-se na curva de lactação e fatores que podem alterá-la. Buscou-se responder, com base em dados de um único rebanho, se as perdas associadas à CCS são uma proporção da produção (perdas relativas), ou se independem do nível de produção (perdas absolutas), bem como o valor de CCS a partir do qual as perdas têm início. 


\subsection{Material e Métodos}

\subsubsection{Os dados}

Foram utilizadas 7.756 observações, provenientes de 855 vacas da raça Holandesa, pertencentes ao rebanho da Fazenda Colorado, situada no município de Araras, Estado de São Paulo, região de clima subtropical, com temperatura média máxima de $35^{\circ} \mathrm{C}$ em dezembro, janeiro e fevereiro, e média mínima de $10^{\circ} \mathrm{C}$ em maio, junho e julho.

As observações são referentes ao período compreendido entre setembro de 2000 e junho de 2002, abrangendo vacas com no máximo 5 lactações e com dias em lactação variando entre 11 e 305 dias.

As vacas estavam confinadas em 9 "free-stalls", dotados de ventiladores e aspersores acionados automaticamente quando a temperatura ambiente ultrapassava $23^{\circ} \mathrm{C}$. Eram alimentadas 7 vezes ao dia, sendo a primeira refeição às 5:00 horas e a última às 21:00 horas. A dieta das vacas foi total e única.

As fêmeas com mais de 150 dias em lactação e com escore de condição corporal maior do que ou igual a 2,75 receberam injeções subcutâneas de somatotropina bovina $\left(\right.$ Boostin $\left.^{\circledR}\right)$ a cada 14 dias.

As ordenhas foram realizadas 3 vezes ao dia, em sala do tipo Espinha de Peixe,

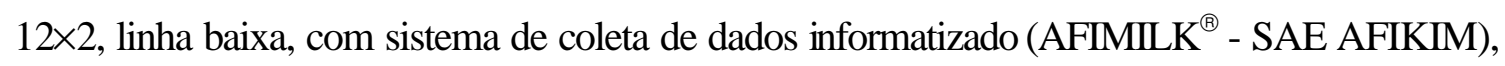
onde cada animal é identificado e a produção de leite é registrada.

As amostras de leite foram coletadas mensalmente, sempre na ordenha da manhã, transferidas diretamente do medidor para os frascos de coleta (os quais continham Bronopol como conservante), homogeneizadas por no mínimo 15 segundos e encaminhadas imediatamente ao Laboratório de Fisiologia da Lactação, da Clínica do Leite, Departamento de Zootecnia da Escola Superior de Agricultura "Luiz de Queiroz", Universidade de São Paulo (ESALQ/USP), para determinação da CCS (em mil células $/ \mathrm{mL}$ ). A CCS foi estimada por citometria de fluxo pelo equipamento Somacount $300^{\circledR}$, da Bentley Instruments, Incorporation. 
O banco de dados comportava, ainda, a ocorrência de doenças no periparto e o escore de condição corporal ao parto (ECCP, com escala de 1 a 5 e variações de 0,25 unidades). As doenças consideradas foram aborto, retenção de placenta (quando os anexos fetais foram retidos por um período superior a 18 horas pós-parto), metrite primária (ocorrida até 20 dias pós-parto) e secundária (após caso de retenção de placenta), febre do leite (confirmada quando o animal respondeu imediatamente ao tratamento endovenoso com solução de gluconato de cálcio), cetose (considerada apenas após diagnóstico de cetose clínica nos primeiros 15 dias pós-parto) e deslocamento de abomaso (caso confirmado após correção cirúrgica).

Um resumo da produção de leite e da CCS é apresentado na Tabela 1, com o intuito de balizar estudos posteriores.

Tabela 1. Número de vacas e de observações (n), média e desvio padrão da produção de leite e da CCS, em função da ordem de lactação e da época do parto

\begin{tabular}{|c|c|c|c|c|c|c|c|c|}
\hline \multirow{2}{*}{$\begin{array}{l}\text { Ordem de } \\
\text { Lactação }\end{array}$} & \multirow{2}{*}{$\begin{array}{c}\text { Época do } \\
\text { Parto }\end{array}$} & \multirow{2}{*}{$\begin{array}{l}\mathrm{N} .{ }^{\circ} \mathrm{de} \\
\text { vacas }\end{array}$} & \multirow[b]{2}{*}{$\mathrm{n}$} & \multicolumn{2}{|c|}{ LEITE (kg/dia) } & \multicolumn{3}{|c|}{$\mathrm{CCS}\left(\times 10^{3}\right.$ células $\left./ \mathrm{mL}\right)$} \\
\hline & & & & Média & $\begin{array}{l}\text { Desvio } \\
\text { Padrão }\end{array}$ & Média & $\begin{array}{l}\text { Desvio } \\
\text { Padrão } \\
\end{array}$ & $\begin{array}{c}\text { Média } \\
\text { Geométrica } \\
\end{array}$ \\
\hline \multirow{2}{*}{1} & Inverno & 245 & 1759 & 32,2 & 6,2 & 184,8 & 565,4 & 54,7 \\
\hline & Verão & 205 & 1150 & 33,0 & 6,2 & 174,0 & 493,5 & 60,7 \\
\hline \multirow{2}{*}{2} & Inverno & 185 & 1280 & 37,8 & 8,4 & 184,7 & 527,6 & 53,6 \\
\hline & Verão & 156 & 914 & 36,7 & 8,4 & 293,9 & 835,2 & 75,9 \\
\hline \multirow{2}{*}{$\begin{array}{c}3 \text { ou } \\
\text { superior }\end{array}$} & Inverno & 210 & 1652 & 38,4 & 9,6 & 376,8 & 925,9 & 87,6 \\
\hline & Verão & 146 & 1001 & 37,8 & 9,5 & 415,9 & 1111,2 & 96,0 \\
\hline
\end{tabular}

\subsubsection{Modelo para descrever a curva de lactação}

Para descrever a curva de lactação das vacas foi utilizado o modelo baseado na função gama incompleta, desenvolvido por Wood (1967):

$$
y_{t}=\alpha t^{\beta} e^{-\gamma t}+\varepsilon,
$$


sendo: $y_{t}$, a produção de leite no dia em lactação $t ; \alpha$, um parâmetro desconhecido a ser estimado que representa a produção de leite no início da lactação, responsável por abaixar ou elevar toda a curva de lactação, não alterando, contudo, seu formato geral; $\beta$, um parâmetro desconhecido a ser estimado que está associado à fase de ascensão da produção de leite no início da lactação; $\gamma$ um parâmetro desconhecido a ser estimado que está associado à fase de declínio da produção de leite após o pico, o qual ocorre quando $t=\beta / \gamma$; e $\varepsilon$, o erro aleatório, suposto homocedástico (com variância $\sigma^{2}$ ), independente e normalmente distribuído.

\subsubsection{Ajuste do modelo usado para descrever a curva de lactação}

Por se tratar de modelo não-linear, porém, totalmente linearizável, o modelo (1) foi ajustado utilizando-se a teoria de modelos lineares generalizados proposta por Nelder \& Wedderburn (1972), utilizando-se o procedimento GENMOD do SAS (SAS Institute, 1999).

Denotando-se a esperança matemática $\mathrm{E}\left[Y_{t}\right]$ por $\mu_{t}$, pode-se linearizar sua expressão aplicando-se logaritmo natural. Logo,

$$
\eta_{t}=\operatorname{Ln}\left(\mu_{t}\right)=\operatorname{Ln}(\alpha)+\beta \operatorname{Ln}(t)-\gamma t,
$$

sendo, $\eta_{t}$ o preditor linear, funcionalmente ligado à média $\mu_{t}$ através da função logaritmo.

Desta maneira, o ajuste do modelo (1) foi efetuado supondo que a distribuição da produção de leite $\left(Y_{t}\right)$ é normal, com média $\mu_{t}$ e variância $\sigma^{2}$, tendo o logaritmo como função de ligação, $\operatorname{Ln}(t)$ e $t$ como variáveis explanatórias.

\subsubsection{Seleção do modelo para curva de lactação}

Considerourse o modelo (1) como modelo minimal (com 3 parâmetros) em relação ao número de parâmetros. Porém, como a curva de lactação pode ser influenciada por outros fatores para os quais se dispõe de informação como ordem de lactação, época do parto, 
ECCP e ocorrência de alguma doença no periparto, foram ajustados 90 modelos contidos entre o modelo minimal e o modelo (3), chamado de maximal (com 108 parâmetros).

$$
\mathrm{E}\left[Y_{t i j k m}\right]=\mu_{t i j k m}=\alpha_{i j k m} t^{\beta_{i j k m}} e^{-\gamma_{i j k m t}},
$$

sendo: $\mathrm{E}\left[Y_{t i j k m}\right]$, a média da produção de leite no dia em lactação $t(t=11, \ldots, 305)$, na ordem de lactação $i$ ( $i=1$, 2 e 3 ou superior), da época do parto $j[j=1$, para verão (meses de outubro a março) e 2, para inverno (meses de abril a setembro)], com a ocorrência de doença no periparto $k(k=1$, para doente e 2, para sadia) e com ECCP $m(m=1$, para ECCP $\leq 3 ; 2$, para $3<\mathrm{ECCP}<4$ e 3 , para ECCP $\geq 4$ ), representada por $\mu_{t i j k m}$; $t$ o número de dias em lactação; $\alpha_{i j k m}, \beta_{i j k m}$ e $\gamma_{i j k m}$, parâmetros desconhecidos e interpretados como em (1), contudo, variando com a ordem de lactação $i$, com a época do parto $j$, com a ocorrência de doença no periparto $k$ e com o ECCP $m$.

A categorização do ECCP foi baseada no trabalho de Ferguson et al. (1994) que sugere um intervalo de 3,25 a 3,75 como ideal.

A escolha do melhor modelo foi baseada no critério de informação de Schwarz $\left[\mathrm{BIC}^{1}=-2 \times \operatorname{Ln}(\right.$ verossimilhança max. $)+$ n. $^{\circ}$ de parâmetros $\times \operatorname{Ln}\left(n .^{\circ}\right.$ de observações $\left.)\right]$, conforme sugerido por SAS Institute (1999), sendo considerado o melhor modelo aquele que apresentou o menor valor do BIC. Esse critério tem a vantagem de considerar o número de observações e o número de parâmetros do modelo.

No Anexo A são mostrados alguns exemplos de sintaxe para o ajuste dos modelos propostos.

\subsubsection{Curva de lactação e CCS}

Após a escolha do melhor modelo para representar a curva de lactação dos animais, adicionoutse a ele um termo denotado por $x$ com os valores de CCS, de modo que as

\footnotetext{
${ }^{1}$ Bayesian information criterion
} 
perdas associadas ao aumento da CCS fossem relativas à produção - modelo (4) - ou absolutas - modelo (5):

$$
\begin{aligned}
& \mathrm{E}\left[Y_{t i j k x}\right]=\mu_{t i j k x}=\mathrm{M}(\phi) I_{x} \delta, \\
& \mathrm{E}\left[Y_{t i j k x}\right]=\mu_{t i j k x}=\mathrm{M}(\phi)+\delta \operatorname{Ln}\left(I_{x}\right),
\end{aligned}
$$

sendo: $\mathrm{E}\left[Y_{t i j k x}\right]$, a média da produção de leite no dia em lactação $t$, na ordem de lactação $i$, na época do parto $j$, com ocorrência de doença no periparto $k$, com ECCP $m$ e com CCS igual a $x$, representada por $\mu_{t i j k m x} ; \mathrm{M}(\phi)$, o modelo escolhido para representar a curva de lactação; $I_{x}=\left\{\begin{array}{l}x-x_{0}+1, \text { se } x>x_{0} \\ 1, \text { caso contrário }\end{array} ; x\right.$, a CCS; $x_{0}$, um parâmetro desconhecido que representa o valor da CCS a partir do qual começam a ocorrer perdas; e $\delta$, um parâmetro desconhecido que, no modelo (4), representa o decréscimo proporcional da produção de leite em função do aumento da CCS, e no modelo (5), a quantidade de leite perdida por unidade logarítmica de aumento da CCS.

\subsubsection{Ajuste e seleção do modelo para CCS}

Com a inclusão da CCS os modelos (4) e (5) passam a ser não-linearizáveis e o ajuste dos mesmos foi realizado através da utilização de métodos de ajuste não-linear, pelo procedimento NLMIXED do SAS (SAS Institute, 1999).

Ademais, considerando que o valor do parâmetro $\delta$ pode variar com a ordem de lactação $i$, com a época do parto $j$, com a ocorrência de doença no periparto $k$, com o ECCP $m$ e com o estágio da lactação $n$ [ $n=$ início (11 a 45 dias), meio (46 a 179 dias) e fim da lactação (180 dias ou mais)], foram ajustados 26 modelos contendo todas as possíveis combinações dessas variáveis ligadas a esse parâmetro, até terceira ordem, para os modelos de perdas relativas e absolutas, totalizando 52 modelos, e dentre os quais foi selecionado como o melhor aquele que apresentou o menor valor de BIC.

Para maiores detalhes do processo de estimação de $x_{0}$ ver Anexo B. 


\subsection{Resultados e Discussão}

\subsubsection{Seleção do modelo para curva de lactação}

Os 90 modelos ajustados para curva de lactação, com seus respectivos números de parâmetros e critérios de informação de Schwarz (BIC) estão apresentados na Tabela 2. Observa-se que o modelo $y=\alpha_{i j} t^{\beta_{i j}} e^{-\gamma_{j} t}$, com 14 parâmetros, foi o que apresentou o menor BIC $(52959,4)$ e, portanto, considerado o melhor modelo. O pior modelo foi $y=\alpha_{j m} t^{\beta_{j m}} e^{-\gamma_{j m} t}$, com 18 parâmetros e BIC $=54569,4$.

Observe-se que, para o melhor modelo, os parâmetros $\alpha$ e $\beta$ da curva de lactação variam em função da ordem de lactação e da época do parto, ao passo que o parâmetro $\gamma$ muda apenas para a época do parto. Isso evidencia que, além do número de dias em lactação, a produção de leite foi significativamente afetada pela ordem de lactação e pela época do parto, o que está de acordo com a literatura citada na introdução deste trabalho.

O ECCP não afetou os parâmetros da curva de lactação, corroborando com o estudo de Lago et al. (2001), que mostraram que esse fator não influenciou significativamente a produção de leite até 8 semanas pós-parto. Broster \& Broster (1998) afirmam que as evidências sobre o efeito do ECCP sobre a produção de leite subseqüente são conflitantes, com alguns experimentos mostrando um benefício relacionado ao aumento do ECCP, mas outros não. Eles atestam que os resultados podem depender do plano nutricional pré-parto.

A ocorrência de doenças no periparto não afetou os parâmetros da curva de lactação, provavelmente porque os aspectos nutricionais e ambientais do rebanho estudado contrabalançaram as possíveis diferenças de produção. 
Tabela 2. Modelos para curva de lactação com seus respectivos números de parâmetros (Par.) e valores do critério de informação de Schwarz (BIC)

\begin{tabular}{|c|c|c|c|c|c|c|c|c|}
\hline Modelo $^{1}$ & Par. & $3 \mathrm{IC}$ & Modelo & Par. & $\mathrm{BIC}$ & Modelo & Par. & $\mathrm{BIC}$ \\
\hline$=\alpha t^{\beta} e^{-\gamma t}$ & 3 & 4557,1 & $=\alpha_{i} t^{\beta_{i}} e^{-\gamma t}$ & 7 & 53015,5 & $y=\alpha_{i j k m} t^{\beta} e^{-\gamma t}$ & 38 & 842,7 \\
\hline$=\alpha_{i} t^{\beta_{i}} e^{-\gamma_{i} t}$ & 9 & 3024,4 & $=\alpha_{i} t^{\beta_{j}} e^{-\gamma t}$ & 6 & 53695,9 & $y=\alpha_{i j} t^{\beta_{i}} e^{-\gamma t}$ & 10 & 53005,2 \\
\hline$y=\alpha_{j} t^{\beta_{j}} e^{-\gamma_{j} t}$ & 6 & 54527,9 & $y=\alpha_{i} t^{\beta_{k}} e^{-\gamma t}$ & 6 & 53689,7 & $y=\alpha_{i j} t^{\beta_{j}} e^{-\gamma t}$ & 9 & 53634,0 \\
\hline$y=\alpha_{k} t^{\beta_{k}} e^{-\gamma_{k} t}$ & 6 & 54423,5 & $y=\alpha_{i} t^{\beta_{m}} e^{-\gamma t}$ & 7 & 53679,9 & $y=\alpha_{i j t} \beta_{k} e^{-\gamma t}$ & 9 & 53686,6 \\
\hline$y=\alpha_{m} t^{\beta_{m}} e^{-\gamma_{m} t}$ & 9 & 54564,0 & $=\alpha_{i} t^{\beta_{i j}} e^{-\gamma t}$ & 10 & 53010,2 & $y=\alpha_{i j} \beta^{\beta_{m e}}{ }^{-\gamma t}$ & 10 & 53679,4 \\
\hline$=\alpha_{i j} t^{\beta_{i j}} e^{-\gamma_{i j} t}$ & 18 & 52988,6 & $y=\alpha_{i} t^{\beta_{i k}} e^{-\gamma t}$ & 10 & 53018,4 & $y=\alpha_{i j} t^{\beta_{i j}} e^{-\gamma t}$ & 13 & 52968,6 \\
\hline$y=\alpha_{i k} t^{\beta_{i k}} e^{-\gamma_{i k} t}$ & 18 & 53057,8 & $=\alpha_{i} t^{\beta_{i m}} e^{-\gamma t}$ & 13 & 53017,8 & $y=\alpha_{i j}{ }_{t} \beta_{i k} e^{-\gamma t}$ & 13 & 53013,6 \\
\hline$=\alpha_{i m} t^{\beta_{i m}} e^{-\gamma_{i m} t}$ & 27 & 53108,2 & $=\alpha_{i} t^{\beta_{j k}} e^{-\gamma t}$ & 8 & 53707,0 & $y=\alpha_{i j} t_{i m} e^{-\gamma t}$ & 16 & 53014,3 \\
\hline$=\alpha_{j k} t^{\beta_{j k}} e^{-\gamma_{j k} t}$ & 12 & 54423,7 & $=\alpha_{i} t_{j m}^{\beta_{j m}} e^{-\gamma t}$ & 10 & 53695,8 & $y=\alpha_{i j} t^{\beta_{j k}} e^{-\gamma t}$ & 11 & 53645,7 \\
\hline$y=\alpha_{j m} t^{\beta_{j m}} e^{-\gamma_{j m} t}$ & 18 & 54569,4 & $=\alpha_{i} t_{k m}^{\beta_{k m}} e^{-\gamma t}$ & 10 & 53698,4 & $y=\alpha_{i j} t^{\beta j m} e^{-\gamma t}$ & 13 & 53643,6 \\
\hline$y=\alpha_{k m}{ }^{\beta_{k m}} e^{-\gamma_{k m} t}$ & 18 & 54481,6 & $=\alpha_{i} t^{\beta_{i j k}} e^{-\gamma t}$ & 16 & 53041,9 & $y=\alpha_{i j} t_{k m} e^{-\gamma t}$ & 13 & 53697,4 \\
\hline$y=\alpha_{i j k} t^{\beta_{i j k}} e^{-\gamma_{i j k} t}$ & 36 & 53100,0 & $=\alpha_{i} t^{\beta_{i j m}} e^{-\gamma t}$ & 22 & 53046,4 & $y=\alpha_{i j} t^{\beta_{i j k}} e^{-\gamma t}$ & 19 & 53001,0 \\
\hline$y=\alpha_{i j m} t^{\beta_{i j m}} e^{-\gamma_{i j m} t}$ & 54 & 53209,8 & $y=\alpha_{i} t^{\beta_{i k m}} e^{-\gamma t}$ & 22 & 53076,6 & $y=\alpha_{i j} t^{\beta_{i j m}} e^{-\gamma t}$ & 25 & 53007,5 \\
\hline$y=\alpha_{i k m} t^{\beta_{i k m}} e^{-\gamma_{i k m} t}$ & 54 & 53282,6 & $y=\alpha_{i} t^{\beta_{j k m}} e^{-\gamma t}$ & 16 & 53728,7 & $y=\alpha_{i j} t_{i k m} e^{-\gamma t}$ & 25 & 53071,7 \\
\hline$y=\alpha_{j k m} t^{\beta_{j k m}} e^{-\gamma_{j k m} t}$ & 36 & 54564,6 & $y=\alpha_{i} t^{\beta_{i j k m}} e^{-\gamma t}$ & 40 & 53153,0 & $y=\alpha_{i j} t^{\beta_{j k m}} e^{-\gamma t}$ & 19 & 53678,4 \\
\hline$y=\alpha_{i j k m} t^{\beta_{i j k m}} e^{-\gamma_{i j k m} t}$ & 108 & 53583,3 & $y=\alpha_{i j} t^{\beta_{i j}} e^{-\gamma_{i} t}$ & 15 & 52984,1 & $y=\alpha_{i j} t^{\beta_{i j k m}} e^{-\gamma t}$ & 43 & 53116,7 \\
\hline$y=\alpha_{i} t^{\beta} e^{-\gamma t}$ & 5 & 53687,0 & & 14 & & & 21 & 53016,5 \\
\hline$y=\alpha_{j}{ }_{t}{ }^{\beta} e^{-\gamma t}$ & 4 & 54565,0 & $y=\alpha_{i j} t^{\beta_{i j}} e^{-\gamma_{k} t}$ & 14 & 52974,0 & $y=\alpha_{i j} t^{\beta_{i j k}} e^{-\gamma_{j} t}$ & 20 & 52992,1 \\
\hline$y=\alpha_{k} t^{\beta} e^{-\gamma t}$ & 4 & 54479,0 & $y=\alpha_{i j} t^{\beta_{i j}} e^{-\gamma_{m} t}$ & 15 & 52972,3 & $y=\alpha_{i j} t^{\beta_{i j k}} e^{-\gamma_{k} t}$ & 20 & 52990,9 \\
\hline$\nu_{t} \beta-\gamma t$ & 5 & 54565,8 & $y=\alpha_{i j} t^{\beta_{i j}} e^{-\gamma_{i j} t}$ & 18 & 52988,6 & $y=\alpha_{i j} t^{\beta_{i j k}} e^{-\gamma_{m} t}$ & 21 & 53004,9 \\
\hline$y=\alpha_{i j} t^{\beta} e^{-\gamma t}$ & 8 & 53683,8 & $y=\alpha_{i j} t^{\beta_{i j}} e^{-\gamma_{i k} t}$ & 18 & 53002,6 & $y=\alpha_{i j} t^{\beta_{i j k}} e^{-\gamma_{i j} t}$ & 24 & 53021,7 \\
\hline$\beta-\gamma t$ & 8 & 53693,8 & $y=\alpha_{i j} t^{\beta_{i j}} e^{-\gamma_{i m} t}$ & 21 & 53000,3 & $y=\alpha_{i j} t^{\beta_{i j k}} e^{-\gamma_{i k} t}$ & 24 & 53024,3 \\
\hline$y=\alpha_{i m} t^{\beta} e^{-\gamma t}$ & 11 & 53701,7 & $y=\alpha_{i j} t^{\beta_{i j}} e^{-\gamma_{j k} t}$ & 16 & 52973,5 & $y=\alpha_{i j}{ }^{\beta_{i j k}} e^{-\gamma_{i m} t}$ & 27 & 53033,4 \\
\hline$y=\alpha_{j k} t^{\beta} e^{-\gamma t}$ & 6 & 54494,5 & $y=\alpha_{i j} t^{\beta_{i j}} e^{-\gamma_{j m} t}$ & 18 & 52979,2 & $y=\alpha_{i j} t^{\beta_{i j k}} e^{-\gamma_{j k} t}$ & 22 & 52991,2 \\
\hline$y=\alpha_{j m} t^{\beta} e^{-\gamma t}$ & 8 & 54577,6 & $y=\alpha_{i j} t^{\beta_{i j}} e^{-\gamma_{k m} t}$ & 18 & 52993,8 & $y=\alpha_{i j} t^{\beta_{i j k}} e^{-\gamma_{j m} t}$ & 24 & 53011,7 \\
\hline$y=\alpha_{k m} t^{\beta} e^{-\gamma t}$ & 8 & 54504,0 & $y=\alpha_{i j} t^{\beta_{i j}} e^{-\gamma_{i j k} t}$ & 24 & 53032,3 & $y=\alpha_{i j} t^{\beta_{i j k}} e^{-\gamma_{k m} t}$ & 24 & 53012,9 \\
\hline$y=\alpha_{i j k} t^{\beta} e^{-\gamma t}$ & 14 & 53713,4 & $y=\alpha_{i j} t^{\beta_{i j}} e^{-\gamma_{i j m} t}$ & 30 & 53039,5 & $y=\alpha_{i j} t^{\beta_{i j k}} e^{-\gamma_{i j k} t}$ & 30 & 53054,5 \\
\hline$y=\alpha_{i j m} t^{\beta} e^{-\gamma t}$ & 20 & 53733,5 & $y=\alpha_{i j} t^{\beta_{i j}} e^{-\gamma_{i k m^{t}}}$ & 30 & 53066,5 & $y=\alpha_{i j} t^{\beta_{i j k}} e^{-\gamma_{i j m} t}$ & 36 & 53074,2 \\
\hline$y=\alpha_{i k m} t^{\beta} e^{-\gamma t}$ & 20 & 53756,5 & $y=\alpha_{i j} t^{\beta_{i j}} e^{-\gamma_{j k m} t}$ & 24 & 53021,1 & $y=\alpha_{i j} t^{\beta_{i j k}} e^{-\gamma_{i k m} t}$ & 36 & 53089,0 \\
\hline$y=\alpha_{j k m} t^{\beta} e^{-\gamma t}$ & 14 & 54537,0 & $y=\alpha_{i j} \beta_{i j} e^{-\gamma_{i j k n t}}$ & 48 & 53159,7 & $y=\alpha_{i j} t^{\beta_{i j k}} e^{-\gamma_{j k m} t}$ & 30 & 53042,3 \\
\hline
\end{tabular}

${ }^{1}$ Os índices $i, j, k, m$ e n, representam ordem de lactação, época do parto, ocorrência de doença no periparto, ECCP e estágio da lactação, respectivamente. 


\subsubsection{Seleção do modelo para CCS}

Uma vez escolhido o modelo para a curva de lactação, prosseguiu-se com as análises, agora incorporando a CCS ao modelo previamente selecionado. Resultados dos novos ajustes são mostrados na Tabela 3. Nota-se que, realmente, a CCS afeta significativamente a produção de leite, pois para todos os modelos ocorreram reduções no valor do BIC quando comparados ao modelo $y=\alpha_{i j} t^{\beta_{i j}} e^{-\gamma_{j} t}$.

O modelo escolhido para CCS foi o de perdas absolutas, $y=\alpha_{i j} t^{\beta_{i j}} e^{-\gamma_{j} t}+\delta_{i} \operatorname{Ln}\left(I_{x}\right)$, com $\delta$ variando apenas com a ordem de lactação, pois apresentou o menor BIC $(52672,9)$.

Devido à proximidade dos valores estimados de $\delta_{\mathrm{i}}$ para as ordens de lactação $2 \mathrm{e}$ 3 ou superior, optou-se por testar se os $\delta_{\text {i }}$ poderiam ser considerados iguais nessas classes de ordem de lactação. $\mathrm{O}$ valor obtido de $\mathrm{BIC}=52664,2$ para o modelo reduzido com $\delta_{\mathrm{i}}$ variando apenas entre vacas primíparas (ordem de lactação 1) e multíparas (ordem de lactação 2 ou superior), é menor do que o BIC = 52672,9 do modelo original, não sendo detectadas diferenças entre as perdas estimadas por $\delta_{i}$ para vacas que estão na lactação de ordem 2 ou superior.

\subsubsection{Estimativas dos parâmetros do modelo escolhido para CCS}

Na Tabela 4 são apresentadas as estimativas dos parâmetros do modelo escolhido.

As estimativas dos parâmetros $\alpha, \beta$ e $\gamma$, podem ser interpretadas como geradoras de curvas de lactação ideais em relação à CCS, para as condições de ordem de lactação e época do parto. Elas representam curvas de lactação para as quais não ocorrem perdas devidas à CCS, em situações em que o número de células somáticas é menor do que ou igual a 14.270 células $/ \mathrm{mL}$, evidenciado por $x_{0}=14,27$. 
Tabela 3. Modelos para CCS, com seus respectivos números de parâmetros (Par.) e valores de BIC, sendo $I_{x}=\left\{x-x_{0}+1\right.$, se $x>x_{0} ; 1$, caso contrário $\}$ e $x$ a CCS

\begin{tabular}{|c|c|c|c|c|c|}
\hline Modelo $^{1}$ & Par. & $\mathrm{BIC}$ & Modelo & Par. & $\mathrm{BIC}$ \\
\hline$y=\alpha_{i j} t^{\beta_{i j}} e^{-\gamma_{j} t} I_{x}^{\delta}$ & 16 & 52719,4 & $y=\alpha_{i j}{ }^{\beta_{i j}} e^{-\gamma_{j} t}+\delta \operatorname{Ln}\left(I_{x}\right)$ & 16 & 52729,4 \\
\hline$y=\alpha_{i j}{ }^{\beta_{i j}} e^{-\gamma_{j} t} I_{x} \delta_{i}$ & 18 & 52684,8 & $y=\alpha_{i j} t^{\beta_{i j}} e^{-\gamma_{j} t}+\delta_{i} \operatorname{Ln}\left(I_{x}\right)$ & 18 & 52672,9 \\
\hline$y=\alpha_{i j} t^{\beta_{i j}} e^{-\gamma_{j}{ }^{t}} I_{x} \delta_{j}$ & 17 & 52726,0 & $y=\alpha_{i j} t^{\beta_{i j}} e^{-\gamma_{j} t}+\delta_{j} \operatorname{Ln}\left(I_{x}\right)$ & 17 & 52736,0 \\
\hline$y=\alpha_{i j}{ }^{\beta_{i j}} e^{-\gamma_{j} t} I_{x} \delta_{k}$ & 17 & 52722,2 & $y=\alpha_{i j} t^{\beta_{i j}} e^{-\gamma_{j} t}+\delta_{k} \operatorname{Ln}\left(I_{x}\right)$ & 17 & 52733,4 \\
\hline$y=\alpha_{i j} t^{\beta_{i j}} e^{-\gamma_{j} t} I_{x} \delta_{m}$ & 18 & 52712,6 & $y=\alpha_{i j} t^{\beta_{i j}} e^{-\gamma_{j} t}+\delta_{m} \operatorname{Ln}\left(I_{x}\right)$ & 18 & 52720,8 \\
\hline$y=\alpha_{i j} \beta^{\beta_{i j}} e^{-\gamma_{j} t} I_{x} \delta_{n}$ & 18 & 52737,1 & $y=\alpha_{i j} t^{\beta_{i j}} e^{-\gamma_{j} t}+\delta_{n} \operatorname{Ln}\left(I_{x}\right)$ & 18 & 52746,7 \\
\hline$y=\alpha_{i j} \beta^{\beta_{i j}} e^{-\gamma_{j} t} I_{x} \delta_{i j}$ & 21 & 52706,7 & $y=\alpha_{i j} t^{\beta_{i j}} e^{-\gamma_{j} t}+\delta_{i j} \operatorname{Ln}\left(I_{x}\right)$ & 21 & 52695,3 \\
\hline$y=\alpha_{i j} t^{\beta_{i j}} e^{-\gamma_{j} t} I_{x} \delta_{i k}$ & 21 & 52700,8 & $y=\alpha_{i j} t^{\beta_{i j}} e^{-\gamma_{j} t}+\delta_{i k} \operatorname{Ln}\left(I_{x}\right)$ & 21 & 52689,2 \\
\hline$y=\alpha_{i j} t_{i j}^{\beta_{i j}} e^{-\gamma_{j} t} I_{x} \delta_{i m}$ & 24 & 52702,3 & $y=\alpha_{i j} t_{i j} e^{-\gamma_{j} t}+\delta_{i m} \operatorname{Ln}\left(I_{x}\right)$ & 24 & 52690,7 \\
\hline$y=\alpha_{i j} t^{\beta_{i j}} e^{-\gamma_{j} t} I_{x} \delta_{i n}$ & 24 & 52731,6 & $y=\alpha_{i j} t^{\beta_{i j}} e^{-\gamma_{j} t}+\delta_{i n} \operatorname{Ln}\left(I_{x}\right)$ & 24 & 52722,4 \\
\hline$y=\alpha_{i j} t^{\beta_{i j}} e^{-\gamma_{j} t} I_{x} \delta_{j k}$ & 19 & 52736,2 & $y=\alpha_{i j} \beta_{i j}^{\beta_{i j}} e^{-\gamma_{j} t}+\delta_{j k} \operatorname{Ln}\left(I_{x}\right)$ & 19 & 52747,5 \\
\hline$y=\alpha_{i j} \beta^{\beta_{i j}} e^{-\gamma_{j} t} I_{x} \delta_{j m}$ & 21 & 52721,2 & $y=\alpha_{i j} \beta_{i j} e^{-\gamma_{j} t}+\delta_{j m} \operatorname{Ln}\left(I_{x}\right)$ & 21 & 52730,8 \\
\hline$y=\alpha_{i j} \beta_{i j} e^{-\gamma_{j} t} I_{x} \delta_{j n}$ & 21 & 52760,0 & $y=\alpha_{i j} \beta_{i j} e^{-\gamma_{j} t}+\delta_{j n} \operatorname{Ln}\left(I_{x}\right)$ & 21 & 52770,3 \\
\hline$y=\alpha_{i j} \beta^{\beta_{i j}} e^{-\gamma_{j} t} I_{x} \delta_{k m}$ & 21 & 52733,3 & $y=\alpha_{i j} \beta^{\beta_{i j}} e^{-\gamma_{j} t}+\delta_{k m} \operatorname{Ln}\left(I_{x}\right)$ & 21 & 52742,5 \\
\hline$y=\alpha_{i j} t^{\beta_{i j}} e^{-\gamma_{j} t} I_{x} \delta_{k n}$ & 21 & 52747,3 & $y=\alpha_{i j} \beta_{i j} e^{-\gamma_{j} t}+\delta_{k n} \operatorname{Ln}\left(I_{x}\right)$ & 21 & 52757,5 \\
\hline$y=\alpha_{i j} t^{\beta_{i j}} e^{-\gamma_{j} t} I_{x} \delta_{m n}$ & 24 & 52761,0 & $y=\alpha_{i j} \beta_{i j} e^{-\gamma_{j} t}+\delta_{m n} \operatorname{Ln}\left(I_{x}\right)$ & 24 & 52768,9 \\
\hline$y=\alpha_{i j} t^{\beta_{i j}} e^{-\gamma_{j} t} I_{x} \delta_{i j k}$ & 27 & 52741,5 & $y=\alpha_{i j} \beta_{i j} e^{-\gamma_{j} t}+\delta_{i j k} \operatorname{Ln}\left(I_{x}\right)$ & 27 & 52730,0 \\
\hline$y=\alpha_{i j} t_{i j} e^{-\gamma_{j} t} I_{x} \delta_{i j m}$ & 33 & 52735,0 & $y=\alpha_{i j} \beta^{\beta_{i j}} e^{-\gamma_{j} t}+\delta_{i j m} \operatorname{Ln}\left(I_{x}\right)$ & 33 & 52723,4 \\
\hline$y=\alpha_{i j} \beta^{\beta_{i j}} e^{-\gamma_{j} t} I_{x} \delta_{i k m}$ & 33 & 52761,6 & $y=\alpha_{i j} \beta^{\beta_{i j}} e^{-\gamma_{j} t}+\delta_{i k m} \operatorname{Ln}\left(I_{x}\right)$ & 33 & 52751,5 \\
\hline$y=\alpha_{i j} t_{i j}^{\beta_{i j}} e^{-\gamma_{j} t} I_{x} \delta_{j k m}$ & 27 & 52756,2 & $y=\alpha_{i j} t^{\beta_{i j}} e^{-\gamma_{j} t}+\delta_{j k m} \operatorname{Ln}\left(I_{x}\right)$ & 27 & 52768,4 \\
\hline$y=\alpha_{i j} t^{\beta_{i j}} e^{-\gamma_{j} t} I_{x} \delta_{i j n}$ & 33 & 52799,4 & $y=\alpha_{i j} t^{\beta_{i j}} e^{-\gamma_{j} t}+\delta_{i j n} \operatorname{Ln}\left(I_{x}\right)$ & 33 & 52790,8 \\
\hline$y=\alpha_{i j} t^{\beta_{i j}} e^{-\gamma_{j} t} I_{x} \delta_{i k n}$ & 33 & 52788,6 & $y=\alpha_{i j} \beta_{i j} e^{-\gamma_{j} t}+\delta_{i k n} \operatorname{Ln}\left(I_{x}\right)$ & 33 & 52778,6 \\
\hline$y=\alpha_{i j} t^{\beta_{i j}} e^{-\gamma_{j} t} I_{x} \delta_{j k n}$ & 27 & 52794,7 & $y=\alpha_{i j}{ }^{\beta_{i j}} e^{-\gamma_{j} t}+\delta_{j k n} \operatorname{Ln}\left(I_{x}\right)$ & 27 & 52806,0 \\
\hline$y=\alpha_{i j t} \beta_{i j} e^{-\gamma_{j} t} I_{x} \delta_{i m n}$ & 42 & 52837,9 & $y=\alpha_{i j} \beta^{\beta_{i j}} e^{-\gamma_{j} t}+\delta_{i m n} \operatorname{Ln}\left(I_{x}\right)$ & 42 & 52828,5 \\
\hline$y=\alpha_{i j t} \beta_{i j} e^{-\gamma_{j} t} I_{x} \delta_{j m n}$ & 33 & 52818,9 & $y=\alpha_{i j} \beta_{i j} e^{-\gamma_{j} t}+\delta_{j m n} \operatorname{Ln}\left(I_{x}\right)$ & 33 & 52828,1 \\
\hline$y=\alpha_{i j}{ }^{\beta_{i j}} e^{-\gamma_{j} t} I_{x} \delta_{k m n}$ & 33 & 52820,1 & $y=\alpha_{i j} \beta_{i j} e^{-\gamma_{j} t}+\delta_{k m n} \operatorname{Ln}\left(I_{x}\right)$ & 33 & 52829,7 \\
\hline
\end{tabular}

${ }^{1}$ Os índices $i, j, k, m$ e n, representam ordem de lactação, época do parto, ocorrência de doença no periparto, ECCP e estágio da lactação, respectivamente. 
Tabela 4. Estimativas dos parâmetros do modelo escolhido e intervalos de confiança (95\%)

\begin{tabular}{cccccc}
\hline $\begin{array}{c}\text { Época do } \\
\text { Parto }\end{array}$ & $\alpha$ & $\beta$ & $\gamma\left(\times 10^{2}\right)$ & $\delta$ & $x_{0}$ \\
\hline \multicolumn{5}{c}{ Ordem de Lactação 1} \\
Verão & $15,75(13,56: 17,94)$ & $0,191(0,157: 0,225)$ & $0,109(0,085: 0,134)$ & $-0,184$ & 14,27 \\
Inverno & $14,14(12,56: 15,71)$ & $0,230(0,203: 0,256)$ & $0,176(0,156: 0,195)$ & $(-0,312:-0,056)$ & $(12,03: 16,52)$ \\
& & \multicolumn{4}{c}{ Ordem de Lactação 2} \\
Verão & $38,46(33,89: 43,03)$ & $0,043(0,012: 0,073)$ & $0,109(0,085: 0,134)$ & $-0,869$ & 14,27 \\
Inverno & $36,94(33,57: 40,31)$ & $0,076(0,052: 0,099)$ & $0,176(0,156: 0,195)$ & $(-0,968:-0,771)$ & $(12,03: 16,52)$ \\
& & Ordem de Lactação 3 ou superior & \\
Verão & $41,09(36,77: 45,41)$ & $0,036(0,009: 0,064)$ & $0,109(0,085: 0,134)$ & $-0,869$ & 14,27 \\
Inverno & $45,80(42,14: 49,47)$ & $0,035(0,013: 0,056)$ & $0,176(0,156: 0,195)$ & $(-0,968:-0,771)$ & $(12,03: 16,52)$ \\
\hline
\end{tabular}

Verifica-se que estimativas do parâmetro $\alpha$ foram crescentes com o decorrer das ordens de lactação, indicando produções inferiores para a 1. ${ }^{\text {a }}$ lactação quando comparada às demais, e da 2. ${ }^{\mathrm{a}}$ quando comparada às posteriores. O comportamento das estimativas do parâmetro $\beta$ foi nverso ao do $\alpha$, mostrando a maior capacidade em manter a produção no decorrer da $1 .^{\text {a }}$ lactação, já que o parâmetro $\gamma$ não varia com a ordem de lactação. Esse resultado está de acordo com os obtidos por Dekkers et al. (1998), Friggens et al. (1999), Lopes et al. (1996) e Neiva et al. (1992).

Em relação à época do parto, que indiretamente determina o estresse calórico, nota-se que as vacas que mais sofreram com o período de temperaturas mais elevadas foram as de 3. ${ }^{a}$ lactação ou superior, o que é evidenciado pela maior diferença entre as estimativas do parâmetro $\alpha$ para inverno e verão (45,80 e 41,09, respectivamente), dado que $\beta$ praticamente não mudou para as épocas do parto e $\gamma$ não varia com a ordem de lactação. As vacas paridas no inverno na maioria das vezes terminam a lactação no verão, período menos favorável para a produção de leite (pelas temperaturas mais elevadas, principalmente) e isso determinou um maior valor de $\gamma$ (que representa o decréscimo de produção após o pico) quando comparado ao verão, o que fi contrabalançado por maiores valores de $\beta$ (que representa o potencial do animal em 
manter a produção no início da lactação) para as ordens de lactação 1 e 2, e não para 3 ou superior.

As estimativas do parâmetro $\delta$ foram, respectivamente, $-0,184$ e $-0,869$ para vacas primíparas e multíparas, e representam as perdas de produção de leite (kg/dia) em função do aumento de uma unidade logarítmica da CCS, a partir de 14.270 células $/ \mathrm{mL}$.

Os resultados indicando diferentes perdas de produção de leite entre vacas primíparas e multíparas estão de acordo com grande parte da literatura consultada. Um dos poucos estudos cujos resultados não evidenciaram essa diferença é o de Gill et al. (1990). Contudo, as estimativas de perdas obtidas por esses autores foram muito semelhantes ao do estudo vertente, no caso das vacas multíparas, mostrando perdas de 1,45 $\mathrm{kg}$ de leite por dia com 25.000 células $/ \mathrm{mL}$ e $4,83 \mathrm{~kg} / \mathrm{dia}$ com 200.000 células $/ \mathrm{mL}$.

As maiores perdas para multíparas podem ser explicadas pelo agravamento na saúde do úbere desses animais, ocasionado pela maior possibilidade de infecção e dano permanente à glândula por infecções prévias (Barttlet et al., 1990), e também, porque vacas mais velhas tendem a ter infecções mais longas, causando danos mais extensos nos tecidos (Reneau, 1986).

A importância do presente trabalho está em, além de mostrar que as perdas são absolutas, identificar matematicamente a partir de que ponto elas começam a ocorrer $\left(x_{0}=\right.$ 14,27). Em outros estudos semelhantes esse resultado foi obtido apenas empiricamente. Por exemplo, Hortet et al. (1999) basearam-se em pesquisas de cultura bacteriológica negativa (Schepers et al., 1997) e de ausência de mastite clínica (Laevens et al., 1997; Wilson et al. 1997) para propor um ponto de corte de 50.000 células $/ \mathrm{mL}$, a partir do qual as perdas começariam a ocorrer, e não nos próprios dados, como foi efetuado no presente trabalho. Kirk (1984) e Reneau (1986) consideraram que as perdas ocorreriam somente a partir de 100.000 células $/ \mathrm{mL}$.

Ao contrário do observado neste trabalho, Hortet et al. (1999) não encontraram diferenças significativas entre os estágios de lactação para as vacas primíparas, mas observaram efeitos significativos nas multíparas, com perdas crescentes no decorrer da lactação. Para eles, vacas na $1 .^{\text {a }}$ lactação apresentaram uma redução de $0,30 \mathrm{~kg}$ de leite para 100.000 células $/ \mathrm{mL}$ e 
0,61 kg para 200.000 células/mL, enquanto que as vacas na 2. ${ }^{a}$ lactação com CCS de 200 mil células $/ \mathrm{mL}$ tiveram uma redução na produção de leite de $0,63 \mathrm{~kg}$ no dia 50 pós-parto, $0,92 \mathrm{~kg}$ no dia 150 e 1,77 kg no dia 250 pós-parto. Vacas de 3. a lactação ou superior, com essa mesma CCS, tiveram redução de $0,60 \mathrm{~kg}, 1,09 \mathrm{~kg}$ e 1,85 kg, nos dias 50, 150 e 250 pós-parto, respectivamente.

\subsubsection{Utilização prática dos resultados}

Os resultados obtidos neste estudo podem ser utilizados, por exemplo, para calcular as perdas de produção de leite para cada vaca em lactação, bastando multiplicar a estimativa correspondente do parâmetro $\delta$ de cada ordem de lactação pelo logaritmo natural de $I_{x}$, sendo $I_{x}=\left\{x-x_{0}+1\right.$, se $x>x_{0} ; 1$, casocontrário $\}, x$ a CCS e $x_{0}=14,27$. A partir do resultado de cada vaca podem-se estimar as perdas médias devidas ao aumento da CCS, refletindo o impacto da mastite subclínica para cada ordem de lactação (no caso, vacas primíparas e multíparas) e para o rebanho, como um todo.

Desse modo, as vacas primíparas do rebanho estudado deixaram de produzir em média 0,617 kg de leite/vaca/dia devido ao aumento da CCS, ao passo que para as multíparas o valor é de 3,266 kg/vaca/dia. Globalmente, o rebanho deixou de produzir 2,273 kg de leite/vaca/dia devido à elevação da CCS.

\subsection{Conclusões}

1. Os ajustes de modelos de curva de lactação mostraram que os parâmetros $\alpha$ e $\beta$ variam com a ordem de lactação e com a época do parto, enquanto o parâmetro $\gamma$ depende apenas da época do parto.

2. Evidencioutse que as perdas de produção de leite devidas ao aumento da CCS são independentes da produção do animal, começam a ocorrer a partir de 14.270 células/mL e são diferentes para vacas primíparas e multíparas. 


\section{CONTAGEM DE CÉlULAS SOMÁTICAS E PRODUÇÃO DE LEITE EM VACAS HOLANDESAS CONFINADAS}

\section{Resumo}

A relação entre contagem de células somáticas do leite (CCS) e produção de leite foi e é objeto de estudo de inúmeras pesquisas em diversos países, porém, no Brasil a literatura a esse respeito é escassa. O objetivo do presente trabalho foi verificar se as perdas na produção de leite devidas ao aumento da CCS são proporcionais à produção, ou absolutas, independendo desta, e a partir de que valor de CCS elas começam a ser evidentes. Para o estudo, foram utilizadas 13.725 observações, colhidas mensalmente de 6 rebanhos, durante o período de janeiro de 2001 a junho de 2002. O modelo de análise, para curva de lactação, foi baseado na função gama incompleta, considerando os feitos de ordem de lactação, rebanho e época do parto. A CCS foi incluída nesse modelo de duas formas: como fator multiplicativo (representando perdas relativas) e como fator aditivo (representando perdas absolutas). A escolha do melhor modelo foi baseada no critério de informação de Schwarz (BIC). Conclui-se que as perdas são absolutas, evidentes a partir de 17.000 células $/ \mathrm{mL}$, e para cada aumento unitário na escala do logaritmo natural a partir desse valor, estimam-se perdas de 238 e 868 g/dia para vacas primíparas e multíparas, respectivamente. 


\section{Summary}

The relationship between milk somatic cells count (SCC) and milk yield has been the aim of countless researches in several countries; however, in Brazil, the literature related to this subject is scarce. The objective of this study was to verify if the losses in milk yield due to SCC increase are proportional to the yield, or absolute (independent of it) and starting from which SCC, the losses become evident. For this study, 13,725 observations were used, collected monthly from 6 different herds, from January/2001 up to June/2002. The analysis model, for lactation curve, was based upon the incomplete gamma function, considering the effects of lactation order, herd and calving season. The SCC entered in that model in two ways: as multiplicative factor (representing relative losses) and as addictive factor (representing absolute losses). The best model was chosen based on the information criteria of Schwarz (BIC). It is concluded that the losses are absolute, becoming evident from 17,000 cells $/ \mathrm{mL}$, and they are 238 and $868 \mathrm{~g}$ /day for each unitary increase in the natural logarithm scale, starting from that SCC, respectively, for primiparous and multiparous cows.

\subsection{Introdução}

No Brasil, a produção de leite, como outros tantos segmentos da atual sociedade, é uma atividade cada vez mais competitiva. É portanto, importante quantificar e qualificar os fatores que podem influenciá-la, buscando ganhos efetivos na quantidade e qualidade do leite produzido, na tentativa de suprir a demanda nacional.

O fator que mais contribui para as perdas econômicas da cadeia produtiva do leite é a mastite (Beck et al., 1992; Janzen, 1970; Kim \& Heald, 1999; Kossaibati \& Esslemont, 1997; Laranja \& Machado, 1994; Lescourret \& Coulon, 1994; Schakenraad \& Dijkhuizen, 1990; Shook, 1989), uma inflamação da glândula mamária. A contagem de células somáticas (CCS) do leite é afetada principalmente pela infecção intramamária (Harmon, 1994, 1998a; Machado et al., 1998, 1999, 2000; Reneau, 1986; Rodriguez-Zas et al., 2000), e sendo um 
indicador de mastite subclínica pode ser utilizada para quantificar as perdas de produção de leite em função dessa infecção.

Apesar da abundância de trabalhos na literatura internacional que quantificam o efeito da mastite subclínica sobre a produção de leite (Bartlett et al., 1990; Batra, 1986; Gill et al., 1990; Graaf \& Dwinger, 1996; Hortet et al. 1999; Jones et al., 1984; Miller et al., 1993; Raubertas \& Shook, 1982; Reneau, 1986), a literatura a esse respeito ainda é escassa no Brasil. Além disso, Schepers \& Dijkhuizen (1991) relatam que as estimativas dos efeitos da mastite no desempenho das vacas leiteiras mostraram grande variação entre estudos. Isso pode ser atribuído às diferenças nas populações estudadas, aos indicadores de mastite e métodos estatísticos utilizados (Lescourret \& Coulon, 1994; Hortet et al., 1999).

Deve-se, ainda, considerar que outras variáveis influenciam a produção de leite dos animais, tais como: número de dias em lactação, representado pela curva de lactação (Ali \& Schaeffer,1987; Cobuci, 1999; García \& Holmes, 2001; Kettunen et al., 2000; Mcnanus et al., 1997; Olori et al., 1999; Rekaya et al., 2001; Rook et al., 1993; Wood, 1967), ordem de lactação, ou idade da vaca (Almeida et al., 1997; Freitas et al., 2001; Friggens et al., 1999; Pereira, 2000; Pires, 1984; Rekaya et al., 2001; Shanks et al., 1981), rebanho (Almeida et al., 1997; Durães et al., 2001; Gasparino, 1996; Jamrozik et al., 1997; Jamrozik \& Schaeffer, 1997; Kettunen et al., 2000; Teixeira et al., 1997) e época do parto (Almeida et al., 1997; Durães et al., 2001; Gasparino, 1996; García \& Holmes, 2001; Mcnanus et al., 1997).

O presente trabalho teve como objetivo encontrar um modelo para as perdas na produção de leite em função do aumento da CCS, baseando-se na curva de lactação e fatores que podem alterá-la. Buscou-se responder se as perdas associadas a CCS são proporcionais (perdas relativas), ou se independem do nível de produção (perdas absolutas), bem como, determinar o número de células somáticas a partir do qual essas perdas começam a ocorrer. 


\subsection{Material e métodos}

\subsubsection{Os dados}

Foram utilizadas 13.725 observações do banco de dados do Programa de Gerenciamento de Rebanhos da Clínica do Leite, Departamento de Zootecnia, da Escola Superior de Agricultura "Luiz de Queiroz”, Universidade de São Paulo (ESALQ/USP). Os dados são provenientes de 1.953 vacas da raça holandesa, mantidas em regime de confinamento total, pertencentes a 6 rebanhos, sendo quatro destes localizados no Estado de São Paulo (Rebanhos 1, 2, 4 e 6), um em Minas Gerais (Rebanho 5) e um em Alagoas (Rebanho 3).

As observações são referentes ao período compreendido entre janeiro de $2001 \mathrm{e}$ junho de 2002, abrangendo vacas com no máximo 5 lactações, e com dias em lactação variando entre 11 e 305 dias. As vacas dos rebanhos 1, 3 e 5 foram ordenhadas três vezes ao dia, enquanto que as dos rebanhos 2,4 e 6 , duas vezes ao dia.

As amostras de leite foram coletadas mensalmente, seguindo os padrões recomendados pelo Laboratório de Fisiologia da Lactação, da Clínica do Leite, ESALQ/USP, e encaminhadas ao mesmo para determinação da CCS (em mil células $/ \mathrm{mL}$ ) por citometria de fluxo, através do equipamento Somacount $300^{\circledR}$, da Bentley Instruments, Incorporation. O tempo máximo entre a coleta e a análise do leite foi de 5 dias.

Um resumo da produção de leite e da CCS é apresentado na Tabela 1, onde se observa que existem diferenças razoáveis na produção de leite e na CCS entre os rebanhos. A média geométrica da CCS foi apresentada por se tratar de medida padrão internacional para essa variável. 
Tabela 1. Número de vacas e de observações (n), média e desvio padrão da produção de leite e da CCS, em função da ordem de lactação e do rebanho

\begin{tabular}{|c|c|c|c|c|c|c|c|c|}
\hline \multirow{2}{*}{$\begin{array}{l}\text { Ordem de } \\
\text { Lactação }\end{array}$} & \multirow[b]{2}{*}{ Rebanho } & \multirow{2}{*}{$\begin{array}{l}\text { N. }{ }^{\circ} \text { de } \\
\text { vacas }\end{array}$} & \multirow[b]{2}{*}{$\mathrm{n}$} & \multicolumn{2}{|c|}{ LEITE (kg/dia) } & \multicolumn{3}{|c|}{$\mathrm{CCS}\left(\times 10^{3}\right.$ células $\left./ \mathrm{mL}\right)$} \\
\hline & & & & Média & $\begin{array}{l}\text { Desvio } \\
\text { Padrão }\end{array}$ & Média & $\begin{array}{l}\text { Desvio } \\
\text { Padrão }\end{array}$ & $\begin{array}{c}\text { Média } \\
\text { Geométrica }\end{array}$ \\
\hline \multirow{6}{*}{1} & 1 & 467 & 2519 & 32,1 & 6,3 & 157,1 & 405,4 & 54,4 \\
\hline & 2 & 208 & 956 & 22,7 & 5,1 & 442,9 & 1008,3 & 160,6 \\
\hline & 3 & 243 & 1276 & 22,9 & 5,3 & 256,3 & 791,3 & 66,6 \\
\hline & 4 & 39 & 241 & 26,7 & 6,1 & 527,6 & 1126,1 & 161,1 \\
\hline & 5 & 56 & 390 & 28,8 & 6,3 & 222,5 & 584,4 & 82,6 \\
\hline & 6 & 156 & 845 & 21,5 & 5,8 & 658,3 & 1437,5 & 169,0 \\
\hline \multirow{6}{*}{2} & 1 & 372 & 1841 & 37,0 & 8,5 & 222,2 & 673,2 & 58,8 \\
\hline & 2 & 149 & 710 & 29,4 & 7,2 & 528,1 & 1040,7 & 200,5 \\
\hline & 3 & 106 & 544 & 23,9 & 7,0 & 269,3 & 778,9 & 62,0 \\
\hline & 4 & 32 & 169 & 29,9 & 8,3 & 783,2 & 1286,7 & 312,4 \\
\hline & 5 & 20 & 105 & 27,6 & 7,2 & 478,7 & 1018,9 & 181,1 \\
\hline & 6 & 72 & 308 & 25,9 & 7,5 & 871,3 & 1523,8 & 295,7 \\
\hline \multirow{6}{*}{3 ou superior } & 1 & 346 & 2183 & 37,7 & 9,7 & 384,8 & 987,9 & 86,4 \\
\hline & 2 & 133 & 808 & 32,0 & 7,9 & 632,5 & 1253,7 & 239,2 \\
\hline & 3 & 37 & 179 & 25,8 & 7,6 & 427,1 & 1385,5 & 73,7 \\
\hline & 4 & 25 & 173 & 27,3 & 8,4 & 1282,0 & 1915,0 & 464,8 \\
\hline & 5 & 45 & 263 & 30,1 & 8,1 & 580,9 & 1150,1 & 211,4 \\
\hline & 6 & 37 & 215 & 26,3 & 8,3 & 993,6 & 1478,2 & 394,5 \\
\hline
\end{tabular}

\subsubsection{Modelo usado para descrever a curva de lactação}

Para descrever a curva de lactação dos animais foi utilizado o modelo baseado na função gama incompleta, desenvolvido por Wood (1967):

$$
y_{t}=\alpha t^{\beta} e^{-\gamma t}+\varepsilon
$$

sendo: $y_{t}$, a produção de leite no dia em lactação $t ; \alpha$, um parâmetro desconhecido a ser estimado que representa a produção de leite no início da lactação, responsável por abaixar ou elevar toda a curva de lactação, não alterando, entretanto, seu formato geral; $\beta$, um parâmetro 
desconhecido a ser estimado que está associado à fase de ascensão da produção de leite no início da lactação; $\gamma$ um parâmetro desconhecido a ser estimado que está associado à fase de declínio da produção de leite após o pico, o qual ocorre quando $t=\beta / \gamma$; e $\varepsilon$, o erro aleatório, suposto homocedástico (com variância $\sigma^{2}$ ), independente e normalmente distribuído.

\subsubsection{Ajuste do modelo usado para descrever a curva de lactação}

Por se tratar de modelo não-linear, porém totalmente linearizável, o modelo (1) foi ajustado utilizando-se a teoria de modelos lineares generalizados proposta por Nelder \& Wedderburn (1972), utilizando-se o procedimento GENMOD do SAS (SAS Institute, 1999).

Denotando-se a esperança matemática $\mathrm{E}\left[Y_{t}\right]$ por $\mu_{t}$, pode-se linearizar sua expressão aplicando-se logaritmo natural. Logo,

$$
\eta_{t}=\operatorname{Ln}\left(\mu_{t}\right)=\operatorname{Ln}(\alpha)+\beta \operatorname{Ln}(t)-\gamma t,
$$

sendo, $\eta_{t}$ o preditor linear, funcionalmente ligado àmédia $\mu_{t}$ através da função logaritmo.

Desta maneira, o ajuste do modelo (1) foi efetuado supondo que a distribuição da produção de leite $\left(Y_{t}\right)$ é normal, com média $\mu_{t}$ e variância $\sigma^{2}$, tendo o logaritmo como função de ligação, $\operatorname{Ln}(t)$ e $t$ como variáveis explanatórias.

\subsubsection{Seleção do modelo para curva de lactação}

Considerourse o modelo (1) como modelo minimal em relação ao número de parâmetros. Entretanto, como a curva de lactação pode ser influenciada por outros fatores para os quais se tem informação, como ordem de lactação, rebanho e época do parto, foram ajustados 48 modelos contidos entre o modelo (1), chamado de modelo minimal, e o modelo (3) chamado modelo maximal.

$$
\mathrm{E}\left[Y_{t i j k}\right]=\mu_{t i j k}=\alpha_{i j k} t^{\beta_{i j k}} e^{-\gamma_{i j k} t},
$$


sendo: $\mathrm{E}\left[Y_{t i j k}\right]=\mu_{t i j k}$, a média da produção de leite no dia em lactação $t(t=11, \ldots, 305)$, na ordem de lactação $i$ ( $i=1,2$ e 3 ou superior), do rebanho $j(j=1, \ldots, 6)$ e na época do parto $k$ ( $k=1$, para verão (meses de outubro a março) e 2, para inverno (meses de abril a setembro)); $t$ o número de dias em lactação; $\alpha_{i j k}, \beta_{i j k}$ e $\gamma_{i j k}$, parâmetros desconhecidos e interpretados como em (1), contudo, variando com a ordem de lactação $i$, com o rebanho $j$ e com a época do parto $k$.

A escolha do melhor modelo foi baseada no critério de informação de Schwarz $\left(\mathrm{BIC}^{1}=-2 \times \operatorname{Ln}(\right.$ verossimilhança max. $)+\mathrm{n}^{\circ}{ }^{\mathrm{o}}$ de parâmetros $\times \operatorname{Ln}\left(\mathrm{n} .^{\circ}\right.$ de observações $\left.)\right)$, conforme sugerido por SAS Institute (1999), sendo considerado o melhor modelo aquele que apresentou o menor valor do BIC. Esse critério tem a vantagem de considerar o número de observações e o número de parâmetros do modelo.

No Anexo A são mostrados alguns exemplos de sintaxe para o ajuste dos modelos propostos.

\subsubsection{Curva de lactação e CCS}

Após a escolha do melhor modelo para representar a curva de lactação dos animais, adicionourse a ele um termo denotado por $x$ com os valores de CCS, de modo que as perdas associadas ao aumento da CCS fossem relativas à produção - modelo (4) - ou absolutas - modelo (5):

$$
\begin{aligned}
& \mathrm{E}\left[Y_{t i j k x}\right]=\mu_{t i j k x}=\mathrm{M}(\phi) I_{x}^{\delta}, \\
& \mathrm{E}\left[Y_{t i j k x}\right]=\mu_{t i j k x}=\mathrm{M}(\phi)+\delta \operatorname{Ln}\left(I_{x}\right),
\end{aligned}
$$

sendo: $\mathrm{E}\left[Y_{t i j k x}\right]=\mu_{t i j k x}$, a média da produção de leite no dia em lactação $t$, na ordem de lactação $i$, do rebanho $j$, na época do parto $k$ e com CCS igual a $x ; \mathrm{M}(\phi)$, o modelo escolhido para representar a curva de lactação; $I_{x}=\left\{\begin{array}{l}x-x_{0}+1, \text { se } x>x_{0} \\ 1, \text { caso contrário }\end{array} ; x\right.$, a CCS; $x_{0}$, o valor da

\footnotetext{
${ }^{1}$ Bayesian information criterion
} 
CCS a partir do qual começam a ocorrer perdas; e $\delta$, um parâmetro desconhecido que, no modelo (4), representa o decréscimo proporcional da produção de leite em função do aumento da CCS, e no modelo (5), a quantidade de leite perdida por unidade logarítmica de aumento da CCS.

\subsubsection{Ajuste e seleção do modelo para CCS}

O ajuste do modelo (4) foi realizado como no modelo (1), tendo como variáveis explanatórias $\operatorname{Ln}(t), t$ e $\operatorname{Ln}\left(I_{x}\right)$, ao passo que o ajuste do modelo (5), por se tratar de um modelo não-linearizável, foi feito utilizando métodos de ajuste não-linear, através do procedimento NLMIXED do SAS (SAS Institute, 1999).

Além disso, considerando-se que o valor do parâmetro $\delta$ pode variar com a ordem de lactação $i$, com o rebanho $j$, com a época do parto $k$ e com o estágio da lactação $m$ ( $m$ = início (11 a 45 dias), meio (46 a 179 dias) e fim da lactação (180 dias ou mais)), foram ajustados 16 modelos contendo todas as possíveis combinações dessas variáveis ligadas a esse parâmetro, para $x_{0}=1,5,10,15,25$ e 50, para os modelos de perdas relativas e absolutas, totalizando 192 modelos, e escolhidos os dois melhores modelos através do BIC.

Após a última seleção, foram ajustados modelos com valores de $x_{0}$ nas proximidades daqueles dos melhores modelos, para encontrar o ponto $x_{0}$, a partir do qual as perdas na produção de leite começam a ocorrer, e também, escolher o melhor dentre os dois modelos.

Para maiores detalhes do processo de estimação de $x_{0}$ ver Anexo C.

\subsection{Resultados e discussão}

\subsubsection{Seleção do modelo para curva de lactação}

Na Tabela 2 são apresentados os 48 modelos ajustados para curva de lactação, com seus respectivos números de parâmetros e critérios de informação de Schwarz (BIC). 
Verifica-se que o modelo $y=\alpha_{i j k} t^{\beta_{i j}} e^{-\gamma_{j k} t}$ com 66 parâmetros foi o que apresentou o menor BIC $(91302,8)$ e, portanto, considerado o melhor modelo. O pior modelo foi $y=\alpha t^{\beta} e^{-\gamma t}$, com apenas 3 parâmetros e BIC = 99199,2.

Observe-se que, para o melhor modelo, o parâmetro $\alpha$ da curva de lactação varia em função da ordem de lactação, do rebanho e da época do parto, ao passo que o parâmetro $\beta$ depende apenas da ordem de lactação e do rebanho, e o $\gamma$, do rebanho e da época do parto.

Esse resultado evidencia que, além do número de dias em lactação, a produção de leite foi significativamente afetada pela ordem de lactação, pelo rebanho e pela época do parto, o que está de acordo com a literatura citada na introdução deste trabalho. Sabendo-se que a produção de leite é afetada por todos esses fatores, pergunta-se: será que as perdas de produção associadas ao aumento da CCS são relativas, ou absolutas?

\subsubsection{Seleção do modelo para CCS}

Uma vez escolhido o modelo para a curva de lactação, prosseguiu-se com as análises, agora incorporando a CCS ao modelo previamente selecionado. Resultados dos novos ajustes são mostrados nas Tabelas 3 e 4 . Nota-se que, realmente, a CCS afeta significativamente a produção de leite, pois para todos os modelos, exceto pelo último, no qual $\delta$ varia com os quatro fatores, ocorreram reduções no valor do BIC quando comparados ao modelo $y=\alpha_{i j k} t^{\beta_{i j}} e^{-\gamma_{j k} t}$. 
Tabela 2. Modelos para curva de lactação com seus respectivos números de parâmetros (Par.) e valores do critério de informação de Schwarz (BIC)

\begin{tabular}{|c|c|c|c|c|c|}
\hline Modelo $^{1}$ & Par. & $\mathrm{BIC}$ & Modelo $^{1}$ & Par. & $\mathrm{BIC}$ \\
\hline$y=\alpha t^{\beta} e^{-\gamma t}$ & 3 & 99199,2 & $y=\alpha_{i j k} t^{\beta_{k}} e^{-\gamma t}$ & 39 & 92193,4 \\
\hline$y=\alpha_{i} t^{\beta_{i}} e^{-\gamma_{i} t}$ & 9 & 96869,7 & $y=\alpha_{i j k} t^{\beta_{i j}} e^{-\gamma t}$ & 55 & 91411,6 \\
\hline$y=\alpha_{j} t^{\beta_{j}} e^{-\gamma_{j} t}$ & 18 & 93856,1 & $y=\alpha_{i j k} t^{\beta_{i k}} e^{-\gamma t}$ & 43 & 91578,3 \\
\hline$y=\alpha_{k} t^{\beta_{k}} e^{-\gamma_{k} t}$ & 6 & 99120,2 & $y=\alpha_{i j k} t^{\beta_{j k}} e^{-\gamma t}$ & 49 & 92098,2 \\
\hline$y=\alpha_{i j} t^{\beta_{i j}} e^{-\gamma_{i j} t}$ & 54 & 91422,1 & $y=\alpha_{i j k} t^{\beta_{i j k}} e^{-\gamma t}$ & 73 & 91509,5 \\
\hline$y=\alpha_{i k} t^{\beta_{i k}} e^{-\gamma_{i k} t}$ & 18 & 96775,7 & $y=\alpha_{i j} t^{\beta_{i j}} e^{-\gamma_{i} t}$ & 39 & 91426,0 \\
\hline$y=\alpha_{j k} t^{\beta_{j k}} e^{-\gamma_{j k} t}$ & 36 & 93782,4 & $y=\alpha_{i j} t^{\beta_{i j}} e^{-\gamma_{j} t}$ & 42 & 91347,3 \\
\hline$y=\alpha_{i j k} t^{\beta_{i j k}} e^{-\gamma_{i j k t}}$ & 108 & 91575,5 & $y=\alpha_{i j} t^{\beta_{i j}} e^{-\gamma_{k} t}$ & 38 & 91414,6 \\
\hline$y=\alpha_{i} t^{\beta} e^{-\gamma t}$ & 5 & 97227,6 & $y=\alpha_{i j} t^{\beta_{i j}} e^{-\gamma_{i k} t}$ & 42 & 91439,5 \\
\hline$y=\alpha_{j} t^{\beta} e^{-\gamma t}$ & 8 & 94009,0 & $y=\alpha_{i j} t^{\beta_{i j}} e^{-\gamma_{j k} t}$ & 48 & 91344,3 \\
\hline$y=\alpha_{k} t^{\beta} e^{-\gamma t}$ & 4 & 99159,7 & $y=\alpha_{i j} t^{\beta_{i j}} e^{-\gamma_{i j k} t}$ & 72 & 91487,7 \\
\hline$y=\alpha_{i j} t^{\beta} e^{-\gamma t}$ & 20 & 92187,7 & $y=\alpha_{i j k} t^{\beta_{i j}} e^{-\gamma_{i} t}$ & 57 & 91418,2 \\
\hline$y=\alpha_{i k} t^{\beta} e^{-\gamma t}$ & 8 & 97172,6 & $y=\alpha_{i j k} t^{\beta_{i j}} e^{-\gamma_{j} t}$ & 60 & 91323,0 \\
\hline$y=\alpha_{j k} t^{\beta} e^{-\gamma t}$ & 14 & 93959,2 & $y=\alpha_{i j k} t^{\beta_{i j}} e^{-\gamma_{k} t}$ & 56 & 91355,9 \\
\hline$y=\alpha_{i j k} t^{\beta} e^{-\gamma t}$ & 38 & 92212,4 & $y=\alpha_{i j k} t^{\beta_{i j}} e^{-\gamma_{i j} t}$ & 72 & 91400,1 \\
\hline$y=\alpha_{i j} t^{\beta_{i}} e^{-\gamma t}$ & 22 & 91574,2 & $y=\alpha_{i j k} t^{\beta_{i j}} e^{-\gamma_{i k} t}$ & 60 & 91370,6 \\
\hline$y=\alpha_{i j} t^{\beta_{j}} e^{-\gamma t}$ & 25 & 92082,8 & $y=\alpha_{i j k} t^{\beta_{i j}} e^{-\gamma_{j k} t}$ & 66 & 91302,8 \\
\hline$y=\alpha_{i j} t^{\beta_{k}} e^{-\gamma t}$ & 21 & 92141,1 & $y=\alpha_{i j k} t^{\beta_{i j}} e^{-\gamma_{i j k} t}$ & 90 & 91470,6 \\
\hline$y=\alpha_{i j} t^{\beta_{i j}} e^{-\gamma t}$ & 37 & 91415,9 & $y=\alpha_{i j k} t^{\beta_{i j k}} e^{-\gamma_{i} t}$ & 75 & 91516,1 \\
\hline$y=\alpha_{i j} t^{\beta_{i k}} e^{-\gamma t}$ & 25 & 91537,0 & $y=\alpha_{i j k} t^{\beta_{i j k}} e^{-\gamma_{j} t}$ & 78 & 91421,1 \\
\hline$y=\alpha_{i j} t^{\beta_{j k}} e^{-\gamma t}$ & 31 & 92057,1 & $y=\alpha_{i j k} t^{\beta_{i j k}} e^{-\gamma_{k} t}$ & 74 & 91466,4 \\
\hline$y=\alpha_{i j} t^{\beta_{i j k}} e^{-\gamma t}$ & 55 & 91429,8 & $y=\alpha_{i j k} t^{\beta_{i j k}} e^{-\gamma_{i j} t}$ & 90 & 91497,8 \\
\hline$y=\alpha_{i j k} t^{\beta_{i}} e^{-\gamma t}$ & 40 & 91590,3 & $y=\alpha_{i j k} t^{\beta_{i j k}} e^{-\gamma_{i k} t}$ & 78 & 91482,7 \\
\hline$y=\alpha_{i j k} t^{\beta_{j}} e^{-\gamma t}$ & 43 & 92100,5 & $y=\alpha_{i j k} t^{\beta_{i j k}} e^{-\gamma_{j k} t}$ & 84 & 91402,1 \\
\hline
\end{tabular}

${ }^{1}$ Os índices $i, j$ e $k$, representam ordem de lactação, rebanho e época do parto, respectivamente. 
Tabela 3. Modelos de perdas relativas em função do aumento da CCS, com seus respectivos números de parâmetros (Par.) e valores do critério de informação de Schwarz (BIC), sendo $I_{x}=\left\{x-x_{0}+1\right.$, se $x>x_{0} ; 1$, casocontrário $\}$ e $x$ a CCS

\begin{tabular}{|c|c|c|c|c|c|c|c|}
\hline \multirow{2}{*}{ Modelo ${ }^{1}$} & \multirow{2}{*}{ Par. } & \multicolumn{6}{|c|}{ BIC } \\
\hline & & $x_{0}=1$ & $x_{0}=5$ & $x_{0}=10$ & $x_{0}=15$ & $x_{0}=25$ & $x_{0}=50$ \\
\hline$y=\alpha_{i j k} t^{\beta_{i j}} e^{-\gamma_{j k} t} I_{x}^{\delta}$ & 67 & 90774,5 & 90768,7 & 90772,5 & 90778,1 & 90810,3 & 90875,1 \\
\hline$y=\alpha_{i j k} t^{\beta_{i j}} e^{-\gamma_{j k} t} I_{x} \delta_{i}$ & 69 & 90734,2 & 90728,6 & 90721,4 & 90719,6 & 90733,0 & 90814,4 \\
\hline$y=\alpha_{i j k} t^{\beta_{i j}} e^{-\gamma_{j k} t} I_{x} \delta_{j}$ & 72 & 90820,5 & 90813,9 & 90816,9 & 90822,3 & 90855,1 & 90919,5 \\
\hline$y=\alpha_{i j k} t^{\beta_{i j}} e^{-\gamma_{j k} t} I_{x} \delta_{k}$ & 68 & 90783,0 & 90777,0 & 90780,6 & 90785,8 & 90818,2 & 90883,6 \\
\hline$y=\alpha_{i j k} t^{\beta_{i j}} e^{-\gamma_{j k} t} I_{x} \delta_{m}$ & 69 & 90789,4 & 90785,2 & 90790,0 & 90796,4 & 90828,4 & 90891,0 \\
\hline$y=\alpha_{i j k} t^{\beta_{i j}} e^{-\gamma_{j k} t} I_{x} \delta_{i j}$ & 84 & 90853,1 & 90846,3 & 90839,1 & 90836,5 & 90847,5 & 90932,3 \\
\hline$y=\alpha_{i j k} t^{\beta_{i j}} e^{-\gamma_{j k} t} I_{x} \delta_{i k}$ & 72 & 90759,9 & 90753,9 & 90746,3 & 90743,5 & 90756,5 & 90839,3 \\
\hline$y=\alpha_{i j k} t_{i j}^{\beta_{i j}} e^{-\gamma_{j k} t} I_{x} \delta_{i m}$ & 75 & 90783,9 & 90779,9 & 90773,7 & 90772,1 & 90785,5 & 90864,7 \\
\hline$y=\alpha_{i j k} t^{\beta_{i j}} e^{-\gamma_{j k} t} I_{x} \delta_{j k}$ & 78 & 90874,5 & 90867,1 & 90868,7 & 90873,3 & 90905,5 & 90972,5 \\
\hline$y=\alpha_{i j k} t^{\beta_{i j}} e^{-\gamma_{j k} t} I_{x} \delta_{j m}$ & 84 & 90924,3 & 90920,7 & 90924,7 & 90931,9 & 90964,3 & 91024,9 \\
\hline$y=\alpha_{i j k} t^{\beta_{i j}} e^{-\gamma_{j k} t} I_{x} \delta_{k m}$ & 72 & 90792,5 & 90788,7 & 90793,1 & 90799,7 & 90830,5 & 90898,9 \\
\hline$y=\alpha_{i j k} t^{\beta_{i j}} e^{-\gamma_{j k} t} I_{x} \delta_{i j k}$ & 102 & 90998,8 & 90991,4 & 90981,2 & 90975,0 & 90983,0 & 91068,4 \\
\hline$y=\alpha_{i j k} t^{\beta_{i j}} e^{-\gamma_{j k} t} I_{x} \delta_{i j m}$ & 120 & 91154,2 & 91151,2 & 91144,6 & 91141,0 & 91148,6 & 91228,2 \\
\hline$y=\alpha_{i j k} t^{\beta_{i j}} e^{-\gamma_{j k} t} I_{x} \delta_{i k m}$ & 84 & 90823,1 & 90820,5 & 90815,3 & 90814,3 & 90828,7 & 90914,5 \\
\hline$y=\alpha_{i j k} t^{\beta_{i j}} e^{-\gamma_{j k} t} I_{x} \delta_{j k m}$ & 102 & 91049,2 & 91045,0 & 91047,8 & 91053,2 & 91083,6 & 91150,6 \\
\hline$y=\alpha_{i j k} t^{\beta_{i j}} e^{-\gamma_{j k} t} I_{x} \delta_{i j k m}$ & 174 & 91559,5 & 91556,9 & 91548,9 & 91541,9 & 91547,3 & 91633,1 \\
\hline
\end{tabular}


Tabela 4. Modelos de perdas absolutas em função do aumento da CCS, com seus respectivos números de parâmetros (Par.) e valores do critério de informação de Schwarz (BIC), sendo $I_{x}=\left\{x-x_{0}+1\right.$, se $x>x_{0} ; 1$, casocontrário $\}$ e $x$ a CCS

\begin{tabular}{|c|c|c|c|c|c|c|c|}
\hline \multirow{2}{*}{ Modelo $^{1}$} & \multirow{2}{*}{ Par. } & \multicolumn{6}{|c|}{ BIC } \\
\hline & & $x_{0}=1$ & $x_{0}=5$ & $x_{0}=10$ & $x_{0}=15$ & $x_{0}=25$ & $x_{0}=50$ \\
\hline$y=\alpha_{i j k} t^{\beta_{i j}} e^{-\gamma_{j k} t}+\delta \operatorname{Ln}\left(I_{x}\right)$ & 67 & 90847,1 & 90832,7 & 90831,7 & 90835,1 & 90865,7 & 90927,5 \\
\hline$y=\alpha_{i j k} t^{\beta_{i j}} e^{-\gamma_{j k} t}+\delta_{i} \operatorname{Ln}\left(I_{x}\right)$ & 69 & 90739,4 & 90725,0 & 90713,2 & $\begin{array}{l}90709 \\
0\end{array}$ & 90724,6 & 90811,8 \\
\hline$y=\alpha_{i j k} t^{\beta_{i j}} e^{-\gamma_{j k} t}+\delta_{j} \operatorname{Ln}\left(I_{x}\right)$ & 72 & 90860,9 & 90849,3 & 90854,3 & 90857,9 & 90893,7 & 90955,9 \\
\hline$y=\alpha_{i j k} t^{\beta_{i j}} e^{-\gamma_{j k} t}+\delta_{k} \operatorname{Ln}\left(I_{x}\right)$ & 68 & 90852,6 & 90838,4 & 90837,2 & 90840,4 & 90872,0 & 90935,2 \\
\hline$y=\alpha_{i j k} t^{\beta_{i j}} e^{-\gamma_{j k} t}+\delta_{m} \operatorname{Ln}\left(I_{x}\right)$ & 69 & 90853,2 & 90842,8 & 90845,4 & 90851,0 & 90883,0 & 90943,2 \\
\hline$y=\alpha_{i j k} t^{\beta_{i j}} e^{-\gamma_{j k} t}+\delta_{i j} \operatorname{Ln}\left(I_{x}\right)$ & 84 & 90844,1 & 90829,9 & 90817,1 & 90814,3 & 90828,3 & 90920,5 \\
\hline$y=\alpha_{i j k} t^{\beta_{i j}} e^{-\gamma_{j k} t}+\delta_{i k} \operatorname{Ln}\left(I_{x}\right)$ & 72 & 90763,3 & 90748,9 & 90737,1 & 90732,1 & 90747,5 & 90836,1 \\
\hline$y=\alpha_{i j k} t^{\beta_{i j}} e^{-\gamma_{j k} t}+\delta_{i m} \operatorname{Ln}\left(I_{x}\right)$ & 75 & 90784,7 & 90773,5 & 90765,5 & 90763,1 & 90779,1 & 90862,5 \\
\hline$y=\alpha_{i j k} t^{\beta_{i j}} e^{-\gamma_{j k} t}+\delta_{j k} \operatorname{Ln}\left(I_{x}\right)$ & 78 & 90918,7 & 90906,5 & 90906,5 & 90910,1 & 90945,1 & 91009,5 \\
\hline$y=\alpha_{i j k} t^{\beta_{i j}} e^{-\gamma_{j k} t}+\delta_{j m} \operatorname{Ln}\left(I_{x}\right)$ & 84 & 90960,3 & 90951,7 & 90956,1 & 90964,5 & 91002,1 & 91059,9 \\
\hline$y=\alpha_{i j k} t^{\beta_{i j}} e^{-\gamma_{j k} t}+\delta_{k m} \operatorname{Ln}\left(I_{x}\right)$ & 72 & 90854,5 & 90844,3 & 90846,5 & 90851,3 & 90882,7 & 90949,7 \\
\hline$y=\alpha_{i j k} t^{\beta_{i j}} e^{-\gamma_{j k} t}+\delta_{i j k} \operatorname{Ln}\left(I_{x}\right)$ & 102 & 90992,2 & 90976,6 & 90961,8 & 90956,8 & 90968,0 & 91059,8 \\
\hline$y=\alpha_{i j k} t^{\beta_{i j}} e^{-\gamma_{j k} t}+\delta_{i j m} \operatorname{Ln}\left(I_{x}\right)$ & 120 & 91151,4 & 91141,6 & 91131,4 & 91127,8 & 91137,2 & 91220,2 \\
\hline$y=\alpha_{i j k} t^{\beta_{i j}} e^{-\gamma_{j k} t}+\delta_{i k m} \operatorname{Ln}\left(I_{x}\right)$ & 84 & 90826,9 & 90818,5 & 90810,7 & 90808,1 & 90825,5 & 90914,1 \\
\hline$y=\alpha_{i j k} t^{\beta_{i j}} e^{-\gamma_{j k} t}+\delta_{j k m} \operatorname{Ln}\left(I_{x}\right)$ & 102 & 91083,8 & 91075,6 & 91081,4 & 91086,8 & 91121,6 & 91185,8 \\
\hline$y=\alpha_{i j k} t^{\beta_{i j}} e^{-\gamma_{j k} t}+\delta_{i j k n} \operatorname{Ln}\left(I_{x}\right)$ & 174 & 91565,3 & 91556,3 & 91545,5 & 91538,9 & 91544,7 & 91633,9 \\
\hline
\end{tabular}

${ }^{1}$ Os índices $i, j, k$ e $m$, representam ordem de lactação, rebanho, época do parto e estágio da lactação, respectivamente.

Globalmente, o melhor modelo é o de perdas absolutas $y=\alpha_{i j k} t^{\beta_{i j}} e^{-\gamma_{j k} t}+\delta_{i} \operatorname{Ln}\left(I_{x}\right)(\mathrm{BIC}=90709,0)$, enquanto que para perdas relativas o melhor modelo é $y=\alpha_{i j k} t^{\beta_{i j}} e^{-\gamma_{j k} t} I_{x}{ }^{\delta_{i}}$ (BIC = 90719,6). Em ambos os casos, as perdas em função do aumento da CCS variaram apenas com a ordem de lactação $i$ e o melhor ponto de corte foi para $x_{0}=15$. Assim, para escolher o melhor dentre os dois modelos e encontrar o valor $x_{0}$, a 
partir do qual as perdas na produção de leite em função do aumento da CCS começam a ocorrer, foram ajustados diversos modelos com valores de $x_{0}$ nas proximidades de 15 , e calculados os valores do BIC (Figura 1).

A Figura 1 mostra que o modelo de perdas absolutas, $y=\alpha_{i j k} t^{\beta_{i j}} e^{-\gamma_{j k} t}+\delta_{i} \operatorname{Ln}\left(I_{x}\right)$, teve os menores valores de BIC para todos os valores de $x_{0}$, sendo, portanto, o melhor dentre os dois modelos. Além disso, a Figura 1 mostra que as perdas na produção leite associadas à CCS iniciam a partir de 17.000 células somáticas por $\mathrm{mL}(\mathrm{BIC}=$ 90706,6).

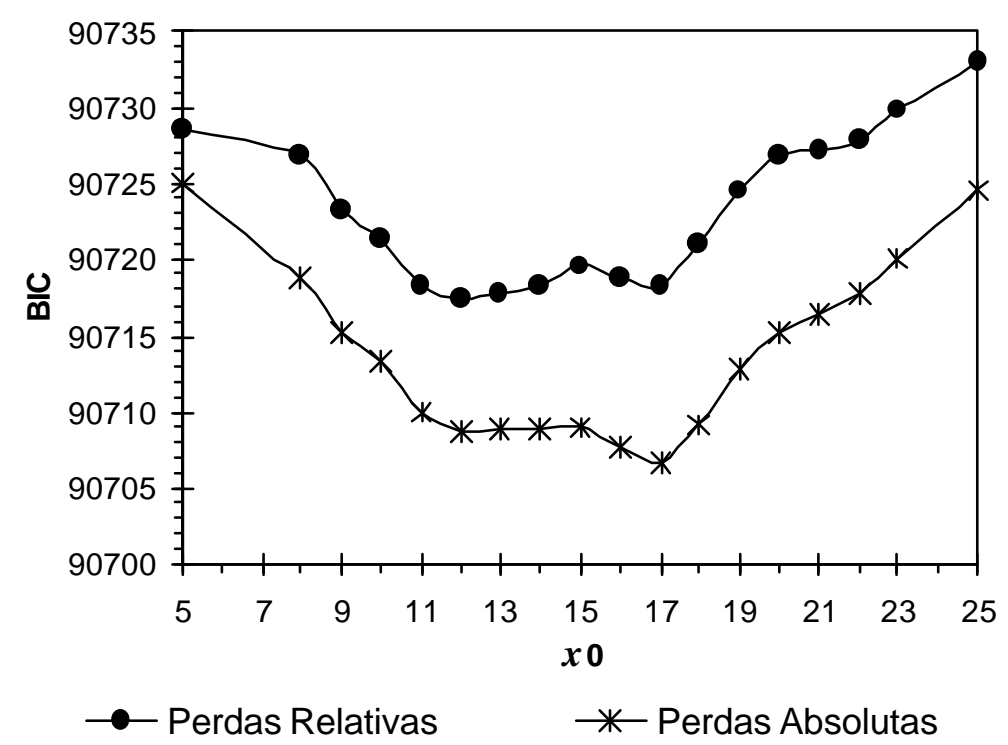

Figura 1 - Valor do critério de informação de Schwarz (BIC) em função do ponto de corte $\left(x_{0}\right)$, para os modelos $y=\alpha_{i j k} t^{\beta_{i j}} e^{-\gamma_{j k} t} I_{x} \delta_{i} \quad$ (perdas relativas) e $y=\alpha_{i j k} \beta_{i j} e^{-\gamma_{j k} t}+\delta_{i} \operatorname{Ln}\left(I_{x}\right) \quad$ (perdas absolutas), sendo $I_{x}=\left\{x-x_{0}+1\right.$, se $x>x_{0} ; 1$, caso contrário $\}$ e $x$ a CCS

Sendo os valores estimados de $\delta_{\text {i }}$ para as ordens de lactação 2 e 3 ou superior muito próximos no modelo escolhido, optou-se por testar se os $\delta_{i}$ poderiam ser considerados iguais nessas classes de ordem de lactação. O valor obtido de $\mathrm{BIC}=90702,6$ para o modelo 
reduzido com $\delta_{\mathrm{i}}$ variando apenas com vacas primíparas (ordem de lactação 1) e multíparas (ordem de lactação 2 ou superior), é menor do que o BIC = 90706,6 do modelo original, indicando que as perdas estimadas por $\delta_{\mathrm{i}}$ são iguais para as vacas que estão na lactação de ordem 2 ou superior.

\subsubsection{Estimativas dos parâmetros do modelo escolhido para CCS}

Na Tabela 5 são mostradas as estimativas dos parâmetros do modelo escolhido.

As estimativas dos parâmetros $\alpha, \beta$ e $\gamma$, podem ser interpretadas como geradoras de curvas de lactação ideais em relação à CCS, para as condições de ordem de lactação, rebanho e época do parto. Elas representam curvas de lactação para as quais não ocorrem perdas devidas à CCS, em situações em que o número de células somáticas é menor do que ou igual a 17.000 células $/ \mathrm{mL}$.

É fácil notar que na ordem de lactação 1 ocorreram as menores estimativas do parâmetro $\alpha$, indicando produções inferiores em relação às demais ordens de lactação, e as maiores do parâmetro $\beta$, mostrando a maior capacidade em manter a produção no decorrer da lactação considerando que o parâmetro $\gamma$ não varia com a ordem de lactação. Esse resultado está de acordo com os obtidos por Batra (1986), Costa et al. (1982), Dekkers et al. (1998) e Sölkner \& Fuchs (1987). 
Tabela 5. Estimativas e intervalos de confiança (95\%) dos parâmetros do modelo $y=\alpha_{i j k} t_{i j} e^{-\gamma_{j k} t}+\delta_{i} \operatorname{Ln}\left(I_{x}\right)$, sendo $I_{x}=\left\{x-x_{0}+1\right.$, se $x>x_{0} ; 1$, casocontrário $\}, x$ a CCS e $x_{0}=17$

\begin{tabular}{|c|c|c|c|c|c|c|}
\hline $\begin{array}{l}\text { Ordem de } \\
\text { Lactação }\end{array}$ & Rebanho & $\begin{array}{c}\text { Época do } \\
\text { Parto }\end{array}$ & $\alpha$ & $\beta$ & $\gamma\left(\times 10^{2}\right)$ & $\delta$ \\
\hline \multirow{12}{*}{1} & \multirow{2}{*}{1} & Verão & $14,46(13,28: 15,65)$ & $0,209(0,189: 0,229)$ & $0,12(0,10: 0,13)$ & \\
\hline & & Inverno & $15,24(14,01: 16,47)$ & $0,209(0,189: 0,229)$ & $0,16(0,15: 0,18)$ & \\
\hline & \multirow{2}{*}{2} & Verão & $10,81(9,29: 12,32)$ & $0,254(0,219: 0,290)$ & $0,31(0,28: 0,34)$ & \\
\hline & & Inverno & $12,01(10,32: 13,69)$ & $0,254(0,219: 0,290)$ & $0,33(0,30: 0,36)$ & \\
\hline & \multirow{2}{*}{3} & Verão & $16,63(13,88: 19,39)$ & $0,117(0,073: 0,161)$ & $0,14(0,10: 0,19)$ & \\
\hline & & Inverno & $17,43(14,56: 20,30)$ & $0,117(0,073: 0,161)$ & $0,16(0,12: 0,20)$ & $-0,238$ \\
\hline & \multirow[b]{2}{*}{4} & Verão & $11,50(8,25: 14,75)$ & $0,287(0,215: 0,359)$ & $0,35(0,28: 0,41)$ & $(-0,316:-0,161)$ \\
\hline & & Inverno & $11,49(8,29: 14,69)$ & $0,287(0,215: 0,359)$ & $0,32(0,26: 0,38)$ & \\
\hline & \multirow{2}{*}{5} & Verão & $11,93(8,97: 14,89)$ & $0,245(0,182: 0,309)$ & $0,21(0,15: 0,27)$ & \\
\hline & & Inverno & $13,47(10,17: 16,76)$ & $0,245(0,182: 0,309)$ & $0,24(0,19: 0,30)$ & \\
\hline & \multirow{2}{*}{6} & Verão & $10,73(8,68: 12,78)$ & $0,226(0,175: 0,276)$ & $0,25(0,19: 0,31)$ & \\
\hline & & Inverno & $12,36(9,99: 14,73)$ & $0,226(0,175: 0,276)$ & $0,30(0,25: 0,34)$ & \\
\hline \multirow{12}{*}{2} & \multirow{2}{*}{1} & Verão & $34,10(31,72: 36,48)$ & $0,067(0,049: 0,085)$ & $0,12(0,10: 0,13)$ & \\
\hline & & Inverno & $37,30(34,81: 39,79)$ & $0,067(0,049: 0,085)$ & $0,16(0,15: 0,18)$ & \\
\hline & \multirow{2}{*}{2} & Verão & $22,97(20,14: 25,80)$ & $0,170(0,138: 0,203)$ & $0,31(0,28: 0,34)$ & \\
\hline & & Inverno & $24,52(21,50: 27,55)$ & $0,170(0,138: 0,203)$ & $0,33(0,30: 0,36)$ & \\
\hline & \multirow{2}{*}{3} & Verão & $22,69(18,18: 27,20)$ & $0,083(0,032: 0,134)$ & $0,14(0,10: 0,19)$ & \\
\hline & & Inverno & $23,02(18,36: 27,69)$ & $0,083(0,032: 0,134)$ & $0,16(0,12: 0,20)$ & $-0,868$ \\
\hline & \multirow{2}{*}{4} & Verão & $18,70(13,81: 23,60)$ & $0,234(0,166: 0,302)$ & $0,35(0,28: 0,41)$ & $(-0,938:-0,799)$ \\
\hline & & Inverno & $18,32(13,42: 23,21)$ & $0,234(0,166: 0,302)$ & $0,32(0,26: 0,38)$ & \\
\hline & \multirow{2}{*}{5} & Verão & $29,81(20,87: 38,74)$ & $0,066(-0,010: 0,142)$ & $0,21(0,15: 0,27)$ & \\
\hline & & Inverno & $34,56(23,14: 45,98)$ & $0,066(-0,010: 0,142)$ & $0,24(0,19: 0,30)$ & \\
\hline & \multirow[b]{2}{*}{6} & Verão & $22,41(18,14: 26,69)$ & $0,146(0,096: 0,196)$ & $0,25(0,19: 0,31)$ & \\
\hline & & Inverno & $23,79(19,38: 28,19)$ & $0,146(0,096: 0,196)$ & $0,30(0,25: 0,34)$ & \\
\hline \multirow{12}{*}{$\begin{array}{c}3 \text { ou } \\
\text { superior }\end{array}$} & & Verão & $40,48(37,89: 43,08)$ & $0,038(0,021: 0,055)$ & $0,12(0,10: 0,13)$ & \\
\hline & & Inverno & $43,64(40,94: 46,34)$ & $0,038(0,021: 0,055)$ & $0,16(0,15: 0,18)$ & \\
\hline & \multirow{2}{*}{2} & Verão & $21,45(19,02: 23,87)$ & $0,197(0,166: 0,227)$ & $0,31(0,28: 0,34)$ & \\
\hline & & Inverno & $23,24(20,68: 25,80)$ & $0,197(0,166: 0,227)$ & $0,33(0,30: 0,36)$ & \\
\hline & \multirow{2}{*}{3} & Verão & $18,19(13,20: 23,18)$ & $0,118(0,054: 0,182)$ & $0,14(0,10: 0,19)$ & \\
\hline & & Inverno & $22,46(16,46: 28,46)$ & $0,118(0,054: 0,182)$ & $0,16(0,12: 0,20)$ & $-0,868$ \\
\hline & \multirow[b]{2}{*}{4} & Verão & $19,12(14,23: 24,00)$ & $0,197(0,131: 0,264)$ & $0,35(0,28: 0,41)$ & $(-0,938:-0,799)$ \\
\hline & & Inverno & $20,71(15,57: 25,86)$ & $0,197(0,131: 0,264)$ & $0,32(0,26: 0,38)$ & \\
\hline & \multirow[b]{2}{*}{5} & Verão & $23,40(18,00: 28,8)$ & $0,147(0,084: 0,210)$ & $0,21(0,15: 0,27)$ & \\
\hline & & Inverno & $25,16(19,07: 31,25)$ & $0,147(0,084: 0,210)$ & $0,24(0,19: 0,30)$ & \\
\hline & \multirow[b]{2}{*}{6} & Verão & $23,32(18,32: 28,33)$ & $0,130(0,076: 0,184)$ & $0,25(0,19: 0,31)$ & \\
\hline & & Inverno & $26,68(21,25: 32,12)$ & $0,130(0,076: 0,184)$ & $0,30(0,25: 0,34)$ & \\
\hline
\end{tabular}


Em relação à época do parto, as vacas que pariram no verão apresentaram, na maioria das vezes, as menores estimativas para os parâmetros $\alpha$ e $\gamma$. Iss o indica que vacas que parem no verão produzem menos leite no início da lactação, e contudo, têm menores decréscimos de produção após o pico. É o efeito do estresse calórico se manifestando, pois as vacas paridas no verão sofrem com as condições ambientais desfavoráveis (temperatura, principalmente) no início da lactação, produzindo menos leite, e na maior parte das vezes terminam a lactação no inverno, período mais favorável para a produção de leite, implicando em valores menores para $\gamma$. As estimativas do parâmetro $\delta$ foram $-0,238$ e $-0,868$ para vacas primíparas e multíparas, respectivamente, e representam as perdas de produção de leite (kg/dia) em função do aumento de uma unidade logarítmica da CCS, a partir de 17.000 células/mL. A Figura 2 ilustra esse resultado, mostrando as perdas estimadas em função da CCS.

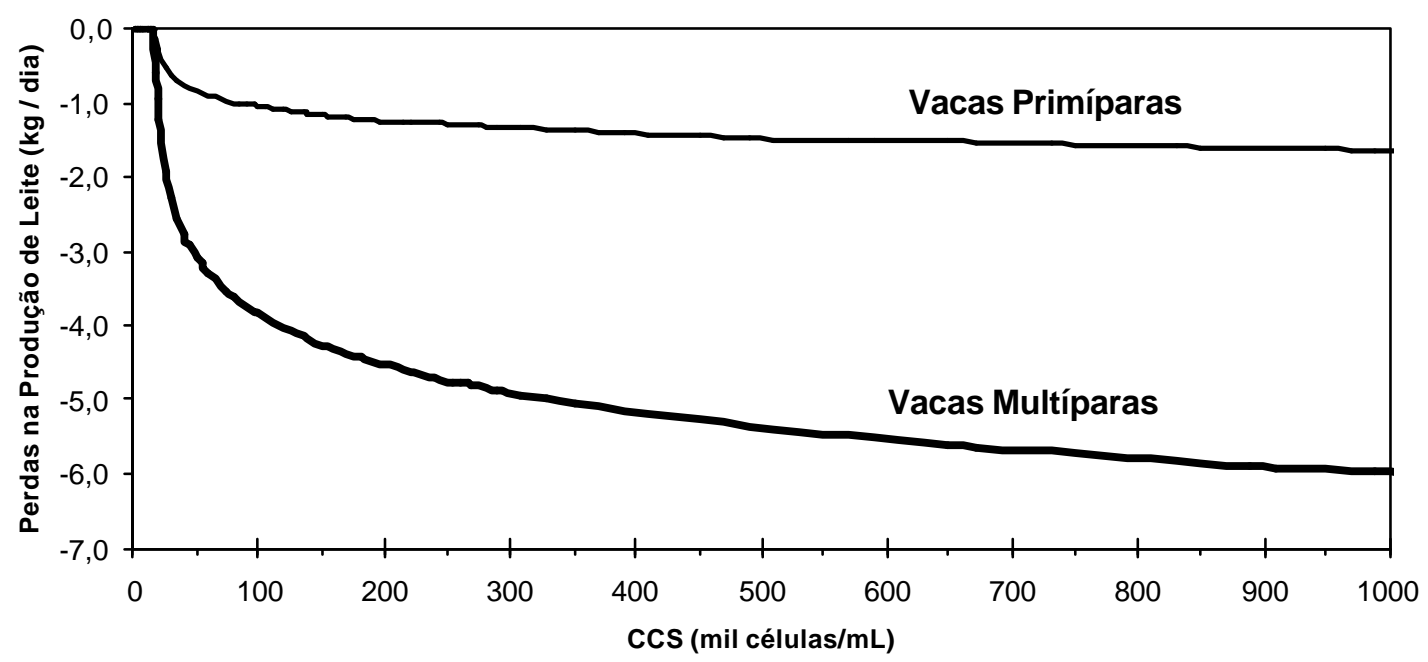

Figura 2 - Perdas de produção de leite em função do aumento da CCS e da ordem de lactação

As perdas maiores em vacas multíparas podem ser explicadas pelo agravamento na saúde do úbere nesses animais, ocasionado pela maior possibilidade de infecção e dano permanente à glândula por infecções prévias (Barttlet et al., 1990). Além disso, vacas mais velhas tendem a ter infecções mais longas, causando danos mais extensos nos tecidos (Reneau, 1986). 
Comparando os resultados encontrados no presente estudo com os obtidos por Kirk (1984), Reneau (1986) e Gill et al. (1990) (Tabela 6), observa-se que para as vacas primíparas, considerando as perdas a partir de 50.000 células $/ \mathrm{mL}$, os resultados obtidos por Kirk (1984) e por Reneau (1986) sofrem acréscimos levemente maiores do que os obtidos nesse trabalho; ao passo que para as vacas multíparas, os resultados aqui encontrados são intermediários aos apresentados por esses dois autores. Já, os resultados alcançados por Gill et al. (1990) foram maiores do que os obtidos no presente estudo para vacas primíparas, porém, não foram muito diferentes do das multíparas. Outra consideração a ser feita é que no estudo vertente mostra-se que as perdas já ocorrem a partir de 17.000 células $/ \mathrm{mL}$, enquanto que os dois primeiros autores consideram que as perdas iniciam somente a partir de 100.000 células $/ \mathrm{mL}$.

Tabela 6. Perdas de produção de leite em função do aumento da CCS $\left(\times 10^{3}\right.$ células $\left./ \mathrm{mL}\right)$, obtidas por Kirk (1984), Reneau (1986), Gill et al. (1990) e no presente estudo

\begin{tabular}{|c|c|c|c|c|c|c|c|}
\hline \multirow{2}{*}{ CCS } & \multicolumn{2}{|c|}{ Estudo } & \multicolumn{2}{|c|}{ Kirk (1984) } & \multicolumn{2}{|c|}{ Reneau (1986) } & \multirow{2}{*}{$\begin{array}{c}\text { Gill et al. } \\
\text { (1990) } \\
\text { P e M }\end{array}$} \\
\hline & $\mathrm{P}$ & M & $\mathrm{P}$ & M & $\mathrm{P}$ & M & \\
\hline células $/ \mathrm{mL} \times 10^{-3}$ & \multicolumn{2}{|c|}{$\mathrm{kg} /$ dia } & \multicolumn{2}{|c|}{$\mathrm{kg} / \mathrm{dia}$} & \multicolumn{2}{|c|}{$\mathrm{kg} / \mathrm{dia}$} & $\mathrm{kg} / \mathrm{dia}$ \\
\hline 12,5 & 0 & 0 & 0 & 0 & 0 & 0 & 0 \\
\hline 25,0 & 0,52 & 1,91 & 0 & 0 & 0 & 0 & 1,45 \\
\hline 50,0 & 0,84 & 3,06 & 0 & 0 & 0 & 0 & 2,74 \\
\hline 100,0 & 1,05 & 3,85 & 0,34 & 0,68 & 0,27 & 0,59 & 3,86 \\
\hline 200,0 & 1,24 & 4,53 & 0,68 & 1,36 & 0,59 & 1,18 & 4,83 \\
\hline 400,0 & 1,42 & 5,17 & 1,02 & 2,04 & 0,91 & 1,78 & 5,63 \\
\hline 800,0 & 1,59 & 5,78 & 1,36 & 2,72 & 1,18 & 2,36 & 6,27 \\
\hline 1600,0 & 1,75 & 6,40 & 1,70 & 3,40 & 1,50 & 2,99 & 6,75 \\
\hline 3200,0 & 1,92 & 7,00 & 2,04 & 4,08 & 1,78 & 3,58 & 7,06 \\
\hline 6400,0 & 2,09 & 7,61 & 2,38 & 4,76 & 2,09 & 4,17 & 7,26 \\
\hline
\end{tabular}

Ao contrário do observado neste trabalho, Hortet et al. (1999) não encontraram diferenças significativas entre os estágios de lactação para vacas primíparas, mas observaram 
efeitos significativos nas multíparas, com perdas crescentes no decorrer da lactação. Para eles, vacas na 1. ${ }^{a}$ lactação apresentaram redução de $0,30 \mathrm{~kg}$ de leite para 100.000 células $/ \mathrm{mL}$ e 0,61 kg para 200.000 células/mL, enquanto que as vacas na 2. ${ }^{a}$ lactação com CCS \& 200 mil células $/ \mathrm{mL}$ tiveram uma redução na produção de leite de $0,63 \mathrm{~kg}$ no $50 .^{\circ}$ dia pós-parto, $0,92 \mathrm{~kg}$ no $150 .^{\circ}$ dia e $1,77 \mathrm{~kg}$ no $2500^{\circ}$ dia pós-parto. Vacas de $3 .^{\mathrm{a}}$ lactação ou superior, com essa mesma CCS, tiveram redução de 0,60 kg, 1,09 kg e 1,85 kg, nos dias 50, 150 e 250 pós-parto, respectivamente.

Salienta-se que Hortet et al. (1999) basearam-se em estudos de cultura bacteriológica negativa (Schepers et al., 1997) e de ausência de mastite clínica (Laevens et al., 1997; Wilson et al. 1997) para propor um ponto de corte de 50.000 células/mL, a partir do qual as perdas começariam a ocorrer, e não nos próprios dados, como foi feito no presente trabalho.

\subsubsection{Utilização prática dos resultados}

Os resultados obtidos neste estudo podem ser utilizados, por exemplo, para estimar as perdas de produção de leite para cada vaca em lactação, bastando multiplicar a estimativa correspondente do parâmetro $\delta$ de cada ordem de lactação pelo logaritmo natural de $I x$, sendo $I_{x}=\left\{x-x_{0}+1\right.$, se $x>x_{0} ; 1$, casocontrário $\}, x$ a CCS e $x_{0}=17$. A partir do resultado de cada vaca, podem-se estimar as perdas médias devidas ao aumento da CCS, refletindo o impacto da mastite subclínica para cada ordem de lactação (no caso, vacas primíparas e multíparas) e para o rebanho, como um todo.

A Tabela 7 mostra que os rebanhos 1 e 3 foram aqueles em que as vacas tiveram menor redução da produção de leite devido ao aumento da CCS, tendo médias de perdas de 2,20 e 1,59 kg/vaca/dia. Os rebanhos 2 e 4 apresentaram as maiores perdas, 3,18 e 3,40 $\mathrm{kg} / \mathrm{vaca} / \mathrm{dia}$, respectivamente, sendo que, para as vacas multíparas, o rebanho 4 perdeu 5,00 $\mathrm{kg} / \mathrm{vaca} / \mathrm{dia}$, o que é uma quantidade elevada.

Tabela 7. Perdas médias de produção de leite devidas ao aumento da CCS, em função do rebanho e da ordem de lactação, durante todo o período do estudo 


\begin{tabular}{cccccccc}
\hline \multirow{2}{*}{ Ordem de Lactação } & \multicolumn{8}{c}{ Rebanho } & \multirow{2}{*}{ Média } \\
\cline { 2 - 6 } & 1 & 2 & 3 & 4 & 5 & 6 & \\
\hline & & \multicolumn{7}{c}{$\mathrm{kg} /$ vaca/dia } \\
Primíparas & 0,75 & 1,14 & 0,82 & 1,12 & 0,92 & 1,13 & 0,90 \\
Multíparas & 3,10 & 4,46 & 2,94 & 5,00 & 4,39 & 4,87 & 3,64 \\
\hline Média & 2,20 & 3,18 & 1,59 & 3,40 & 2,60 & 2,56 & 2,40
\end{tabular}

Com base nesse resultado pode-se inferir que os rebanhos 2 e 4 seriam os que mais responderiam a uma melhoria no programa de controle de mastite, já que suas perdas são elevadas, e talvez, com pouco investimento pudessem ser niveladas àdos rebanhos 1 e 3 .

Harmon (1998b) evidencia que, nos Estados Lhidos, a queda na produção de leite representa $66 \%$ das perdas advindas da mastite. Logo, se aplicado esse resultado às condições brasileiras, as perdas médias dos rebanhos estudados chegariam a 3,64 kg/vaca/dia.

\subsection{Conclusões}

Os ajustes de modelos para as curvas de lactação mostraram que o parâmetro $\alpha$ varia com a ordem de lactação, o rebanho e a época do parto, enquanto $\beta$ depende apenas dos dois primeiros fatores, e $\gamma$, do rebanho e da época do parto. O presente estudo permitiu evidenciar que as perdas de produção de leite devidas ao aumento da CCS são absolutas, isto é, independem do nível de produção dos animais. Ademais, elas começam a ocorrer a partir de uma CCS de 17.000 células/mL e são diferentes para vacas primíparas e multíparas. 


\section{CONCLUSÕES}

Considerando as metodologias empregadas no presente trabalho e os resultados obtidos, as seguintes conclusões foram alcançadas:

1) A utilização da teoria de modelos lineares generalizados facilita muito o ajuste da função gama incompleta e, além disso, mantém a estrutura aditiva dos erros e a suposição de normalidade da produção de leite, diferentemente do ajuste da variável transformada (logaritmo natural da produção de leite) através de mínimos quadrados ordinários, em que a estrutura dos erros é multiplicativa e a suposição de normalidade é para a variável transformada, e não para a variável original;

2) A comparação de modelos de curva de lactação via BIC pode ser considerada como uma "análise multivariada" dos parâmetros quando comparada com aquela em que a estimativa de cada parâmetro é avaliada como se fosse independente dos outros parâmetros, o que não é verdade;

3) A estratégia de estimação do ponto de corte $x_{0}$ usada no segundo estudo, em que um mesmo modelo foi ajustado 6 vezes (para $x_{0}=1,5,10,15,25$ e 50), tem a vantagem de mostrar numericamente, através do valor do BIC, a melhora do ajuste em função do valor de $x_{0}$. Contudo, essa estratégia é muito trabalhosa, e é preferível, em estudos posteriores, utilizar a processo de estimação proposto no primeiro estudo, em que $x_{0}$ foi incluído como um parâmetro no próprio modelo, e estimado via ajuste de um único modelo, tendo as vantagens de ser menos trabalhoso e a possibilidade de se calcularem os intervalos de confiança para $x_{0}$; 
4) Os ajustes de modelos para curva de lactação mostraram que:

a) No primeiro estudo, os parâmetros $\alpha$ e $\beta$ variaram com a ordem de lactação e com a época do parto, enquanto o parâmetro $\gamma$ dependeu apenas da época do parto;

b) No segundo estudo, o parâmetro $\alpha$ variou com a ordem de lactação, o rebanho e a época do parto, enquanto $\beta$ dependeu apenas dos dois primeiros fatores, e $\gamma$, do rebanho e da época do parto.

5) Em ambos os estudos, os ajustes dos modelos para CCS indicaram que as perdas de produção de leite associadas ao aumento da CCS são absolutas, isto é, independem da produção de leite, e variam apenas com a ordem de lactação (vacas primíparas ou multíparas). Além disso:

a) No primeiro estudo estimou-se que as perdas começam a ocorrer a partir de 14.270 células/mL e são de 184 e 869 g/dia para vacas primíparas e multíparas, respectivamente, para cada aumento unitário na escala do logaritmo natural a partir desse valor;

b) No segundo caso os dados mostraram que as perdas iniciam a partir de 17.000 células $/ \mathrm{mL}$, e para cada aumento unitário na escala do logaritmo natural a partir desse valor estimam-se perdas de 238 e $868 \mathrm{~g} /$ dia para vacas primíparas e multíparas, respectivamente.

6) Em novos estudos parece ser interessante considerar o efeito da vaca (efeito aleatório) e a estrutura de dependência das medidas de produção de leite e de CCS ao longo do tempo para um mesmo animal. Ademais, pode-se pensar em modelos que contemplem diferentes pontos de corte $x_{0}$ em função dos fatores que podem influenciar a produção de leite. 
ANEXOS 


\section{ANEXO A. Ajuste do Modelo Usado para Descrever a Curva de Lactação}

Na teoria de modelos linerares generalizados, a estimação dos parâmetros do modelo é efetuada através do método de máxima verossimilhança, usando-se processos numéricos iterativos do tipo Newton-Raphson (Demétrio, 2001). Os softwares GLIM ou SAS podem ser utilizados para tal fim.

Neste item serão apresentados alguns exemplos de sintaxe do procedimento GENMOD do SAS para o ajuste de modelos para curva de lactação utilizando a função gama incompleta proposta por Wood (1967), com o intuito de facilitar estudos posteriores que desejem utilizar a proposta de análise deste trabalho.

O modelo minimal, $y=\alpha t^{\beta} e^{-\gamma t}$, para curva de lactação foi ajustado utilizadose a seguinte sintaxe:

proc genmod;

model leite=lndel del/link=log;

run;

sendo que, a variável leite representa a produção de leite no dia em lactação t, enquanto que as variáveis explanatórias Indel e del representam, respectivamente, o logaritmo natural do número de dias em lactação e o número de dias em lactação. Já, a opção link=log, no comando model define a função logaritmo como função de ligação.

Para o modelo $y=\alpha_{i} t^{\beta} e^{-\gamma t}$, em que $\alpha$ varia com a ordem de lactação, foi usada a sintaxe abaixo para o ajuste.

proc genmod; 
class nl;

model leite=nl lndel del/noint link=log;

run;

A variável explanatória nl, definida como classificatória no comando class, representa a ordem de lactação (1, 2 e 3 ou superior), ao passo que a opção noint, no comando model define que o modelo é sem intercepto. Os demais termos são como no ajuste do modelo minimal.

Pensando que todos os parâmetros da curva de lactação variam com a ordem de lactação, o modelo a ser ajustado é $y=\alpha_{i} t^{\beta_{i}} e^{-\gamma_{i} t}$, podendo-se utilizar as seguintes linhas de programação, cujas variáveis já foram mostradas anteriormente.

proc genmod;

class nl;

model leite=nl lndel(nl) del(nl)/noint link=log;

run;

Para o segundo estudo, o modelo maximal $y=\alpha_{i j k} t^{\beta_{i j k}} e^{-\gamma_{i j k} t}$, em que todos os parâmetros da curva de lactação dependem da ordem de lactação, do rebanho e da época do parto, utilizourse a seguinte sintaxe para o ajuste.

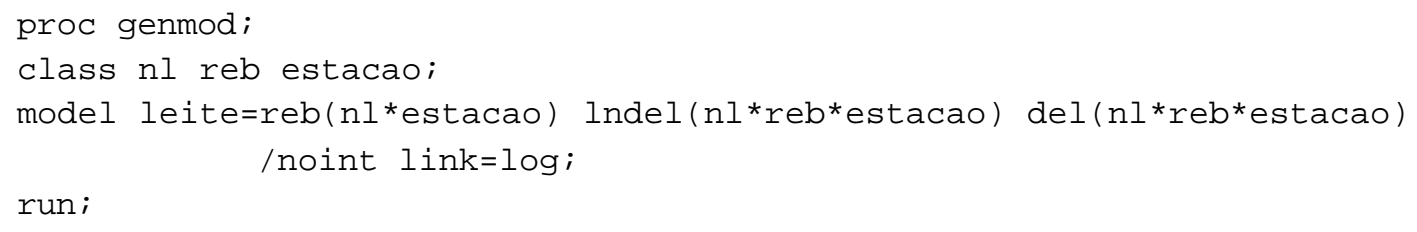

sendo que, as variáveis explanatórias reb e estacao, definidas como classificatórias no comando class, representam o rebanho $(1,2,3,4,5$ e 6$)$ e a época do parto (verão = meses de outubro a março, e inverno $=$ meses de abril a setembro), respectivamente. Os demais itens foram definidos anteriormente.

Para o modelo maximal do primeiro estudo, $y=\alpha_{i j k m} t^{\beta_{i j k m}} e^{-\gamma_{i j k n t}}$, foi usada sintaxe a seguir para o ajuste. 
proc genmod;

class nl estacao doenca ecc;

model leite=nl (estacao*doenca*ecc) lndel (nl*estacao*doenca*ecc)

del (nl*estacao*doenca*ecc) / noint link=log;

run;

As variáveis explanatórias doenca e ecc, definidas como classificatórias no comando class, representam, respectivamente, a ocorrência, ou não, de alguma doença no periparto e o escore de condição corporal ao parto $(\leq 3$, entre 3 e 4 , e $\geq 4)$. Os outros termos são como definidos anteriormente.

$\mathrm{O}$ ajuste de modelos intermediários pode ser feito utilizando-se as sintaxes apresentadas, mudando-se apenas as variáveis explanatórias do modelo. 


\section{ANEXO B. Estimação de $x_{0}$ via Ajuste de Um Único Modelo}

Visa-se, neste item, ilustrar o processo de estimação do ponto de corte $x_{0}$, a partir do qual as perdas de produção de leite começam a ocorrer, utilizado no primeiro trabalho, mostrando a programação em linguagem SAS para o ajuste dos modelos e estimação de $x_{0}$. A estimação dos parâmetros foi efetuada através do método de máxima verossimilhança, usando-se o algoritmo quase-Newton (SAS Institute, 1999).

Para o ajuste dos modelos para CCS considerou-se o modelo escolhido para curva de lactação, $y=\alpha_{i j} t^{\beta_{i j}} e^{-\gamma_{j} t}$, em que os parâmetros $\alpha$ e $\beta$ variam em função ordem de lactação e da época do parto, enquanto que o parâmetro $\gamma$ depende apenas da época do parto.

Dessa forma, por exemplo, o modelo para perdas relativas, $y=\alpha_{i j} t^{\beta_{i j}} e^{-\gamma_{j} t} I_{x} \delta_{i}$, cujo parâmetro $\delta$ depende apenas da ordem de lactação foi ajustado usando as seguintes linhas de programação no procedimento NLMIXED.

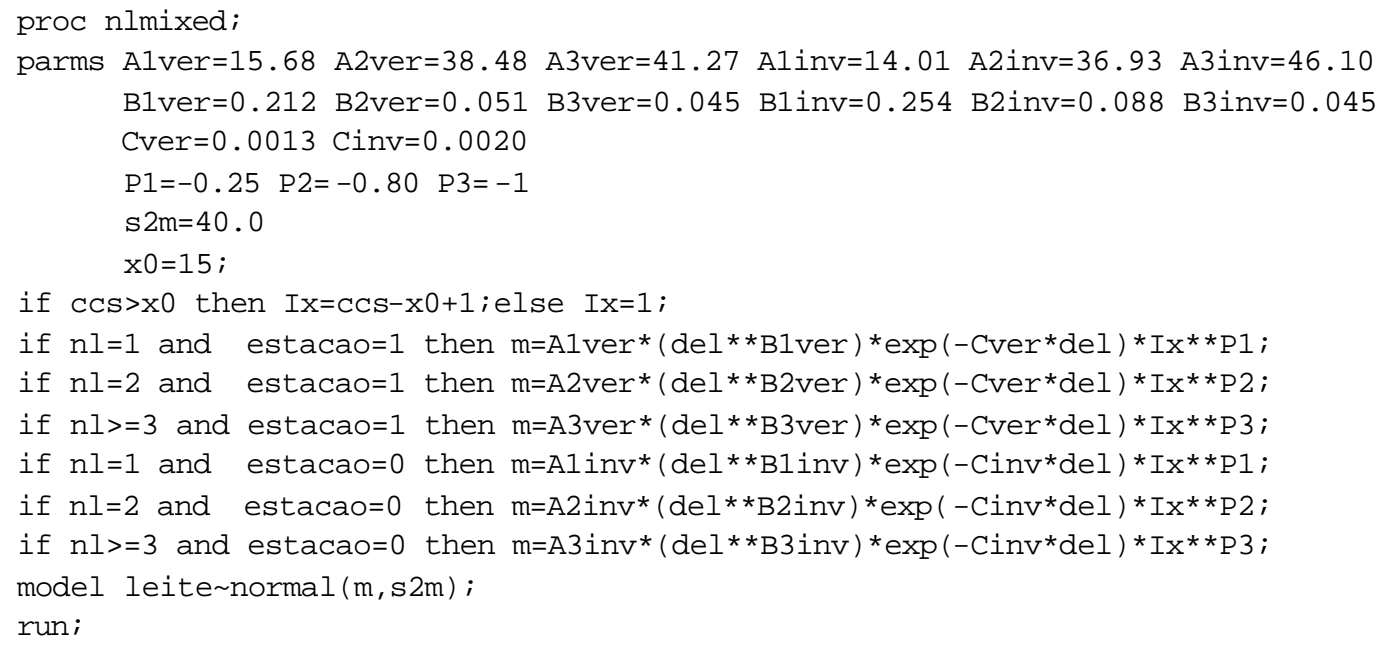


A variável leite representa a produção de leite no dia em lactação t, enquanto que as variáveis explantórias del e Ix representam, respectivamente, o número de dias em lactação e $\mathrm{I}_{\mathrm{x}}=\left\{\begin{array}{l}\mathrm{x}-\mathrm{x}_{0}+1, \text { se } \mathrm{x}>\mathrm{x}_{0} \\ 1, \text { caso contrário }\end{array} ; x\right.$ a CCS e $x_{0}$, o valor da CCS a partir do qual começam a ocorrer perdas; as variáveis explanatórias nl e estacao representam respectivamente a ordem de lactação (1, 2 e 3 ou superior) e a época do parto (verão = meses de outubro a março, e inverno $=$ meses de abril a setembro). No comando parms são definidos os valores iniciais dos parâmetros, sendo, no caso, utilizados os valores obtidos através do procedimento GENMOD para os parâmetros da curva de lactação $(\alpha, \beta$ e $\gamma)$ escolhida. O parâmetro $\mathbf{s} 2 \mathbf{m}$ representa a variância residual.

$\mathrm{O}$ ajuste dos modelos de perdas absolutas foi realizado da mesma maneira que para os de perdas relativas, apenas mudando-se o modelo no NLMIXED. Para ilustrar, considere-se a sintaxe que se segue, usada para ajustar o modelo $y=\alpha_{i j} \beta_{i j} e^{-\gamma_{j} t}+\delta_{i} \operatorname{Ln}\left(I_{x}\right)$, em que $\delta$ varia com a ordem de lactação.

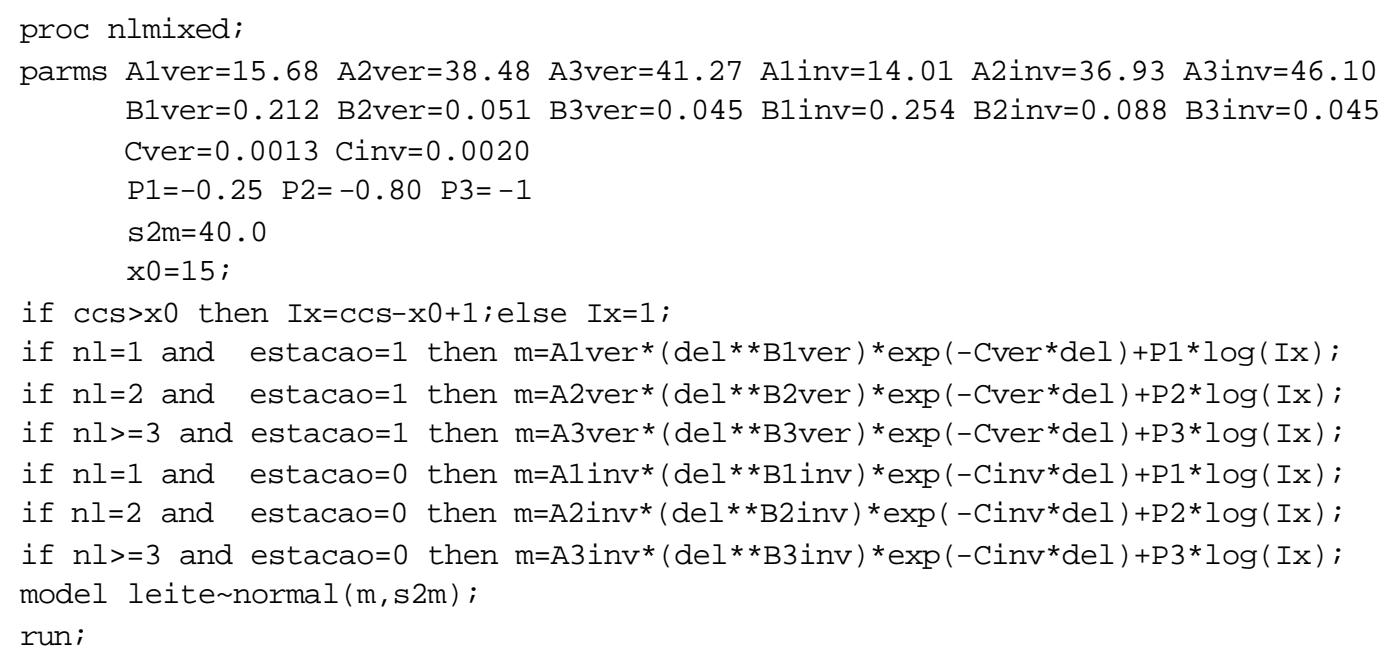

Os termos dessa sintaxe são como foram definidos acima. Note-se que, nesse caso basta ajustar um único modelo para encontrar o ponto de corte $x_{0}$, diferentemente da metodologia adotada no segundo estudo, em que foi ajustado o mesmo modelo com 6 pontos de 
corte $\left(x_{0}=1,5,10,15,25\right.$ e 50) com o intuito de encontrar o ponto de corte mais satisfatório para cada um dos modelos.

Sintaxes semelhantes a essas foram usadas para o ajuste dos outros 50 modelos (25 para perdas relativas e 25 para perdas absolutas), considerando os outros fatores que podem influenciar a estimativa do parâmetro $\delta$. 


\section{ANEXO C. Estimação de $x_{0}$ via Ajuste de Vários Modelos}

Este anexo visa esclarecer, ainda mais, o processo de estimação do ponto de corte $x_{0}$, a partir do qual as perdas de produção de leite começam a ocorrer, utilizado no segundo trabalho, mostrando a programação em linguagem SAS para o ajuste dos modelos.

Primeiramente, foi criado um arquivo de dados (dados1) a partir dos dados existentes (dados), considerando 6 pontos de corte $\left(x_{0}=1,5,10,15,25\right.$ e 50) através da variável $I_{x}=\left\{\begin{array}{l}x-x_{0}+1, \text { se } x>x_{0} \\ 1, \text { caso contrário }\end{array}\right.$, sendo $x$ a CCS e $x_{0}$ o valor da CCS a partir do qual começam a ocorrer perdas. Como no ajuste dos modelos, $I_{x}$ entra na escala logarítmica, essa variável foi criada nessa escala. A sintaxe é como segue:

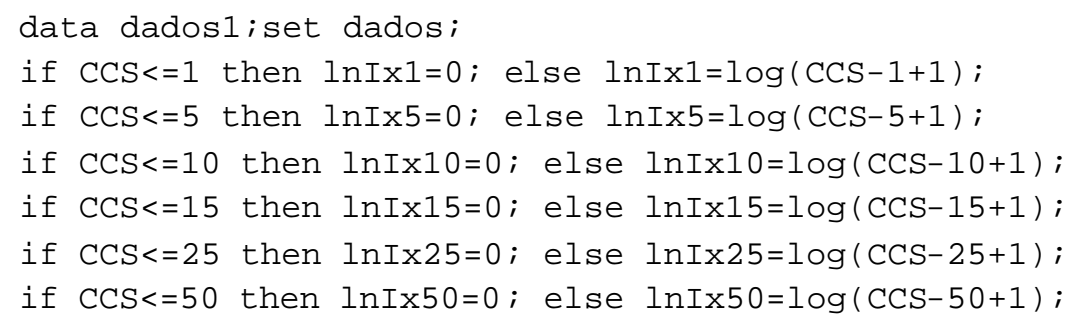

Para o ajuste dos modelos para CCS considerou-se o modelo escolhido para curva de lactação, $y=\alpha_{i j k} t^{\beta_{i j}} e^{-\gamma_{j k} t}$, em que o parâmetro $\alpha$ varia em função ordem de lactação, do rebanho e da época do parto, ao passo que o parâmetro $\beta$ depende apenas da ordem de lactação e do rebanho, e o $\gamma$, do rebanho e da época do parto. Assim, por exemplo, o modelo para perdas relativas, $y=\alpha_{i j k} t^{\beta_{i j}} e^{-\gamma_{j k} t} I_{x} \delta_{i}$, cujo parâmetro $\delta$ depende apenas da 
ordem de lactação e $x_{0}=1$ foi ajustado usando as seguintes linhas de programação no procedimento GENMOD.

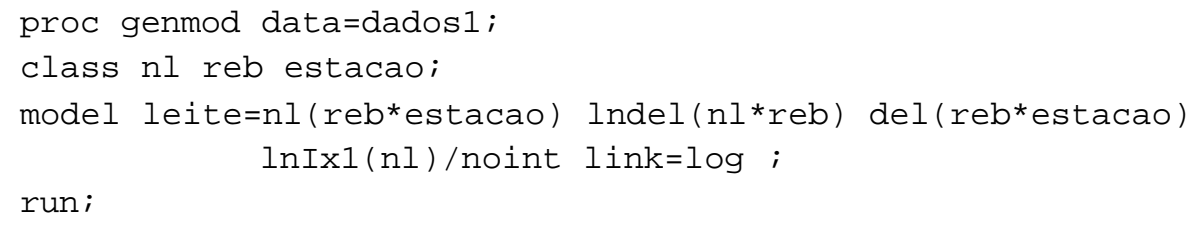

sendo que, a variável leite representa a produção de leite no dia em lactação t, enquanto que as variáveis explantórias Indel, del e $\mathbf{l n I x 1}$ representam, respectivamente, o logaritmo natural do número de dias em lactação, o número de dias em lactação e o logaritmo natural de $I_{x}$ para $x_{0}=$ 1; e as variáveis explanatórias nl, reb e estacao, definidas como classificatórias no comando class, representam respectivamente a ordem de lactação (1, 2 e 3 ou superior), o rebanho (1, 2, $3,4,5$ e 6 ) e a época do parto (verão = meses de outubro a março, e inverno $=$ meses de abril a setembro). A opção link=log, no comando model, define a função logaritmo como função de ligação, e a opção noint define o modelo sem intercepto.

Para o modelo de perdas absolutas, por se tratar de um modelo não-linearizável, o ajuste foi efetuado utilizando-se o procedimento NLMIXED do SAS. Assim, por exemplo, o ajuste do modelo $y=\alpha_{i j k} t^{\beta_{i j}} e^{-\gamma_{j k} t}+\delta_{i} \operatorname{Ln}\left(I_{x}\right)$, em que o parâmetro $\delta$ varia apenas com a ordem de lactação e para $x_{0}=1$, foi feito através da sintaxe dada a seguir.

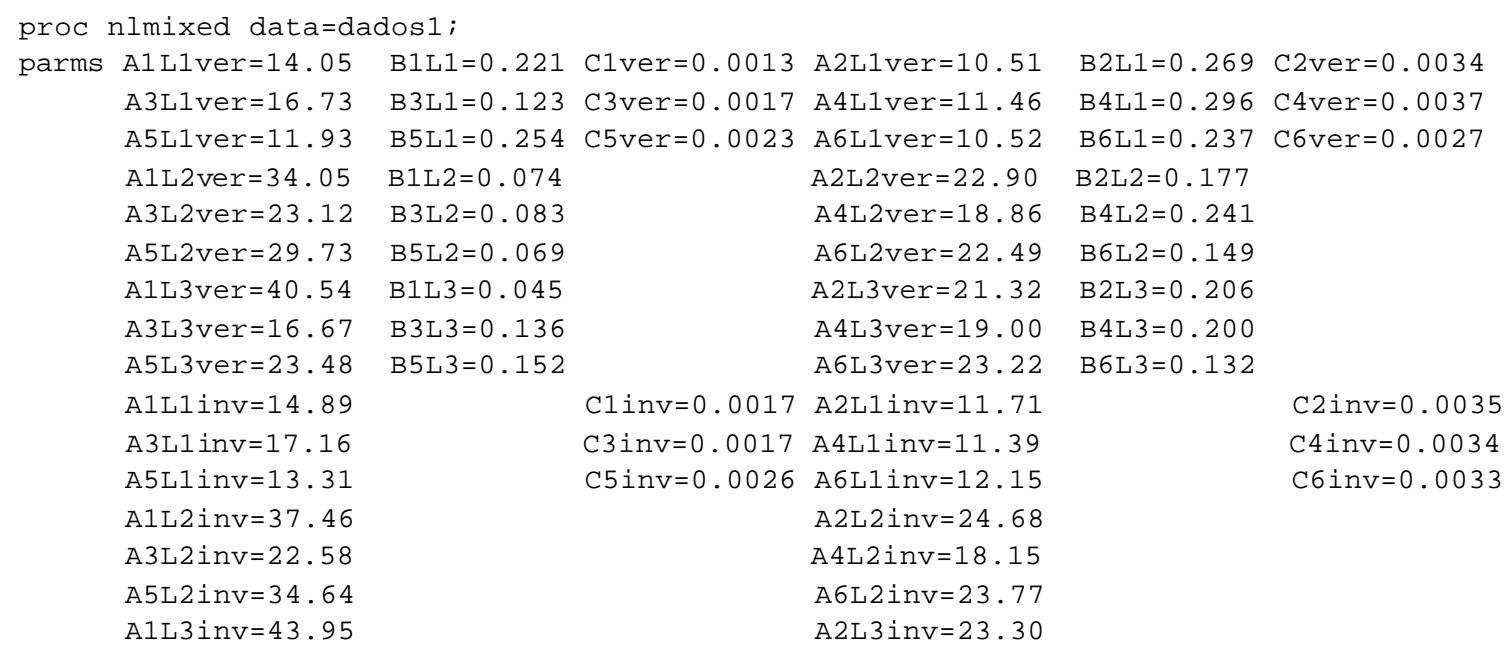




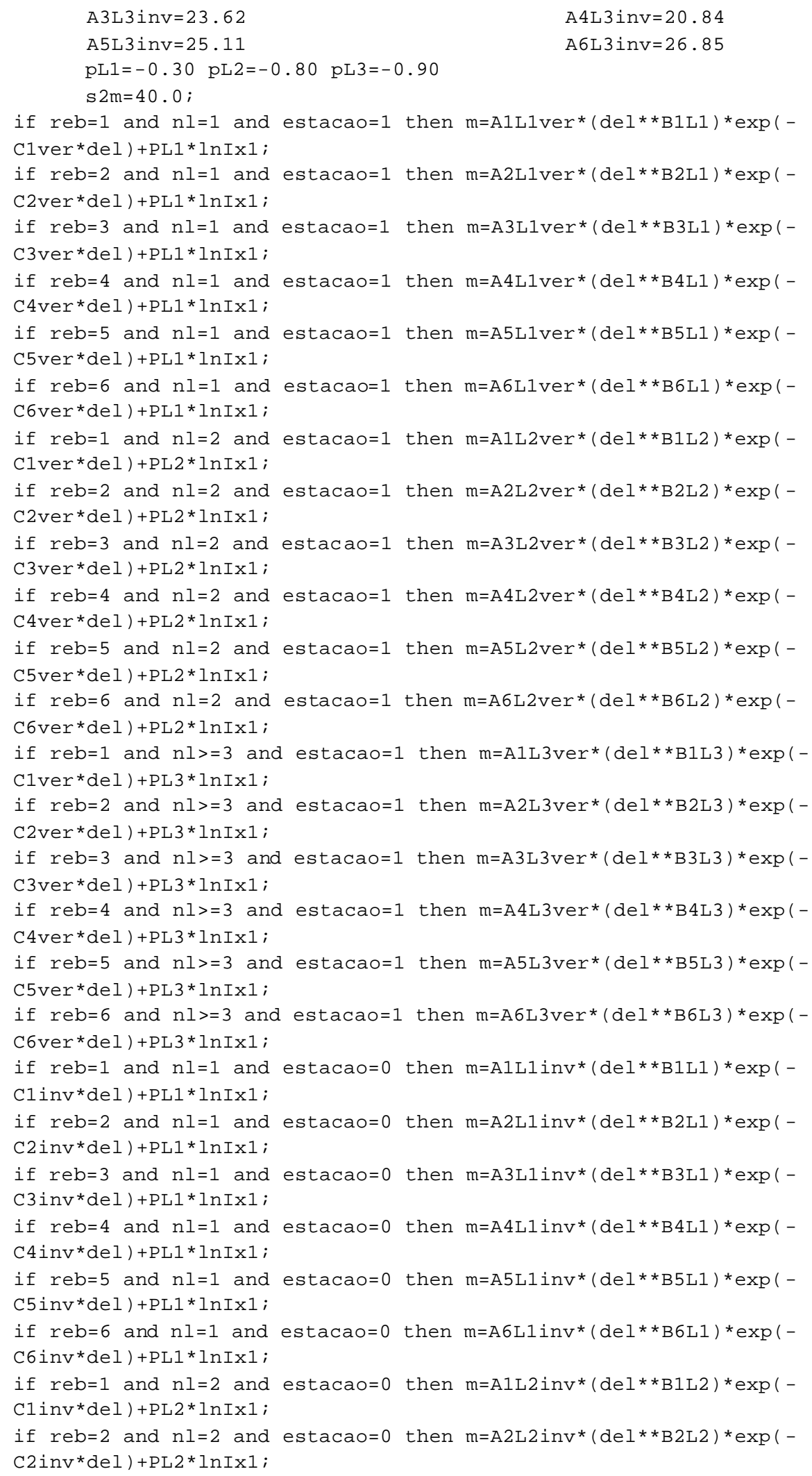




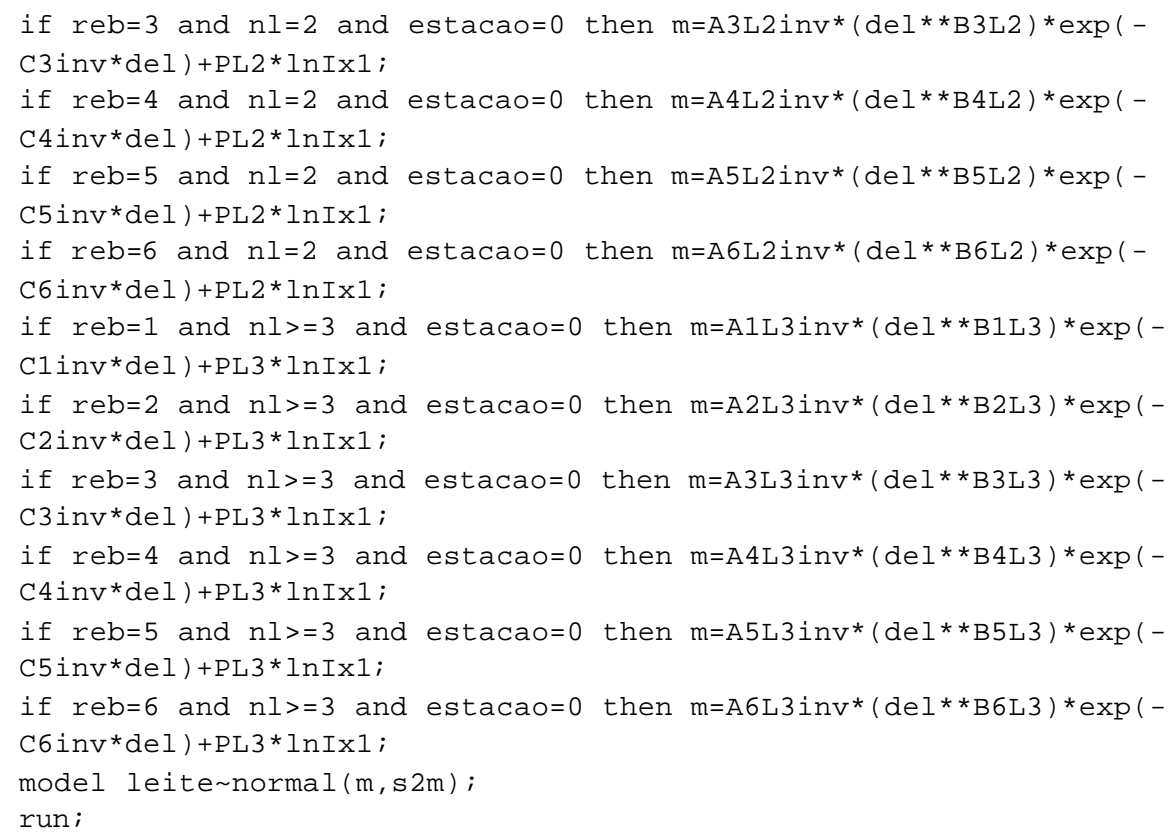

sendo s2m a variância residual, e as demais variáveis são como definidas anteriormente. No comando parms são definidos os valores iniciais dos parâmetros, que no caso, para os parâmetros da curva de lactação $(\alpha, \beta$ e $\gamma)$ foram usados os valores obtidos através do procedimento GENMOD para o modelo de curva de lactação escolhido. Veja-se que a sintaxe do procedimento NLMIXED é bem mais complicada do que a do GENMOD.

Os outros 190 modelos (95 para perdas absolutas e 95 para perdas relativas) foram ajustados utilizando-se sintaxes semelhantes às apresentadas, e escolhidos os melhores modelos através do valor do BIC.

O procedimento final de estimação de $x_{0}$ somente considerou mais valores de $x_{0}$ nas proximidades do valor de $x_{0}$ dos modelos escolhidos. 


\section{REFERÊNCIAS BIBLIOGRÁFICAS}

ALI, T.E.; SCHAEFFER, L.R. Accounting for covariances among test day milk yields in dairy cows. Canadian Journal of Animal Science, v.67, n.3, p.637-644, 1987.

ALMEIDA, R.; RIBAS, N.P.; MONARDES, H. Estudo dos efeitos de meio ambiente sobre as características produtivas de vacas da raça holandesa na região da Batavo, Paraná. In: REUNIÃO ANUAL DA SOCIEDADE BRASILEIRA DE ZOOTECNIA, 34., Juiz de Fora, 1997. Anais. Juiz de Fora: SBZ, 1997. p.65-67.

ALLORE, H.G.; WILSON, D.J.; ERB, H.N. et al. Selecting linear-score distributions for modelling milk-culture results. Preventive Veterinary Medicine, v.33, p.11-29, 1998.

AMARAL, L.A. Aspectos epidemiológicos da mastite bovina. In: ENCONTRO DE PESQUISADORES EM MASTITES, 3., Botucatu, 1999. Anais. Botucatu: UNESP, FMVZ, 1999. p.19-26.

BALDASSI, L.; FERNANDES FILHO, M.; HIPÓLITO, M. et al. Etiologia a mastite subclínica na bacia leiteira de Ribeirão Preto, Estado de São Paulo. Arquivos do Instituto Biológico, v.58, n.1/2, p.29-36, 1991.

BALIEIRO, J.C.C.; MILAGRES, J.C.; FREITAS, A.F. et al. Aspectos genéticos e fenotípicos em características produtivas do rebanho leiteiro da Universidade Federal de Viçosa. In: REUNIÃO ANUAL DA SOCIEDADE BRASILEIRA DE ZOOTECNIA, 34., Juiz de Fora, 1997. Anais. http://www.sbz.org.br (24 mar. 2003). 
BARBOSA, P.F.; COSTA, J.L; CRUZ, G.M. et al. Causas de variação da produção de kite e duração do período de lactação em vacas mestiças EuropeuxZebu. In: REUNIÃO ANUAL DA SOCIEDADE BRASILEIRA DE ZOOTECNIA, 33., Fortaleza, 1996. Anais. http://www.sbz.org.br (24 mar. 2003).

BARBOSA, P.F.; CRUZ, G.M.; COSTA, J.L. et al. Causas de variação da produção de leite e duração da lactação em um rebanho da raça holandesa na região de São Carlos, SP. In: REUNIÃO ANUAL DA SOCIEDADE BRASILEIRA DE ZOOTECNIA, 34., Juiz de Fora, 1997. Anais. http://www.sbz.org.br (24 mar. 2003).

BARKEMA, H.W.; DELUYKER, H.A.; SCHUKKEN, Y.H. et al. Quarter-milk somatic cell count at calving and at the first six milkings after calving. Preventive Veterinary Medicine, v.38, p.1-9, 1999.

BARTLETT, P.C.; MILLER, G.Y.; ANDERSON, C.R. et al. Milk production and somatic cell count in Michigan dairy herds. Journal of Dairy Science, v.73, n.10, p.2794-2800, 1990.

BARTLETT, P.C.; WIJK, J.V.; WILSON, D.J. et al. Temporal patterns of lost milk production following clinical mastitis in a large Michigan Holstein herd. Journal of Dairy Science, v.74, n.5, p.1561-1572, 1991.

BATRA, T.R. Comparison of two mathematical models in fitting lactation curves for pureline and crossline dairy cows. Canadian Journal of Animal Science, v.66, n.2, p.405-414, 1986.

BEAUDEAU, F.; FOURICHON, C.; SEEGERS, H. Risk of clinical mastitis in dairy herds with a high proportion of low individual milk somatic-cell counts. Preventive Veterinary Medicine, v.53, p.43-54, 2002.

BECK, H.S.; WISE, W.S.; DODD, F.H. Cost-benefit analysis of bovine mastitis in the UK. Journal of Dairy Research, v.59, p.449, 1992. 
BLOOD, D.C.; RADOTITIS, O.M. Veterinary medicine: a textbook of diseases of cattle, sheep, pigs, goats and horses. London: Bailliere Tindall, 1989. 1502p.

BLOSSER, T.H. Economic losses from and the National Research Program on mastitis in the United States. Journal of Dairy Science, v.62, n.1, p.119-127, 1979.

BRANT, M.C.; FIGUEIREDO, J.B. Prevalência da mastite subclínica e perdas de produção em vacas leiteiras. Arquivos Brasileiros de Medicina Veterinária e Zootecnia, v.46, n.6, p.595-606, 1994.

BRASIL. Ministério da Agricultura, Pecuária e Abastecimento. Instrução Normativa n.51. Diário Oficial da União. Brasília, DF, 15 ago. 2002. Seção 1, p.2-4.

BREER, C.; LUTZ, H.; SUPER, B.S. Counting somatic cells in milk with a rapid flow-through cytophotometer. Journal of Milk Food Technology, v.39, n.9, p.624-627, 1976.

BROLUND, L. Cell counts in bovine milk: Causes of variation and applicability for diagnosis of subclinical mastitis. Acta Veterinaria Scandinava, suppl. 80, p.1-123, 1985.

BROSTER, W. H.; BROSTER, V. J. Body score of dairy cows. Journal of Dairy Research, v. 65, p. 155-173, 1998.

BUELOW, K.L.; THOMAS, C.B.; GOODGER, W.J. et al. Effect of milk sample collection strategy on the sensitivity and specificity of bacteriologic culture and somatic cell count for detection of Staphylococcus aureus intramammary infection in dairy cattle. Preventive Veterinary Medicine, v.26, p.1-8, 1996.

CASSOLI, L.D.; MACHADO, P.F.; CORASSIN, C.H. et al. Efeitos das ocorrências sanitárias do periparto, sobre o desempenho produtivo e reprodutivo de vacas holandesas. In: SIMPÓSIO INTERNACIONAL DE INICIAÇÃO CIENTÍFICA DA UNIVERSIDADE DE SÃO PAUlO, 8., Piracicaba, $2000 . \quad$ Anais. http://www.usp.br/siicusp/8osiicusp/index_2000.htm (24 mar. 2003). 
CHALUPA, W.; GALLIGAN, D.T.; FERGUSON, J.D. Animal nutrition and management in the $21^{\text {st }}$ century: dairy cattle. Animal Feed Science and Technology, v.58, p.1-18, 1996.

COBUCI, J.R. Estudo da curva de lactação em vacas da raça guzerá. Viçosa, 1999. 65p. Dissertação (Mestrado) - Universidade Federal de Viçosa.

CONGLETON JUNIOR, W.R.; EVERETT, R.W. Error and bias in using the incomplete gamma function to describe lactation curves. Journal of Dairy Science, v.63, n.1, p.101$108,1980$.

COSTA, C.N.; MILAGRES, J.C.; CASTRO, A.C.G. et al. Efeitos da estação e idade ao parto sobre a curva de lactação de vacas da raça holandesa. Revista da Sociedade Brasileira de Zootecnia, v.11, n.2, p.320-330, 1982.

COSTA, E.O.; BENITES, N.R.; MELVILLE, P.A. et al. Estudo etiológico da mastite clínica bovina. Revista Brasileira de Medicina Veterinária, v.17, n.4, p.156-158, 1995a.

COSTA, E.O.; MELVILLE, P.A.; RIBEIRO, A.R. et al. Índices de mastite clínica e subclínica nos Estados de São Paulo e Minas Gerais. Revista Brasileira de Medicina Veterinária, v.17, n.5, p.215-217, 1995 b.

DEKKERS, J.C.M.; TEN HAG, J.H. WEERSINK, A. Economic aspects of persistency of lactation in dairy cattle. Livestock Production Science, v.53, p.237-252, 1998.

DEMÉTRIO, C.G.B. Modelos lineares generalizados em experimentação agronômica. Piracicaba: ESALQ, 2001. 113p.

DETILLEUX, J.; ARENDT, J.; LOMBA, F. et al. Methods for estimating areas under receiveroperating characteristics curves: illustration with somatic-cell scores in subclinical intramammary infections. Preventive Veterinary Medicine, v.41, p.75-88, 1999. 
DOHOO, I.R. An evaluation of the validity of individual cow somatic cell counts from cows in early lactation. Preventive Veteri nary Medicine, v.16, p.103-110, 1993.

DOHOO, I.R. Setting SCC cutpoints for cow and herd interpretation. In: ANNUAL MEETING NATIONAL MASTITIS COUNCIL, 40., Reno, 2001. Proceedings. Madison: National Mastitis Council, 2001. p.10-18.

DOHOO, I.R.; LESLIE, K.E. Evaluation of changes in somatic cell counts as indicators of new intramammary infections. Preventive Veterinary Medicine, v.10, p.225-237, 1991.

DOHOO, I.R.; MARTIN, S.W.; MEEK, A.H. et al. Disease, production and culling in HolsteinFriesian cows: I. The data. Preventive Veterinary Medicine, v.1, p.321-334, 1983.

DURÃES, M.C.; FREITAS, A.F.; TEIXEIRA, N.M. et al. Fatores de ajustamento da produção de leite e de gordura na raça holandesa para idade e núcleo de controle leiteiro. Arquivo Brasileiro de Medicina Veterinária e Zootecnia, v.52, n.2, p.178-184, 2000.

DURÃES, M.C.; FREITAS, A.F.; VALENTE, J. et al. Tendência genética para a produção de leite e de gordura em rebanhos da raça holandesa no Estado de Minas Gerais. Revista Brasileira de Zootecnia, v.30, n.1, p.66-70, 2001.

EDMONSON, A.J.; LEAN, I.J.; WEAVER, L.D. et al. A body condition scoring chart for Holstein dairy cows. Journal of Dairy Science, v.72, n.1, p.68-78, 1989.

EDMONDSON, P.W. Estratégias para a produção de leite de alta qualidade. In: CONGRESSO PANAMERICANO DE QUALIDADE DO LEITE E CONTROLE DE MASTITE, 2., Ribeirão Preto, 2002. Anais. São Paulo: Instituto Fernando Costa, 2002. p.61-69.

FERGUSON, J.D., BYERS, D., FERRY, J. et al. Roundtable discussion: body condition of lactation cows. Agri-Practice, v.15, n.4, p.17-21, 1994. 
FERREIRA, W.J.; TEIXEIRA, N.M.; EUCLYDES, R.F. et al. Parâmetros genéticos e fenotípicos para produção de leite no dia do controle, como medidas repetidas, e produção até 305 dias de lactação de vacas da raça holandesa. In: REUNIÃO ANUAL DA SOCIEDADE BRASILEIRA DE ZOOTECNIA, 37., Viçosa, 2000. Anais. http://www.sbz.org.br (24 mar. 2003).

FETROW, J.; ANDERSON, K. SEXTON, S. et al. Herd composite somatic cell counts: average linear score and weighted average somatic cell score and milk production. Journal of Dairy Science, v.71, n.1, p.257-260, 1988.

FETROW, J.; MANN, D.; BUTCHER, K. et al. Production losses from mastitis: carry-over from the previous lactation. Journal of Dairy Science, v.74, n.3, p.833-839, 1991.

FETROW, J.; STEWART, S.; EICKER, S. et al. Mastitis: an economic consideration. In: ANNUAL MEETING NATIONAL MASTITIS COUNCIL, 39., Atlanta, 2000. Proceedings. Madison: National Mastitis Council, 2000. p.3-47.

FREITAS, A.F.; DURÃES, M.C.; VALENTE, J. et al. Parâmetros genéticos para produções de leite e gordura nas três primeiras lactações de vacas holandesas. Revista Brasileira de Zootecnia, v.30, n.3, p.709-713, 2001.

FREITAS, M.A.R.; FARO, L.E.; GADINI, C.H. Estudo da persistência da lactação de vacas da raça holandesa. In: REUNIÃO ANUAL DA SOCIEDADE BRASILEIRA DE ZOOTECNIA, 34., Juiz de Fora, 1997. Anais. http://www.sbz.org.br (24 mar. 2003).

FRIGGENS, N.C.; EMMANS, G.C.; VEERKAMP, R.F. On the use of simple ratios between lactation curve coefficients to describe parity effects on milk production. Livestock Production Science, v.62, p.1-13, 1999. 
FUENTE, L.F.; PRIMITIVO, F.S.; FUERTES, J.A. et al. Daily and between-milking variations and repeatabilities in milk yield, somatic cell count, fat and protein of dairy ewes. Small Ruminant Research, v.24, n.2, p.133-139, 1997.

GABRIEL, J.E.R.; OLIVEIRA, M.D.S.; TONHATI, H. et al. Análise de algumas características produtivas e reprodutivas da raça holandesa. In: REUNIÃO ANUAL DA SOCIEDADE BRASILEIRA DE ZOOTECNIA, 35., Botucatu, 1998. Anais. http://www.sbz.org.br (24 mar. 2003).

GADINI, C.H.; KEOWN, J.F.; VLECK, L.D.V. Parâmetros genéticos do escore de células somáticas. In: REUNIÃO ANUAL DA SOCIEDADE BRASILEIRA DE ZOOTECNIA, 34., Juiz de Fora, 1997. Anais. Juiz de Fora: SBZ, 1997a. v.3, p.41-43.

GADINI, C.H.; KEOWN, J.F.; VLECK, L.D.V. Parâmetros genéticos das produções de leite, gordura e proteína, e do escore de células somáticas em 305 dias de lactação. In: REUNIÃO ANUAL DA SOCIEDADE BRASILEIRA DE ZOOTECNIA, 34., Juiz de Fora, 1997. Anais. Juiz de Fora: SBZ, 1997b. v.3, p.47-49.

GARCÍA, S.C.; HOLMES, C.W. Lactation curves of autumn- and spring-calved cows in pasture-based dairy systems. Livestock Production Science, v.68, p.189-203, 2001.

GARNSWORTHY, P.C. (Ed.) Nutrition and lactation in the dairy cow. London: AnchorBrendon, 1988. 429p.

GASPARINO, E. Estudo de fatores genéticos e de meio que influenciam o desempenho de vacas mestiças à primeira cria. Viçosa, 1996. 112p. Dissertação (Mestrado) - Universidade Federal de Viçosa.

GEISHAUSER, T.; QUERENGASSER, K.; NITSCHKE, M. et al. Milk yield, somatic cell counts, and risk of removal from the herd for dairy cows after covered teat canal injury. Journal of Dairy Science, v.82, n.7, p.1482-1488, 1999. 
GILL, R.; HOWARD, W.H.; LESLIE K.E. et al. Economics of mastitis control. Journal of Dairy Science, v.73, n.11, p.3340-3348, 1990.

GIRAUDO, J.A. Conceptos basicos sobre inmunologia de la glandula mamaria y utilizacion de vacunas contra mastitis. In: ENCONTRO DE PESQUISADORES EM MASTITE BOVINA DO ESTADO DE SÃO PAUlO, 2., Nova Odessa, 1996. Palestras. Nova Odessa: Instituto de Zootecnia, 1996. p.73-86.

GIRAUDO, J.A.; CALZOLARI, A.; RAMPONE, H. et al. Field trials of vaccine against bovine mastitis. 1. Evaluation in heifers. Journal of Dairy Science, v.80, n.5, p.845-853, 1997.

GRAAF, T.; DWINGER, R.H. Estimation of milk production losses due to sub-clinical mastitis in dairy cattle in Costa Rica. Preventive Veterinary Medicine, v.26, p.215-222, 1996.

GUIDRY, A.J. Mastitis and the immune system of the mammary gland. In: LARSON, B.L. (Ed.) Lactation. Ames: The Iwoa State University Press, 1985. cap.7, p.299-362.

HAILE-MARIAM, H.; BOWMAN, P.J.; GODDARD, M.E. Genetic and environmental correlations between test-day somatic cell count and milk yield traits. Livestock Production Science, v.73, p.1-13, 2001.

HAMANN, J. Somatic cells: factors of influence and practical measures to keep a physiological level. Newsletters of the International Dairy Federation,n.144, p.9-11, 1996.

HARGROVE, G.L. Bias in composite milk samples with unequal milking intervals. Journal of Dairy Science, v.77, n.7, p.1917-1921, 1994.

HARMON, R.J. Physiology of mastitis and factors affecting somatic cell counts. Journal of Dairy Science, v.77, n.7, p.2103-2112, 1994. 
HARMON, R.J. Fatores que afetam a contagem de células somáticas. In: SIMPÓSIO INTERNACIONAL SOBRE QUALIDADE DO LEITE, 1., Curitiba, 1998. Anais. Curitiba: UFPR, 1998a. p.7-15.

HARMON, R.J. Aspectos econômicos da mastite bovina. In: SIMPÓSIO INTERNACIONAL SOBRE QUALIDADE DO LEITE, 1., Curitiba, 1998. Anais. Curitiba: UFPR, 1998b. p.36-39.

HARMON, R.J. Somatic cell counts: a primer. In: ANNUAL MEETING NATIONAL MASTITIS COUNCIL, 40., Reno, 2001. Proceedings. Madison: National Mastitis Council, 2001. p.3-9.

HORTET, P.; SEEGERS, H. Loss in milk yield and related composition changes resulting from clinical mastitis in dairy cows. Preventive Veterinary Medicine,v.37, p.1-20, 1998.

HORTET, P.; BEAUDEAU, F.; SEEGERS, H. et al. Reduction in milk yield associated with somatic cell counts up to 600.000 cells $/ \mathrm{mL}$ in French Holsteins cows without clinical mastitis. Livestock Production Science, v.61, n.1, p.33-42, 1999.

JAIN, N.C. Common mammary pathogens and factors in infection and mastitis. Journal of Dairy Science, v.62, n.1, p.128-134, 1979.

JAMROZIK, J.; SCHAEFFER, L.R. Estimates of genetic parameters for a test day model with random regressions for yield traits of first lactation Holsteins. Journal of Dairy Science, v.80, n.4, p.762-770, 1997.

JAMROZIK, J.; KISTEMAKER, G.J.; DEKKERS, J.C.M. et al. Comparison of possible covariates for use in a random regression model for analyses of test day yields. Journal of Dairy Science, v.80, n.10, p.2550-2556, 1997.

JANZEN, J.J. Economic losses resulting from mastitis. A review. Journal of Dairy Science, v.53, n.9, p.1151-1161, 1970. 
JONES, G.M.; PEARSON, R.E.; CLABAUGH, G.A. et al. Relationships between cell counts and milk production. Journal of Dairy Science, v.67, p.1823-1831, 1984.

JOOSTEN, I.; STELWAGEN, J.; DIJKHUIZEN, A.A. Economic and reproductive consequences of retained placenta in dairy cattle. The Veterinary Record, v.123, p.53-57, 1988.

KELLOGG, D.W.; URQUHART, N.S.; ORTEGA, A.J. Estimating Holstein lactation curves with a gamma curve. Journal of Dairy Science, v.60, n.8, p.1308-1315, 1977.

KENNEDY. B.W.; SETHAR, M.S.; MOXLEY, J.E.; DOWNEY, B.R. Heritability of somatic cell counts an its relationship with milk yield and composition in Holsteins. Journal of Dairy Science, v.65, n.5, p.843-847, 1982.

KEOWN, J.F.; VAN VLECK, L.D. Extending lactation records in progress to 305-day equivalent. Journal of Dairy Science, v.56, n.8, p.1070-1079, 1973.

KETTUNEN, A.; MÄNTYSAARY, E.A.; PÖSÖ, J. Estimation of genetic parameters for daily milk yield of primiparous Ayrshire cows by random regression test-day models. Livestock Production Science, v.66, p.251-261, 2000.

KIM, T.; HEALD, C.W. Inducing inference rules for the classification of bovine mastitis. Computers and Electronics in Agriculture, v.23, p.27-42, 1999.

KIRK, J.H. Programmable calculator program for linear somatic cell scores to estimate mastitis yield losses. Journal of Dairy Science, v.67, n.2, p.441-443, 1984.

KIRK, J.H.; BARTLETT, P.C. Economic impact of mastitis in Michigan Holstein dairy herds using a computerized records system. Agri-Practice, v.9, n.1, p.3-6, 1988. 
KIRK, J.H.; WRIGHT, J.C.; BERRY, S.L. et al. Relationships of milk status at calving with somatic cell counts and milk production of dairy heifers during early lactation on a Californian dairy. Preventive Veterinary Medicine, v.28, p.187-198, 1996.

KOSSAIBATI, M.A.; ESSLEMONT, R.J. The cost of production diseases in dairy herds in England. The Veterinary Journal, v.154, p.41-51, 1997.

LAEVENS, H.; DELUYKER, H.; SCHUKKEN, Y.H. et al. Influence of parity and stage of lactation on the somatic cell count in bacteriologically negative dairy cows. Journal of Dairy Science, v.80, n.12, p.3219-3226, 1997.

LAGO, E.P.; PIRES, A.V.; SUSIN, I. et al. Efeito da condição corporal ao parto sobre alguns parâmetros do metabolismo energético, produção de leite e incidência de doenças no pósparto de vacas leiteiras. Revista Brasileira de Zootecnia, v.30, n.5, p.1544-1549, 2001.

LANGENEGGER, J.; COELHO, N.M.; LANGENEGGER, C.H. et al. Estudo da incidência da mastite bovina na bacia leiteira do Rio de Janeiro. Pesquisa Agropecuária Brasileira, v.5, p.437-440, 1970 .

LANGONI, H. Importância do diagnóstico microbiológico nas mastites bovinas. In: ENCONTRO DE PESQUISADORES EM MASTITE BOVINA DO ESTADO DE SÃO PAUlO, 2., Nova Odessa, 1996. Anais. Nova Odessa: Instituto de Zootecnia, 1996. p.29-32.

LANGONI, H. Tendências de modernização do setor lácteo: monitoramento da qualidade do leite pela contagem de células somáticas. Revista Educação Continuada, v.3, p.57-64, 2000.

LARANJA, L.F.; MACHADO, P.F. Ocorrência de mastite bovina em fazendas produtoras de leite B no Estado de São Paulo. Scientia Agricola, v.51, n.3, p.578-585, 1994. 
LEE, C.S.; WOODING, F.B.P.; KEMP, P. Identification, properties, and differential counts of cells populations using electron microscopy of dry cows secretions, colostrum and milk from normal cows. Journal of Dairy Research, v.47, p.39-50, 1980.

LESCOURRET, F.; COULON, J.B. Modelling the impact of mastitis on milk production by dairy cows. Journal of Dairy Science, v.77, n.8, p.2289-2301, 1994.

LOPES, M.A.; NEIVA, R.S.; VALENTE, J. et al. Aplicação da função tipo gama incompleta no estudo da curva de lactação de vacas da raça holandesa, variedade preto-e-branca, mantidas em sistema intensivo de produção. Revista da Sociedade Brasileira de Zootecnia, v.25, n.6, p.1086-1101, 1996.

LUCEY, S.; ROWLANDS, G.J. The association between clinical mastitis and milk yield in dairy cows. Animal Production, v.39, p.162-175, 1984.

MACHADO, P.F.; BARANCELLI, G.; PEREIRA, A.R. CCS: Leite com mais qualidade e melhor rendimento industrial. Indústria de Laticínios, n.13, p.65-68, 1998.

MACHADO, P.F.; PEREIRA, A.R.; SARRIÉS, G.A. Efeitos da contagem de células somáticas na qualidade do leite e a atual situação de rebanhos brasileiros. Revista do Instituto de Laticínios “Cândido Tostes”, v.54, n.309, p.10-16, 1999.

MACHADO, P.F.; PEREIRA, A.R.; SILVA, L.F.P. et al. Células somáticas no leite em rebanhos brasileiros. Scientia Agrícola, v.57, n.2, p.359-361, 2000.

MATOS, R.S.; RORATO, P.R.N.; FERREIRA, G.B. et al. Estudo do efeito de alguns fatores de meio sobre as produções de leite e gordura da raça holandesa no Rio Grande do Sul. In: REUNIÃO ANUAL DA SOCIEDADE BRASILEIRA DE ZOOTECNIA, 33., Fortaleza, 1996. Anais. http://www.sbz.org.br (24 mar. 2003). 
MCNANUS, C.; GUTH, T.L.F.; SAUERESSIG, M.G. Curva de lactação em gado holandês em confinamento total no DF. In: REUNIÃO ANUAL DA SOCIEDADE BRASILEIRA DE ZOOTECNIA, 34., Juiz de Fora, 1997. Anais. Juiz de Fora: SBZ, 1997. p.74-76.

MEJIA, N.A.; MILAGRES, J.C.; CASTRO, A.C.G. et al. Fatores genéticos e de meio ra produção de leite de bovinos das raças suíça parda e holandesa, na República de Honduras, América Central. Revista da Sociedade Brasileira de Zootecnia, v.82, n.2, p.289-306, 1982.

MEYER, P.M.; MACHADO, P.F.; COLDEBELLA, A. et al. Methods of milk storage and age of samples on milk components percentage, somatic cells count and urea nitrogen. Journal of Dairy Science, v.85, suppl.1, p.285, 2002.

MIETTINEN, P.V.A.; SETÄLÄ, J.J. Relationships between subclinical ketosis, milk production and fertility in Finnish dairy cattle. Preventive Veterinary Medicine, v.17, p.1-8, 1993.

MILLER, R.H.; MCDANIEL, B.T.; CORLEY, E.L. Variation in ratio factors for age-adjusting part-lactation records. Journal of Dairy Science, v.50, n.11, p.1819-1823, 1967.

MILLER, R.H.; PAAPE, M.J.; FULTON, L.A. et al. The relationship of milk somatic cell count to milk yields for holstein heifers after first calving. Journal of Dairy Science, v.76, n.3, p.728-733, 1993.

MOLENTO, C.F.M.; RIBAS, N.P.; MONARDES, H. et al. Persistência da lactação em vacas da raça holandesa no Estado do Paraná. In: REUNIÃO ANUAL DA SOCIEDADE BRASILEIRA DE ZOOTECNIA, 33., Fortaleza, 1996. Anais. http://www.sbz.org.br (24 mar. 2003).

MORANT, S.V.; GNANASAKTHY, A. A new approach to the mathematical formulation of lactation curves. Animal Production, v.49, p.151-162, 1989. 
MORSE, D.; DELORENZO, M.A.; NATZKE, R.P. et al. Factors affecting days of discarded milk due to clinical mastitis and subsequent cost of discarded milk. Journal of Dairy Science, v.70, n.11, p.2411-2418, 1987.

MOTA, A.F.; VERNEQUE, R.S.; PORTELA, J.S. et al. Curvas de lactação de vacas holandesas do rebanho do CPPSUL - EMBRAPA - Bagé - RS. In: REUNIÃO ANUAL DA SOCIEDADE BRASILEIRA DE ZOOTECNIA, 33., Fortaleza, 1996. Anais. http://www.sbz.org.br (24 mar. 2003).

NADER FILHO, A.; SCHOCKEN-ITURRINO, R.P.; ROSSI JUNIOR, O.D. et al. Prevalência e etiologia da mastite bovina na região de Ribeirão Preto. Pesquisa Veterinária Brasileira, v.5, n.2, p.53-56, 1985.

NEAVE, F.K.; DODD, F.H; KINGWILL, R.G. et al. Control of mastitis in the dairy herd by hygiene and manegement. Journal of Dairy Science, v.52, n.5, p.696-707, 1969.

NEIVA, R.S.; OLIVEIRA, A.I.G.; COELHO, M.M. et al. Fatores de meio e genéticos em características produtivas e reprodutivas nas raças Holandesa e Pardo Suíça. I - Estudo de características produtivas. Revista da Sociedade Brasileira de Zootecnia, v.21, n.4, p.605-616, 1992.

NELDER, J.A.; WEDDERBURN, R.W.M. Generalized linear models. Journal of the Royal Statistical Society A, v.135, n.3, p.370-384, 1972.

NICKERSON, S.C. Immune mechanisms of the bovine udder: An overview. Journal of the American Veterinary Medical Association, v.187, n.1, p.41-45, 1985.

NICKERSON, S.C. Estratégias para controlar a mastite bovina. In: SIMPÓSIO INTERNACIONAL SOBRE QUALIDADE DO LEITE, 1., Curitiba, 1998. Anais. Curitiba: UFPR, 1998a. p.20-27. 
NICKERSON, S.C. O papel das vacinas no controle da mastite. In: SIMPÓSIO INTERNACIONAL SOBRE QUALIDADE DO LEITE, 1., Curitiba, 1998. Anais. Curitiba: UFPR, 1998b. p.20-27.

NICOLAU, E.S.; NADER FILHO, A.; AMARAL, L.A. et al. Influência da mastite subclínica estafilocócica sobre a produção láctea dos quartos afetados. ARS Veterinária, v.8, n.2, p.118-124, 1992.

OLORI, V.E.; BROTHERSTONE, S.; HILL, W.G. et al. Fit of standard models of the lactation curve to weekly records of milk production of cows in a single herd. Livestock Production Science, v.58, p.55-63, 1999.

OMORE, A.O.; MCDERMOTT, J.J.; ARIMI, S.M. et al. A longitudinal study of milk somatic cell counts and bacterial culture from cows on smallholder dairy farms in Kiambu District, Kenya. Preventive Veterinary Medicine, v.26, p.77-89, 1996.

OSTERGAARD, S.; SORENSEN, J.T.; KRISTENSEN, A.R. A stochastic model simulating the feeding-health-production complex in a dairy herd. Journal of Dairy Science, v.83, n.4, p.721-733, 2000.

OSTRENSKY, A.; RIBAS, N.P.; MONARDES, H.G. et al. Fatores de ambiente sobre o escore de células somáticas no leite de vacas da raça holandesa do Paraná. In: REUNIÃO ANUAL DA SOCIEDADE BRASILEIRA DE ZOOTECNIA, 37., Viçosa, 2000. Anais. http://www.sbz.org.br (21 ago. 2002).

PAAPE, M.J.; CAPUCO, A.V. Cellular defense mechanisms in the udder and lactation of goats. Journal of Animal Science, v.75, p.556-565, 1997.

PAAPE, M.J.; SCHULTZE, W.D.; MILLER, R.H. et al. Thermal stress and circulating erythrocytes, leukocytes, and milk somatic cells. Journal of Dairy Science, v.56, n.1, p.8491, 1973. 
PAAPE, M.J.; WERGIN, W.P.; GUIDRY, A.J. et al. Leukocytes second line of defense against invading mastitis pathogens. Journal of Dairy Science, v.62, n.1, p.135-153, 1979.

PAAPE, M.J.; GUIDRY, A.J.; JAIN, N.C. et al. Leukocytic defense mechanisms in the udder. In: BURVENICH, C.; VANDEPUTTE-VAN-MESSOM, G.; HILL, A.W. (Ed.). New insights into the pathogenesis of mastitis. Ghent: Rijkuniversiteit Gent, 1991. p.95-109.

PAPAJCSIK, I.A.; BODERO, J. Modelling lactation curves of Friesian cows in subtropical climate. Animal Production, v.47, p.201-207, 1988.

PARK, Y.H.; JACOBSON, N. Glândula mamária e lactação. In: SWENSON, M.J.; REECE, W.O. Dukes - Fisiologia dos animais domésticos. 11.ed. Rio de Janeiro: Guanabara Koogan, 1996. cap.37, p.645-659.

PEDRON, O.; CHELI, F. SENATORE, E. et al. Effect of body condition score at calving on performance, some blood parameters, and milk fatty acid composition in dairy cows. Journal of Dairy Science, v.76, n.9, p.2528-2535, 1993.

PEREIRA, A.R. Contagem de células somáticas e características produtivas de vacas em lactação da raça holandesa. Piracicaba, 2000. 53p. Dissertação (Mestrado) - Escola Superior de Agricultura “Luiz de Queiroz”, Universidade de São Paulo.

PERSSON, K. Studies on inflamation in the bovine teat, with regard to its role in the defence against udder infections. Uppsala, 1992. 61p. Dissertation - Swedish University of Agriculturas Sciences.

PHILPOT, W.N. Control of mastitis by hygiene and therapy. Journal of Dairy Science, v.62, n.1, p.168-176, 1979.

PHILPOT, W.N. Importância da contagem de células somáticas e outros fatores que afetam a qualidade do leite. In: SIMPÓSIO INTERNACIONAL SOBRE QUALIDADE DO LEITE, 1., Curitiba, 1998. Anais. Curitiba: UFPR, 1998. p.28-35. 
PHILPOT, W.N. Qualidade do leite e controle de mastite: passado, presente e futuro. In: CONGRESSO PANAMERICANO DE QUALIDADE DO LEITE E CONTROLE DE MASTITE, 2., Ribeirão Preto, 2002. Anais. São Paulo: Instituto Fernando Costa, 2002. p.23-38.

PHILPOT, W.N.; NICKERSON, S.C. Mastitis: Counter Attack. Naperville: Babson Bros., 1991. 150p.

PIRES, A.V. Fatores genéticos e ambientais que afetam a produção de leite e a duração da lactação de um rebanho com diferentes grupos genéticos Holandês:Guzerá. Piracicaba, 1984. 112p. Dissertação (Mestrado) - Escola Superior de Agricultura "Luiz de Queiroz", Universidade de São Paulo.

POLITIS, I.; HIDIROGLOU, M.; BATRA, T.R. et al. Effects of vitamin E on immune function of dairy cows. American Journal Veterinary Research, v.56, n.2, p.179-184, 1995.

PRADO, E.; CRUZ, F.E.R.; VIANA, F.C. et al. Problemas sanitários do rebanho de leite: percepção dos criadores. Arquivos Brasileiros de Medicina Veterinária e Zootecnia, v.49, n.1, p.19-29, 1997.

PRYCE, J.E.; NIENSEN, B.L.; VEERKAMP, R.F. et al. Genotype and feeding system effects and interactions for health and fertility traits in dairy cattle. Livestock Prodution Science, v.57, n.3, p.193-201, 1999.

QUEIROZ, S.A.; GIANNONI, M.A.; RAMOS, A.A. et al. Environmental effects on the variation of productive traits in Holstein-Friesian $\times$ Zebu cross-bred cattle in the region of São Carlos, State of São Paulo, Brazil. I. Milk yield. Revista Brasileira de Genética, v.10, n.1, p.63-73, 1987. 
RAJALA-SCHULTZ, P.J.; GROHN, Y.T.; MCCULLOCH, C.E. et al. Effects of clinical mastitis on milk yield in dairy cows. Journal of Dairy Science, v.82, n.6, p.1213-1220, 1999.

RAUBERTAS, R.F.; SHOOK, G.E. Relationship between lactation measures of somatic cell concentration and milk yield. Journal of Dairy Science, v.65, n.3, p.419-425, 1982.

REBHUN, W.C. Diseases of dairy cattle. Media: Williams \& Wilkins, 1995. 530p.

REKAYA, R.; WEIGEL, K.A.; GIANOLA, D. Hierarchical nonlinear model for persistency of milk yield in the first three lactations of Holsteins. Livestock Production Science, v.68, p.181-187, 2001.

RENEAU, J.K. Effective use of dairy herd improvement somatic cell counts in mastitis control. Journal of Dairy Science, v.69, n.6, p.1708-1720, 1986.

RIBAS, N.P.; MOLENTO, C.F.M.; ALMEIDA, R. et al. Pico de lactação em vacas da raça holandesa no Estado do Paraná. In: REUNIÃO ANUAL DA SOCIEDADE BRASILEIRA DE ZOOTECNIA, 33., Fortaleza, 1996a. Anais. http://www.sbz.org.br (24 mar. 2003).

RIBAS, N.P.; MONARDES, H.; MOLENTO, C.F.M. et al. Estudo dos efeitos de meio ambiente sobre as características produtivas de vacas da raça holandesa no Estado do Paraná. In: REUNIÃO ANUAL DA SOCIEDADE BRASILEIRA DE ZOOTECNIA, 33., Fortaleza, 1996b. Anais. http://www.sbz.org.br (24 mar. 2003).

RISCO, C.A.; MOREIRA, F.; THATCHER, W.W. Management of the postpartum transition cow to maximize pregnancy rates. In: TEIXEIRA, J.C.; DAVID, F.M.; ANDRADE, G.A. et al. (Ed.). Avanços em produção e manejo de bovinos leiteiros. Lavras: Editora UFLA, 2002. cap.5, p.137-160.

RODRIGUEZ-ZAZ, S.L.; GIANOLA, D.; SHOOK, G.E. Evaluation of models for somatic cell score lactation patterns in Holsteins. Livestock Production Science, v.67, p.19-30, 2000. 
ROOK, A.J.; FRANCE, J.; DHANOA, M.S. On the mathematical description of lactation curves. Journal of Agricultural Science, v.121, n.1, p.97-102, 1993.

RUEGG, P.L.; MILTON, R.L. Body condition scores of Holstein cows on Prince Edward Island, Canada: Relationships with yield, reproductive performance, and disease. Journal of Dairy Science, v.78, n.3, p.552-564, 1995.

RUPP, R.; BOICHARD, D. Relationship of early first lactation somatic cell count with risk of subsequent first clinical mastitis. Livestock Production Science, v.62, p.169-180, 2000.

RUPP, R.; BEAUDEAU, F.; BOICHARD, D. Relationship between milk somatic-cell counts in the first lactation and clinical mastitis occurrence in the second lactation of French Holstein cows. Preventive Veterinary Medicine, v.46, p.99-111, 2000.

SAMARA, S.I.; PRATA, L.F.; DUTRA, I.S. Diagnóstico da situação sanitária do gado leiteiro em Pitangueiras-SP: III-Mastite. ARS Veterinária, v.12, n.2, p.141-147, 1996.

SANTOS, M.V. Efeito da mastite sobre a qualidade do leite e dos derivados lácteos. In: CONGRESSO PANAMERICANO DE QUALIDADE DO LEITE E CONTROLE DE MASTITE, 2., Ribeirão Preto, 2002. Anais. São Paulo: Instituto Fernando Costa, 2002. p.179-188.

SAS Institute. SAS/STAT User's Guide 8.0. Cary: SAS Institute, 1999. (compact disc).

SCHAKENRAAD, M.H.W.; DIJKHUIZEN, A.A. Economic losses due to bovine mastitis in Dutch dairy herds. Netherlands Journal of Agricultural Science, v.38, p.89-92, 1990.

SCHALLIBAUM, M. Impact of SCC on the quality of fluid milk and cheese. In: ANNUAL MEETING NATIONAL MASTITIS COUNCIL, 40., Reno, 2001. Proceedings. Madison: National Mastitis Council, 2001. p.38-46. 
SCHALM, O.W.; NOORLANDER, D.O. Experiments and observations leading to development of the California Mastitis Test. Journal of the American Veterinary Medical Association, v.130, n.5, p.199-204, 1957.

SCHEPERS, J.A.; DIJKHUIZEN, A.A. The economics of mastitis and mastitis control in dairy cattle: a critical analysis of estimates published since 1970. Preventive Veterinary Medicine, v.10, p.213-224, 1991.

SCHEPERS, J.A.; LAM, T.J.G.M.; SCHUKKEN Y.H. et al. Estimation of variance components for somatic cell counts to determine thresholds for uninfected quarters. Journal of Dairy Science, v.80, p.1833-1840,1997.

SHANKS, R.D.; BERGER, P.J.; FREEMAN, A.E. et al. Genetic aspects of lactation curves. Journal of Dairy Science, v.64, n.9, p.1852-1860, 1981.

SHELDRAKE, R.F.; HOARE, R.J.T., MCGREGOR, G.D. Lactation stage, parity, and infection affecting somatic cells, eletrical conductivity, and serum albumin in milk. Journal Dairy Science, v.66, n.3, p.542-547, 1983.

SHOOK, G.E. A linear scale for scoring somatic cell count. Journal of Dairy Science, v.65, suppl.1, p.108, 1982.

SHOOK, G.E. Selection for disease resistance. Journal of Dairy Science, v.72, n.5, p.1349$1362,1989$.

SHOOK, G.E. Breeding, selection and somatic cell counts: where are we today? In: ANNUAL MEETING NATIONAL MASTITIS COUNCIL, 40., Reno, 2001. Proceedings. Madison: National Mastitis Council, 2001. p.113-127.

SMITH, K.L. Standards for somatic cells in milk: Physiological and regulatory. Newsletters of the International Dairy Federation, n.144, p.7-9, 1996. 
SOLKNER, J.; FUCHS, W. A comparison of different measures of persistency with special respect to variation of test-day milk yields. Livestock Production Science, v.16, p.305319, 1987.

SORDILLO, L.M.; NICKERSON, S.C. Morphologic changes in the bovine mammary gland during involution and lactogenesis. Animal Journal of Veterinary Research v.49, n.7, p.1112-1120, 1988.

SORDILLO, L.M.; SHAFER-WEAVER, K.; DE ROSA, D. Immunobiology of mammary gland. Journal of Dairy Science, v.80, n.8, p.1851-1865, 1997.

SURIYASATHAPORN, W.; SCHUKKEN, Y.H.; NIELEN, M. et al. Low somatic cell count: a risk factor for subsequent clinical mastitis in a dairy herd. Journal of Dairy Science, v.83, n.6, p.1248-1255, 2000.

TEIXEIRA, N.M.; VALENTE, J.; VERNEQUE, R.S. et al. Fatores de ajustamento para período de serviço na raça holandesa. In: REUNIÃO ANUAL DA SOCIEDADE BRASILEIRA DE ZOOTECNIA, 34., Juiz de Fora, 1997. Anais. Juiz de Fora: SBZ, 1997. p.3-6.

TSENKOVA, R.; ATANASSOVA, S.; KAWANO, S. et al. Somatic cell count determination in cow's milk by near-infrared spectroscopy: A new diagnostic tool. Journal of Animal Science, v.79, p.2550-2557, 2001.

VAN VLECK, L.D.; HENDERSON, C.R. Ratio factors for adjusting monthly test-day data for age and season of calving and ratio factors for extending part lactation records. Journal of Dairy Science, v.44, n.6, p.1092-1102, 1961. 
VASCONCELOS, C.G.C.; NADER FILHO, A.; AMARAL, L.A. et al. Influência da estação do ano, do estádio de lactação e da hora de ordenha sobre o número de células somáticas no leite bovino. Arquivo Brasileiro de Medicina Veterinária e Zootecnia, v.49, n.4, p.483491, 1997.

WATTS, J.L. Etiological agents of bovine mastitis. Veterinary Microbiology, v.16, n.1, p.4166, 1988.

WILDMAN, E.E.; JONES, G.M.; WAGNER, P.E. et al. A dairy cow body condition scoring system and its relationship to selected production characteristics. Journal of Dairy Science, v.65, n.3, p.495-501, 1982.

WILSON, D.J.; SEARS, P.M. Clinical mastitis caused by different types of pathogens: differences in milk production loss, recovery, age at onset, and milk NAGase. Agri-practice, v.13, n.8, p.13-21, 1992.

WILSON, D.J.; GONZALEZ, R.N.; DAS, H.H. Bovine mastitis pathogens in New York and Pennsylvania: prevalence and effects on somatic cell count and milk production. Journal of Dairy Science, v.80, n.10, p.2592-2598, 1997.

WOOD, P.D.P. Algebraic model of the lactation curve in cattle. Nature, v.216, p.164-165, 1967.

ZECCONI, A. Somatic cells and their significance for milk processing (Technology).

Newsletters of the International Dairy Federation, n.144, p.11-14, 1996. 